\title{
WestVirginiaUniversity
}

THE RESEARCH REPOSITORY @ WVU

Graduate Theses, Dissertations, and Problem Reports

2006

\section{Evaluation of a tube feeding decision aid for substitute decision makers}

\author{
Emily H. Bower \\ West Virginia University
}

Follow this and additional works at: https://researchrepository.wvu.edu/etd

\section{Recommended Citation}

Bower, Emily H., "Evaluation of a tube feeding decision aid for substitute decision makers" (2006). Graduate Theses, Dissertations, and Problem Reports. 2385.

https://researchrepository.wvu.edu/etd/2385

This Thesis is protected by copyright and/or related rights. It has been brought to you by the The Research Repository @WVU with permission from the rights-holder(s). You are free to use this Thesis in any way that is permitted by the copyright and related rights legislation that applies to your use. For other uses you must obtain permission from the rights-holder(s) directly, unless additional rights are indicated by a Creative Commons license in the record and/ or on the work itself. This Thesis has been accepted for inclusion in WVU Graduate Theses, Dissertations, and Problem Reports collection by an authorized administrator of The Research Repository @ WVU. For more information, please contact researchrepository@mail.wvu.edu. 


\title{
Evaluation of a Tube Feeding Decision Aid for Substitute Decision Makers
}

\section{Emily H. Bower}

\author{
Thesis submitted to the \\ Eberly College of Arts and Sciences \\ at West Virginia University \\ in partial fulfillment of the requirements \\ for the degree of
}

\author{
Master of Science \\ in \\ Psychology
}

\author{
Barry Edelstein, Ph.D., Chair \\ William Fremouw, Ph.D. \\ JoNell Strough, Ph.D.
}

\author{
Department of Psychology \\ Morgantown, West Virginia \\ 2006
}

Keywords: decision aid, substitute decision-making, tube feeding, medical decision, older adult 


\begin{abstract}
Evaluation of a Tube Feeding Decision Aid for Substitute Decision Makers
\end{abstract}

\title{
Emily H. Bower
}

Substitute decision makers may be in a position to make "preference-sensitive" decisions for their patient, including whether to approve tube feeding. The present study evaluated the only known tube feeding decision aid for substitute decision makers (Mitchell, Tetroe, \& O'Conner, 2001). Sixty adults completed a pre-questionnaire, read an active control brochure (control group) or decision aid (experimental group), and completed a post-questionnaire. Both groups demonstrated increased knowledge and decisional conflict at post-test, although the experimental group had higher scores in both. Participants who were either in favor or against tube feeding at pre-test rarely changed their decision at post-test. Control group participants did not report less satisfaction with their decision than the experimental group, and the decision aid was highly acceptable. More research is needed to determine why decisional conflict may increase following the use of a decision aid, and what factors might promote decreased decisional conflict. 


\section{Table of Contents}

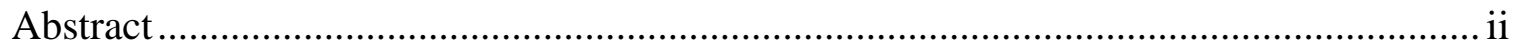

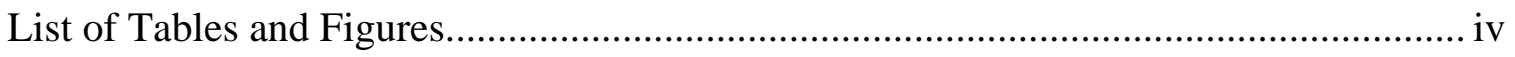

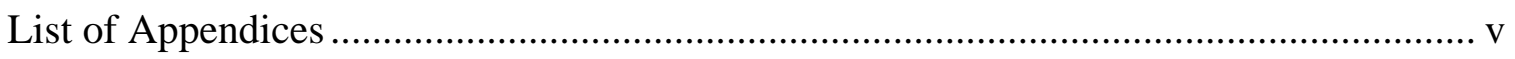

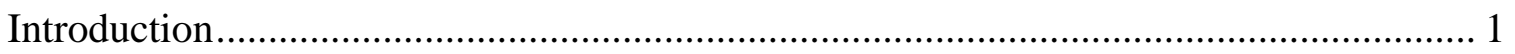

Cognition and Decision Making in Older Adults............................................................ 2

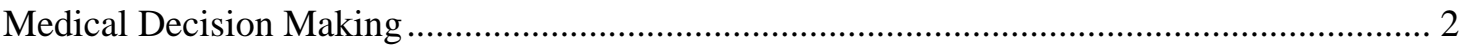

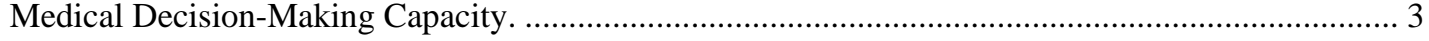

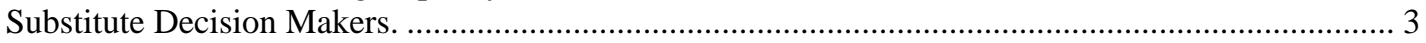

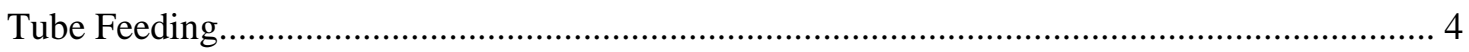

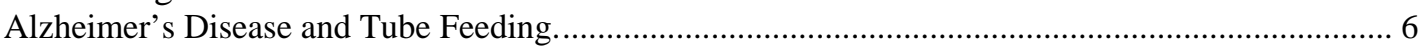

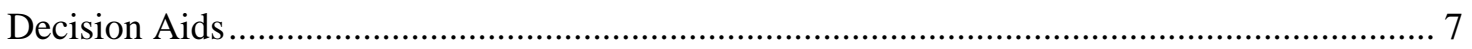

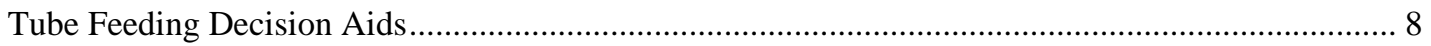

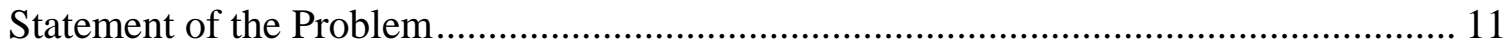

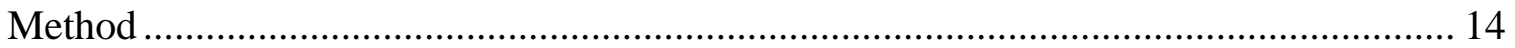

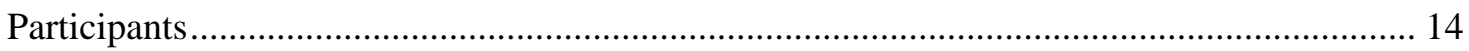

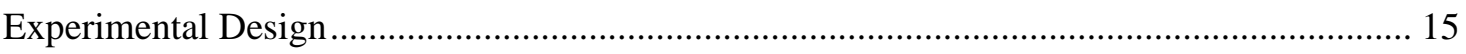

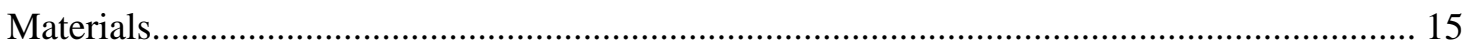

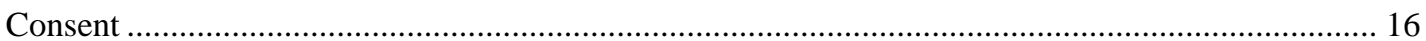

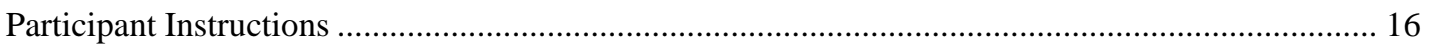

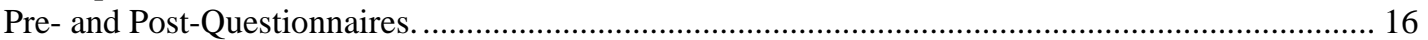

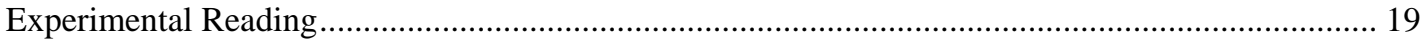

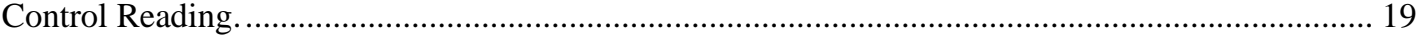

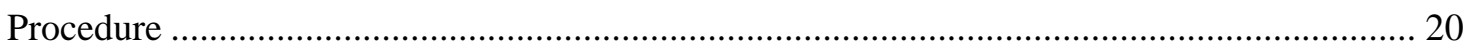

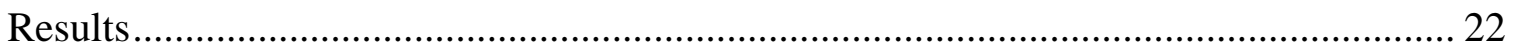

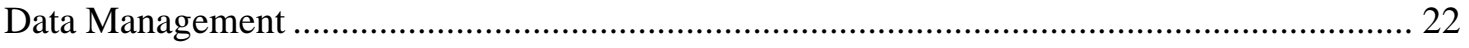

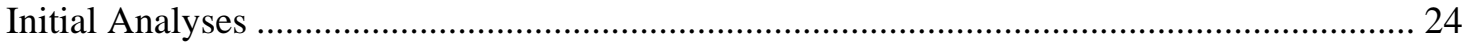

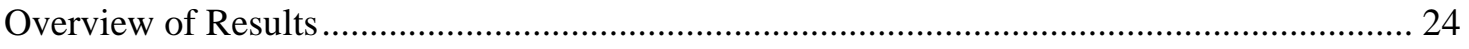

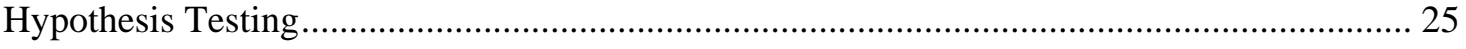

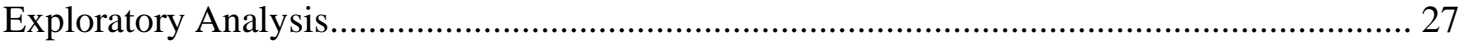

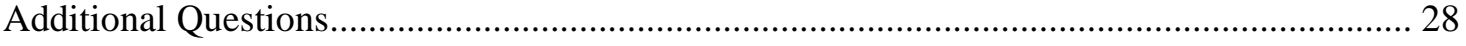

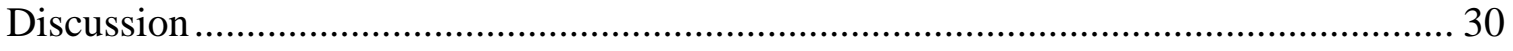

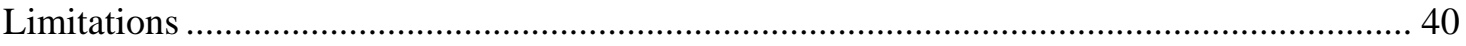

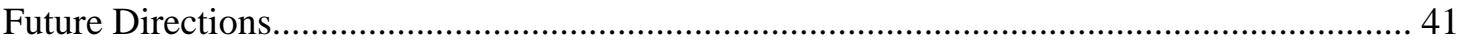

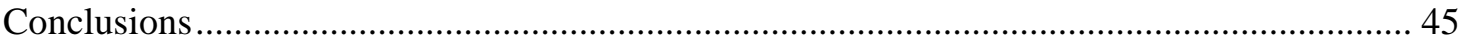

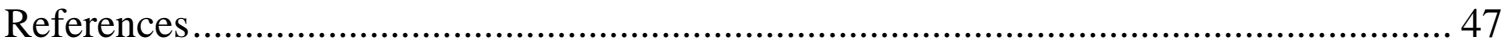


List of Tables and Figures

Table 1. Study Design by Dependent Variable................................57

Table 2. Participant Characteristics by Group...............................58

Table 3. Comparison of Substitute Decision Makers on Dependent Measures......59

Table 4. Comparison of Substitute Decision Makers on Dependent Measures: T-

Test Results...................................................60

Table 5. Descriptive Statistics for Dependent Variables by Group...............61

Figure 1. Knowledge Interaction........................................ 63

Figure 2. Decisional Conflict Interaction................................64

Figure 3. Decision at Pre-and Post-Test: Control Group.......................65

Figure 4. Decision at Pre-and Post-Test: Experimental Group...................66

Table 6. Questionnaire Responses by Actual Substitute Decision Makers ........67

Table $7 . \quad$ Post-Test Tube Feeding Decision by Age Group......................68 


\section{List of Appendices}

Appendix 1. Consent Form.....................................................69

Appendix 2. Cover Letter for Actual Substitute Decision Makers....................74

Appendix 3. Cover Letter for Other Substitute Decision Makers.....................75

Appendix 4. Participant Instructions for Substitute Decision Makers and Other

Substitute Decision Makers..............................................76

Appendix 5. Pre-Questionnaire................................................ 78

Appendix 6. Post-Questionnaire.............................................. 89

Appendix 7. Experimental Reading: "Making Choices: Long-term Tube Feeding in

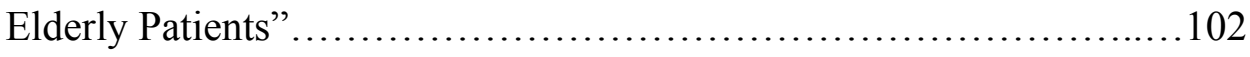

Appendix 8. Control Reading: “What are My Choices Regarding Life Support?”...125 
Introduction

Older Americans are growing in number. Twelve percent of the U.S. population was 65 years or older in 2002, which is expected to increase to $20 \%$ by 2030 (U.S. Administration on Aging, 2003). Life expectancy in 1995 for 65-year-old men was 80 years, and women, 84 years. By 2050, the Administration on Aging predicts 65-year-old men can expect to live to age 85, and women to age 87 (U. S. Administration on Aging, 1996, Table 17, middle series data). Americans may live a quarter of their lifetimes as older adults.

Older adults may experience illness. Medical progress has promoted a shift in the leading causes of death from acute illness and infectious disease, to chronic disease and deteriorating illnesses (Merck, 2004). Chronic diseases are experienced longer and have many decision points. The shift has brought about increased disability and higher dependence on others. It is estimated that $80 \%$ of older adults have one chronic condition, half of whom have two or more conditions (such as hypertension, arthritis, and heart disease) (Merck, 2004). Further, an estimated 28 million older adults are currently disabled, compared to 45 million people age 16-64.

With the aging cohort's growth, there are more occasions for medical decisions. Frequency of contact with health providers is one way to estimate the frequency of such decisions. For example, 12.5 million older adults were discharged from hospitals in 2002 (U. S. Administration on Aging, 2003), representing half of all hospital beds used (Merck, 2005). Hospitals bill 30\% of their expenditures to Medicare (Merck, 2005). Also in 2002, the Centers for Disease Control estimated that about $30 \%$ of older adults had one to three "health care visits" (doctor's office, emergency department, home visits), and 
24\% had ten or more such visits (National Center for Health Statistics, 2004, Table 71).

The older adult cohort comprises $40 \%$ of all physician visits (Zwahr, 1999).

Cognition and Decision Making in Older Adults

Informed, well-reasoned decisions require cognitive abilities that often decline with age. Approximately $14 \%$ of Americans aged $75-79$ and $30 \%$ of those over 85 years have moderate or severe cognitive impairment (Federal Interagency Forum on AgingRelated Statistics, 2004). This may be due to brain injury or degenerative processes that occur naturally. Salthouse (1999) reports that compared to younger adults, older adults show age-related declines in cognition. Further, Maitland, Intrieri, Schaie, and Willis (2000) found that older adults demonstrated declines in inductive reasoning, spatial orientation, numeric facility, perceptual speed, and verbal recall. Older adult males also exhibited deficits in verbal comprehension. Taken together, it appears that tasks requiring complex, effortful, and novel processing, flexibility, and inference become more difficult (Park, 1999; Sanfey \& Hastie, 2000; Salthouse, 1999; Zwahr, 1999).

\section{Medical Decision Making}

The decision-making literature supports the idea that younger and older adult cohorts do not make different medical decisions, but arrive at them differently (Brown \& Park, 2003). For example, Meyer, Russo, and Talbot (1995) found that older women sought less information and made quicker decisions about breast cancer treatment than did their younger counterparts. However, the treatment outcomes were equivalent. In addition to differences in medical decision-making processes, medical decision-making preferences may also differ. For example, Levinson et al. (2005) found that older adults, compared to younger adults, preferred less involvement in medical decision-making. 
Medical Decision-Making Capacity. Informed consent encompasses the rights of patients to accept or decline medical care and to be given necessary information to make informed decisions (American Bar Association, 2005), which was affirmed in The Patient Self-Determination Act of 1990. However, the ability to provide consent is compromised when cognitive impairments affect decision-making capacity. Capacity is "an individual's ability to understand the significant benefits, risks, and alternatives to proposed health care and to make and communicate a health-care decision" (Uniform Health-Care Decisions Act, 1993). Appelbaum and Grisso (1988) identified four legal standards that are common among state guardianship and conservatorship laws that define decision-making competence. These include understanding, appreciation, reasoning, and expressing a choice. When patients are evaluated and fail to meet these standards, a medical decision may be made on their behalf. This can be accomplished through "substituted judgments," where decisions are made with the patient's wishes in mind, either using a formal advance directive or informally with knowledge of the patient's preferences. When the patient's wishes are unknown, the decision can reflect the "best interest" standard. This is based on what a "reasonable person" would decide (Karp \& Wood, 2003; Perry, 2002).

Substitute Decision Makers. People who are incapacitated may be represented by a substitute decision maker. Often referred to as agents or surrogates, it is their responsibility to make a decision that "reflects the preferences and values of the patient and should arise from a clear determination of the overall goals of care" (Gillick, 2000, p. 206). 
In step with the informed consent standard, it is important for substitute decision makers to be educated by the health care team and included in decision-making. In one study, half of substitute decision makers reported being satisfied with the education they received from their health care team (Mitchell, 1999). If adequate education does not occur, substitute decision makers may have difficulty determining goals of care and making an informed decision. In one study of tube feeding, a third of decision makers reported uncertainty about having made the right decision to insert a tube (Van Rosendaal, 1997). Likewise, it is important for physicians to seek information from decision makers. In a study of 73 surrogates, $61 \%$ were not asked for input before a feeding tube was inserted (Van Rosendaal, 1999). Complicating this communication, physicians may be wary of seeking a decision maker's input if the physician suspects that the substitute may have cognitive deficits themselves (Bramstedt, 2003). Further, substitute decision-making can be difficult if there is a lack of information about the patient's preferences. In one study, low concordance was found between decisions of the substitute decision maker and patient if the medical situation had not been discussed during a time of capacity (O'Brien, 1997). Such “educated guesses” about what the patient would decide are particularly difficult when the decision is "preference-sensitive" (O’Conner, 2005). That is, values and beliefs will influence decisions differently for different decision makers.

\section{Tube Feeding}

Tube feeding, or the artificial delivery of nutrients to the stomach, is an example of a preference-sensitive decision. In one study, $78 \%$ of decision makers reported a "moral obligation" to approve tube feeding (Mitchell, 1999). Additionally, of the 
decisions that are covered in advance directives, Ouslander (1993) asserts that tube feeding is one of the most important due to the increased prevalence of conditions where self-feeding is problematic (O'Brien, 1997). Such conditions include dementia, Parkinson's disease, some cancers, stroke, and other neuromuscular problems that complicate swallowing (Drickamer, 1993). Feeding tubes (in this case percutaneous endoscopic gastrostomy tube, or PEG, which is inserted through a stoma into the stomach), are traditionally indicated for patients who have a "long-term need for enteral feeding" as an option that will increase patient comfort (Drickamer, 1993).

However, it is important to articulate the risks for decision makers. Placement of a tube involves indefinite monitoring of the nutrients being delivered, potential infection, and the continued need for the tube. Short-term risks include pneumonia, aspiration and complications of aspiration pneumonia, infection, leakage, perforation, and peritonitis (inflammation of the abdominal wall). Long-term complications include leakage around the PEG, tube displacement, erosion of the tube's bulb through the gastric wall, intestinal obstruction, diarrhea, nausea, dehydration, vomiting, hyperglycemia, agitation requiring restraints, weight loss, and loss of lean and fat body mass (Drickamer, 1993; Mitchell, 1999; Volicer, 1993). Some of these side effects (e.g., aspiration, malnutrition, and dehydration) are exactly what some decision makers think they may prevent in initiating tube feeding (Gillick, 2000; McNamara, 2001; Van Rosendaal, 1999). Further, tube feeding does not promote interaction with staff members during feeding and the tasting of food, both simple and important connections to non-institutionalized life (Volicer, 1993).

Based on these risks and poor prognosis, standards of care have changed.

Historically, if the introduction of a tube seemed feasible, a tube was inserted. However, 
the current standard of care is that every effort should be made to enable oral feeding before considering tube feeding (McNamara, 2001). This is based on findings that refute earlier beliefs. For example, physicians now have clinical evidence that tube feeding does not reduce mortality over hand feeding or extend life (Finucane, 1999). Fifty percent of tube-fed patients die within six months (Drickamer, 1993). The course of the illness is influential as well. Additionally, hand feeding does not have a higher mortality rate than tube feeding (Volicer, 1989). However, Solomon reported that $34 \%$ of medical attending physicians and $45 \%$ of surgical attending physicians in their study would continue tube feeding even if all other forms of life support were terminated (1993). This bias is communicated to decision makers as well. Mitchell (1999) found that decision makers cited prolongation of life and prevention of aspiration most commonly as benefits reported by the physician. Change in quality of life should be considered (Drickamer, 1993; Mitchell, 1999). If the aforementioned perceived benefits are inaccurate, and life is not prolonged, some substitute decision makers may find quality of life as a critical deciding factor.

Alzheimer's Disease and Tube Feeding. Alzheimer's Disease is a condition that often promotes deterioration in the ability to self-feed. Rabeneck (1996) found that $30 \%$ of American older adults receiving feeding tubes had dementia, all of whom would have to rely on substitute decision makers to express preferences about tube feeding in late stages of the illness (McNamara, 2001). Accounting for $60-75 \%$ of all U.S. dementia cases (American Bar Association, 2005), Alzheimer's affects 4.5 million Americans (Herbert, 2003). 
In studies of patients with severe dementia, the data bears out clear conclusions that contraindicate tube feeding: there is not evidence that aspiration pneumonia is a lower risk in non-tube-fed patients, or that there is lower risk of infection, improved comfort, or survival (Brockett, 1999; Finucane, 1999; Gillick, 2000; Lacey, 2004; McNamara, 2001). Patients with dementia also have a tendency to pull out the tubes (Gillick, 2000), and physical restraints may have to be used (O’Brien, 1997).

Additionally, the patient's cognitive status is influential in the decision maker's decision (O'Brien, 1997). That is, if cognitive impairment is high, fewer people will choose tube feeding (McNamara, 2001). O’Brien (1997) found that 33\% of nursing home residents preferred tube feeding "when not able to eat due to brain damage." In comparison, Kayser-Jones (1990) found that 53\% of nursing home residents would prefer tube feeding in the situation of being "unable to eat" (regardless of cognitive status).

\section{Decision Aids}

Decision aids are educational materials that inform and enhance the involvement of patients and substitute decision makers with health care providers (Molenaar, 2000). They have become more common in recent years as patients take more responsibility in treatment decisions, there is less paternalism in medicine (Estabrooks, 2001), and as medical technology offers more treatment options (Molenaar, 2000). As paternalism has declined, there has been a shift towards shared decision making between health care provider and patient. Estabrooks described this as a shift from informed consent to informed choice.

Aids have been created for many different kinds of medical decisions, including treatment questions for acute and chronic illness and prevention (Molenaar, 2000). 
Examples include whether to start a hormone replacement therapy regimen, have a prostate cancer screen, and have chemotherapy. Formats include counseling, brochures and booklets, oral presentations, videos, computer-based programs, and combinations of these (Molenaar, 2000), and may be designed for patients or substitute decision makers. Currently, relatively few exist for substitute decision makers.

Systematic reviews of decision aids (e.g., Estabrooks, 2001; Molenaar, 2000; O'Conner, 1999), including the 2005 Cochrane Review of patient aids (O'Conner, 2005), have revealed a wide range of benefits for decision makers, including increased knowledge (Estabrooks, 2001; Molenaar, 2000; O'Conner, 1999; O’Conner, 2005), greater perceived choice (Estabrooks, 2001), more realistic expectations (Estabrooks, 2001; O’Conner, 2005), increased satisfaction with the decision making process (Estabrooks, 2001; O’Conner, 1999), greater acceptance rates by patients (Molenaar, 2000), decreased decisional conflict (Estabrooks, 2001; Molenaar, 2000; O’Conner, 1999; O’Conner, 2005), improved agreement between values and choice (Molenaar, 2000; O'Conner, 2005), decreased proportion of people unable to decide (O'Conner, 2005), and increased patient involvement as a result of the aids (O'Conner, 1999; O'Conner, 2005). Estabrooks et al. (2001), in their review of medical decision aids, found that use of a decision aid did not change the ultimate treatment decision, although knowledge increased. This is supported by Mitchell's (2001) finding that substitute decision makers who were firm in their decision did not change as a result of the aid; however, substitute decision makers who were unsure reported benefiting from the aid. Tube Feeding Decision Aids. There is a paucity of research on decision aids for tube feeding for patients or substitute decision makers as decision makers. Ouslander, 
Tymchuk, and Krynski (1991, 1993, 1994), in the only known examinations of tube feeding decision aids for patients, performed a series of studies using a clinical vignette as the intervention to inform patients about the tube feeding decision. They found that understanding scores improved as a result of the intervention, with community dwellers achieving greater understanding than board-and-care residents $(1991,1994)$. Half of their participants chose the hypothetical decision to tube feed (1993), represented equally in community dwellers and board-and-care residents (1991).

Mitchell's (1999) tube feeding decision aid is the only published aid designed for substitute decision makers. Mitchell's studies $(1999,2000,2001)$ are also unique in the decision aid literature for employing substitute decision makers that are actually making the decision in real life, rather than presenting hypothetical vignettes to potential decision makers. In their pre/post quasi-experimental study evaluating the aid, Mitchell, O'Conner, and Tetroe (2001) recruited 15 substitute decision makers who were referred from health care providers. A "substitute decision maker" was defined as someone who was legally appointed or next-of-kin and informally acting as a proxy. The substitute decision makers were in the real-life situation of needing to make a decision about a cognitively-impaired older adult patient as a candidate for a feeding tube. The patients had the following conditions that indicated possible tube feeding: acute cerebrovascular accident, dementia, postoperative complications with delirium, and Huntington's disease.

Participants were given a pre-questionnaire that assessed existing knowledge, decisional conflict, and their "leaning" or decision (also known as predisposition) about the whether or not to approve tube feeding. Knowledge scores were based on questions created by Mitchell, covering, "swallowing problems, PEG's risks and benefits, 
supportive care, and the role of being a substitute decision maker" (2001). Decisional conflict scores were measured using a modified version of the Decisional Conflict Scale (O’Conner, 1995) which was incorporated into Mitchell's pre/post questionnaire.

Decision was assessed with one direct question in the pre- and post-questionnaires. The aid, administered next, was developed by Mitchell, Tetroe, and O'Conner based on the Ottawa Decision Support Framework (refer to O'Conner et al., 2002 and Ottawa Health Research Institute, 2005a for more information), which has been used as the basis for decision aids on a variety of health decisions. It covers "information on options and outcomes of tube feeding, steps and issues in decision-making, and a worksheet designed to operationalize the decision making steps" (Mitchell, 2001, p. 314). The choice presented is to continue with supportive care only (e.g., hand feeding and/or pain control), or to introduce the feeding tube with supportive care.

The post-questionnaire was administered next. The questionnaire was used to collect information on knowledge, decisional conflict, final decision, and acceptability of the aid. Acceptability questions were created by Mitchell, covering opinions about length, clarity, and helpfulness (Mitchell, 2001).

The aid was beneficial overall. Knowledge scores increased and decisional conflict scores decreased. The change in decision was greatest for those who were unsure prior to completing the aid (seven participants were unsure prior to the aid, and these changed to four against, one in favor, and two unsure at post-test), and the aid was acceptable by all 15 substitute decision makers. Those who were clearly for or against tube feeding did not change their decision. 
In spite of these supportive findings, the Mitchell (2001) study had shortcomings that preclude definitive conclusions regarding the adequacy of this decision aid. A control group was not used, and variables, such as satisfaction with decision, that contribute towards a greater understanding of decision-making, were not used. Further, the statistical power would be improved with a larger sample size.

In summary, medical decision aids have been shown to be beneficial, improving factors such as comprehension and patient involvement in decision making. There are few studies on decision aids for tube feeding, with all but one oriented to patients as decision makers. Mitchell's (2001) study of a tube feeding decision aid for substitute decision makers contributed to the literature by presenting a tool effective in increasing knowledge, decreasing decisional conflict, and assisting substitute decision makers in making a final decision. The study also presented opportunities for further research, most notably in adding a control group.

\section{Statement of the Problem}

Older adults, as a cohort, are increasing in number. Many older adults are affected by illness, and will either need to make, or have made for them, medical decisions. Substitute decision makers can assume the role of decision maker, but "preferencesensitive" decisions are particularly difficult to make for another person. Decision aids have been developed to assist patients and substitute decision makers in organizing and prioritizing medical information and personal values. Whether to initiate tube feeding is a particular decision that is considered for many older adults with conditions that make swallowing difficult. 
Mitchell, Tetroe, and O'Conner (2001) published the only study of a decision aid for the substitute decision makers of patients considered for tube feeding, but no published evaluative studies have followed. Strengths of the study included incorporating assessment of personal values and beliefs, the evaluation of knowledge, decisional conflict, and acceptability of the aid, and the use of substitute decision makers who were making real-time decisions.

These strengths are consistent with recommendations made by Molenaar (2000), based on their systematic review, about the content and experimental design of aids. In terms of content, aids should be "in line with patients' values and needs and 1) reduce patients' decisional conflict or decision uncertainty; 2) lead to decisions that are satisfactory to patients; and 3) increase patients' well-being or quality of life" (p. 125). Further, to enable better evaluation of decision aids "1) patients need to be facing the medical decision at the time of administering the decision aid, 2) studies should include experimental and control groups, and the power and sample size to make comparisons about multiple independent variables, 3) studies should account for mediator variables such as baseline treatment preferences and communication between health care provider and patient, and 4) designs should include long-term follow-up, since health care decisions are about evolving, not static, situations" (p. 126).

Using Molenaar's recommendations, there are criteria that the Mitchell study did not meet. The study did not analyze patient satisfaction and quality of life, include a control group or sufficient sample size for parametric or more sophisticated analyses, account for mediator variables, or follow substitute decision makers over a long period of time. Therefore, to this point the aid has been inadequately evaluated. 
The present study was designed to partially replicate and extend Mitchell's study, using Molenaar's recommendations where possible. First, a dependent variable, satisfaction with decision, was added to measure satisfaction of the potential substitute decision maker's decision and more fully explain the decision making process. Second, a control group was introduced to the pre-post design, yielding an experimental design that enabled a more definitive conclusion regarding the adequacy of the educational materials. Mitchell was able to determine that knowledge scores increased, for example, but could not attribute the change to the aid without the comparison data of a control group. Third, an increased sample size allowed for additional statistical power. Fourth, departing from Molenaar, the pre-questionnaire was modified to acquire additional data, including how long physicians spent educating decision makers. These data provided descriptive information about physician education. Fifth, the study sample was expanded to two groups: substitute decision makers for people with Alzheimer's Disease, Parkinson's Disease, and history of stroke; and "other" substitute decision makers, adults who were asked to hypothetically consider a substitute decision making situation. The choice of patient illnesses was based on the Ratnaike and Hatherly (2002) finding that stroke and neurodegenerative disorders were the most common indications for tube feeding in older adults (40.7\% and $34.7 \%$, respectively).

The following hypotheses and exploratory questions were addressed.

Hypothesis 1: Knowledge scores in the experimental group will improve significantly more than those of the control group from pre-test to post-test. This is based on Mitchell's findings, where knowledge scores increased from pre-test to post-test. 
Hypothesis 2: Decisional conflict scores in the experimental group will improve significantly more than those of the control group from pre-test to post-test (i.e., scores in the experimental group will decrease reflecting reduced conflict). This is based on Mitchell's findings, where decisional conflict scores improved from pre-test to post-test.

Hypothesis 3: Decision of "unsure" participants in the experimental group will change to "against" or "in favor" significantly more often than those of the control group from pre-test to post-test. This is based on Mitchell's (2001) findings, where fewer participants were undecided at post-test.

Exploratory Question: Do younger adults (18-60 years) differ from older adults (60 years and older) in post-test decision ("in favor," "against," "unsure")? This question examines age differences in decision-making. The older adult age range, while arbitrary, was chosen to balance group sample size.

Method

\section{Participants}

Sixty adult participants $($ males $=18[30 \%]$, females $=42[70 \%])$ ranging in age from 23 to $81(M=52.42, S D=15.28)$ were recruited from many sources focused in West Virginia, Georgia, and Ohio. Organizations participated by hanging flyers, contacting patients' families via mail, including advertisements in newsletters, and forwarding a pre-approved email. Organizations included long term care institutions (28 contacted, 17 participated), community organizations like the Alzheimer's Association (15 contacted, 7 participated), religious institutions ( 8 contacted, 5 participated), and support groups ( 3 contacted, 3 participated). The most productive strategy was personal email, which was forwarded to friends and family. Half of the participants were known to 
the experimenter. Fifty-four (90\%) of the participants were Caucasian $(3.3 \%$ Asian $[n=$ 2], 5\% African American $[n=3])$, and 1.7\% $(n=1)$ self-identified ethnically as Hispanic/Latino. Twenty-seven (45\%) of the participants were substitute decision makers for a person with Alzheimer's Disease, Parkinson's Disease, or a victim of stroke. Thirtythree $(55 \%)$ of the participants were typical adults from the community, recruited to supplement the sample due to difficulty in recruiting established substitute decision makers. These adults are referred to as "other" substitute decision makers in this manuscript. All participants were randomly assigned to experimental and control groups ( $n=29$ and 31, respectively).

Experimental Design

The study employed a two-group pre-test/post-test design, as illustrated in Table 1. Pre- and post-questionnaires were used to detect change in the decision maker's knowledge, decision, decisional conflict, acceptability of the aid, and satisfaction with the decision before and after the administration of a decision aid booklet or control brochure.

The statistical software PASS was used to determine a desired sample size of 52. This sample size was consistent with an expected power of $80 \%$ (as used in Krynski, 1994), $p=0.05$, and a medium effect size of $f=0.40$ (Hemphill, 2003).

\section{Materials}

Mailed packets contained a cover letter, a consent form, a copy of the consent form to keep, participant instructions, the pre-questionnaire, experimental or control reading (i.e., the decision aid booklet or active control brochure), post-questionnaire, and raffle information. Copies of all materials may be found in the Appendix. 
Consent. The consent form introduced the study, presented the purposes, study design, risks, benefits, and explained confidentiality.

Participant Instructions. Participant instructions guided the participant step-bystep through the completion of the questionnaires and reading material.

Pre- and Post-Questionnaires. Mitchell's (2001) paper pre- and postquestionnaires, developed in tandem with the tube feeding decision aid, were used. The questionnaires utilized Likert-type and fill-in-the-blank item formats. No data has been published on the psychometric properties of the questionnaires. The questionnaires included questions about demographics, knowledge, decision, decisional conflict, acceptability of the aid, and satisfaction with the decision. The latter was added to Mitchell's version. Each of these outcome variables will be discussed in turn.

Knowledge measures an awareness of a health dilemma, including the options and possible results (O’Conner, 2002). Questions about swallowing problems, feeding tubes, tube feeding outcomes, and the role of a substitute decision maker were included.

Decision is defined as a person's “stated choice among alternatives" (O’Conner, 1996). A 3-point Likert-type scale was used in the present study, with $1=$ "against," $2=$ “in favor," and 3 = "unsure." This was a modified, categorical version of Mitchell's (2001) scoring technique, which used an 11-point Likert-type scale. Mitchell's scale is associated with the "predisposition" construct rather than the "decision" construct. However, the assessment of the decision construct in the present study, according to the current conceptualization by the Ottawa Health Decision Centre (O’Conner, 2002), is in keeping with the term "decision," therefore it is used here rather than "predisposition." 
Decisional conflict measures the "uncertainty about the course of action to take" (O'Conner, 2002, p. 2). The DCS addresses the following characteristics of decisional conflict: “(a) uncertainty in choosing options; (b) modifiable factors contributing to uncertainty such as feeling uninformed, unclear about personal values, and unsupported in decision making; and (c) effective decision making such as feeling the choice is informed, values-based, likely to be implemented, and is deemed satisfactory" (O’Conner, 1995; Ottawa Health Research Institute, 2005b). The Scale includes five subscales: informed, values clarity, support, uncertainty, and effective decision, which were not assessed in the present study.

The 17 questions in Mitchell's pre- and post-questionnaires included a customized version of the Decisional Conflict Scale (DCS) (O'Conner, 1995) and one item by Mitchell. The extra question, "I feel that my patient would agree with my choice," was included for information about confidence in the decision. The DCS is intended to be customized to particular health decisions, e.g., tube feeding decisions. Questions were modified by Mitchell; for example, "I have enough advice to make a choice" was changed to, "I feel I have had enough advice about the choices being offered to manage my patient's eating/swallowing problem." As a measure used for both substitute decision makers and "other" substitute decision makers, the DCS total score had limitations. Specifically, the item that referred to the patient's swallowing problem would likely not be applicable to all participants, but all participants answered the item. Questions used a 5-point Likert-type scale, with $0=$ "strongly agree" and 4 = "strongly disagree." However, coding in the present study used $1=$ "strongly agree" and $5=$ "strongly disagree." To maintain consistency with the original DCS, scores on the original 16 
questions were summed, divided by 16 , and multiplied by 25 . (The multiplication standardizes all scores to a maximum 100 points.) To account for the difference in coding (i.e., 5 rather than $4=$ "strongly disagree") with the original DCS, 16 was subtracted after the summing procedure. Thus, scores were standardized with a maximum score of 100 representing higher decisional conflict. The psychometric properties of the original scale were examined in a study of 909 decision makers, and are provided here as background information for the modified scale. The test-retest reliability coefficient was 0.78 , and Cronbach's alpha coefficients ranged from $0.78-0.92$. The measure effectively discriminated between participants who made and delay decisions $(p<.0002$, effect size of 0.4 to 1.2 ). Construct validity was established by examining the relations between DCS scores of known groups, revealing weak relations with groups of people identified as making decisions and strong relations with groups of people identified as delaying decisions (O’Conner, 1995; Ottawa Health Research Institute, 2005b).

Acceptability was measured to capture opinions about the aid in terms of length, clarity of information, fairness, and helpfulness. Four- and 5-point Likert-type scales were used. Further, three open-ended questions were included.

Satisfaction with the decision was measured using the Satisfaction with Decision Scale (SWD) (Holmes-Rovner, 1996). The six-item scale is intended to "measure global satisfaction with the decision and the three attributes of an effective decision and differentiate satisfaction with the decision from related aspects of satisfaction" (HolmesRovner, 1996, p. 58). The measure employs a 5-point Likert-type scale. In their evaluation, the author found high internal consistency $(n=252$, Cronbach's alpha $=0.86)$ and good discriminant validity based on the measure's relationship to the Decisional 
Conflict Scale $(r=0.54)$ and similar scales. Additionally, the SWD scores, along with knowledge scores, predicted decision certainty $(\mathrm{r}=0.38$; Holmes-Rovner, 1996).

Experimental Reading. Mitchell’s decision aid, “Making Choices: Long-term Feeding Tube Placement in Elderly Patients" (1999), was used as the intervention for the treatment group. The aid is self-paced, walking the decision maker through components of the decision. There are three modules, including: (1) education about the medical aspects of tube feeding, including risks, benefits, and goals, (2) orientation to the substitute decision maker role, including consideration of values and representing the voice of another person, and (3) a worksheet which assists the substitute decision maker in organizing information, including three example scenarios that conclude with different decisions (Mitchell, 2001). The aid does not emphasize research findings for patients with Alzheimer's Disease, Parkinson's Disease, or stroke specifically, but assumes that the patient is "cognitively impaired" to the extent that he or she does not have medical decision-making capacity.

Control Reading. A six-panel brochure entitled "What are My Choices Regarding Life Support?” (Society of Critical Care Medicine, 2002) was given to the control group as an alternative active control for the tube feeding decision aid. The brochure is structured as a glossary, defining terms such as "do-not-resuscitate order," "palliative care," "defibrillation," and "dialysis." "Tube feeding" is accompanied by the following text, which does not include a discussion of risks and benefits and other details included in the experimental reading:

Tube feeding is the administration of a chemically balanced mix of nutrients and fluids through a feeding tube. Most commonly, a feeding tube is inserted into the 
stomach via the nasal passage (nasogastric or " $\mathrm{NG"} \mathrm{tube)} \mathrm{or} \mathrm{through} \mathrm{the} \mathrm{wall} \mathrm{of}$ the abdomen (gastronomy tube or "PEG") by means of a surgical procedure. Another tube of feeding tube is inserted surgically through the abdominal wall into the small intestine (jejunostomy tube) (p. 4).

\section{Procedure}

Participants were recruited from around the United States using methods described in the participant section. Participants were randomly assigned to experimental and control groups in the order they contacted the experimenter, using a computergenerated participant number list. Typically, participants called or emailed the investigator after learning of the study, and a study packet was mailed to the participant to complete at his or her leisure. With the exception of three participants who completed an in-person administration, all participants completed the study through the mail.

Participants were provided all materials in one envelope with instructions about the order of completion. Instructions for substitute decision makers and "other" substitute decision makers were identical, except for a few phrases in the cover letter. For the substitute decision makers, emphasis was placed on the possibility that tube feeding could present a future dilemma, but that the decision regarding the use of tube feeding was not necessarily imminent. "Other" substitute decision makers were asked to consider a hypothetical situation, for example, that the medical condition of an older adult relative indicated tube feeding. Participants were instructed to complete the consent form first, followed by the pre-questionnaire, which included demographic information. Next, members of the experimental group were instructed to complete the tube feeding decision aid as the intervention. Alternatively, members of the control group were instructed to 
read a brochure about end of life care. The intervention period was followed by a postquestionnaire comprised of the same questions as the pre-questionnaire, with additional questions about satisfaction and acceptability. As they completed each step, participants were instructed to seal the pre-questionnaire and reading material in a provided envelope, so as to not influence responses in the post-questionnaire. All materials were returned to the investigator in the mail. As a financial incentive, participants were given an opportunity to win one of two $\$ 50$ cash prizes in a raffle at the end of the study.

Questions about knowledge were answered in a true/false/unsure format and the number of correct answers were summed to arrive at a knowledge score (maximum score reflecting more knowledge $=35$ ). In the pre-questionnaire, Sections C1, C2, E1, E2, F1, F2, and D were summed; in the post-questionnaire, Sections B1, B2, C, D1, D2, E1, and E2 were summed. Analysis of this continuous variable included descriptive statistics and analyses of variance.

Questions about decision were posed before and after the intervention/control reading, asking, "At the present time, what is your overall leaning about placing a feeding tube in the patient?" (pre-questionnaire item A8, post-questionnaire item A2). Descriptive statistics were used to analyze this categorical variable.

Questions about decisional conflict (i.e., the Decisional Conflict Scale) appeared in the study questionnaires in Sections G (pre) and H (post). The customized DCS questions were scored according to O'Conner's (1995) recommendations. A total score was obtained by summing each participant's scores, dividing by 16 (the number of items), and multiplying by 25 . Therefore, scores ranged from $0=$ "no decisional conflict" to $100=$ "extremely high decisional conflict." The extra question, "I feel that my patient 
would agree with my choice," was analyzed separately from the DCS questions.

Decisional conflict, a continuous variable, was analyzed using descriptive statistics and analyses of variance.

Quantitative and open-ended questions about acceptability were included in postquestionnaire Section J. The responses were analyzed and reported individually, but collectively represented the construct of acceptability. Analysis included examination of means.

Questions about satisfaction (i.e., Satisfaction with Decision Scale) were inserted in the post-questionnaire (Section I) before the acceptability questions. Scores were summed, with a maximum score of 30 reflecting greater satisfaction. Analysis of this continuous variable included descriptive statistics and analyses of variance.

The study was approved by the Institutional Review Board (IRB) at West Virginia University, and was partially funded by the West Virginia University Department of Psychology Alumni Fund.

Results

\section{Data Management}

All data were reviewed for appropriateness for analysis. There were three nonextreme outliers, which were not altered based on their nominal influence on the mean. Assumptions of the two-way mixed ANOVA included the following: independent variables were categorical, dependent variables were measured at the interval/ratio level, the distribution of residuals was normal (assessed by the Wilk-Shapiro and KolmogorovSmirnov tests of normality), the distributions had equal variances (assessed by Levene's 
test with significance greater than .05), and homogeneity of intercorrelations (assessed by Box's Test with significance greater than .001).

Assumptions of categorical independent variables and dependent variables measured at the interval level were met for the two research questions involving continuous data, Hypothesis 1 (knowledge) and Hypothesis 2 (decisional conflict). All scores were non-significant for the Wilk-Shapiro test of normality, indicating that the present sample likely came from a normally distributed population. However, a second test of normality, the Kolmogorov-Smirnov analysis, indicated that the Knowledge Total - Post scores were not likely comparable to the population distribution $(p=.03)$. Because the Wilk-Shapiro test has more power, a decision was made not to transform the Knowledge Total - Post scores to improve the fit to the population distribution. Levene's test of homogeneity of variance indicated that knowledge and decisional conflict scores were homogenous $(p>.05)$ for all variables except Knowledge Total - Pre $(p=.04)$. Therefore, variances in Knowledge Total - Pre scores were slightly different from other scores, and equal variances were not assumed in the reporting of test statistics. Box's Test of Equality of Covariance Matrices produced a statistic greater than .001 , indicating that the assumption of homogeneity of variance-covariance matrices (or homogeneity of intercorrelations) was met. The significance level for the two planned ANOVAs (Hypotheses 1 and 2) was set to $p<.05$.

A non-parametric loglinear analysis (e.g., using a Chi-Square statistic or likelihood ratio statistic) would have been appropriate for the categorical variables in Hypothesis 3 (tube feeding decisions) and Exploratory Question 1 (age group differences in decisions), but assumptions were not met. For example, cells contained fewer than five 
observations (Howell, 2002), three cells contained zero observations (Field, 2000), and observations were not independent (Tabachnick \& Fidell, 2001). Therefore, tube feeding decisions were analyzed using descriptive statistics.

Correlation analyses were performed for Exploratory Question 5 (knowledge and decisional conflict). The analyses met all assumptions: continuous variables, related pairs of data, independence of observations, normality, linearity, and homoscedasticity (Pallant, 2005).

Initial Analyses

Descriptive statistics of demographic variables are summarized in Table 2. To determine whether data from the substitute decision maker and "other" substitute decision maker groups (knowledge, decisional conflict, and decision) could be combined for analysis, the groups were compared using analyses of variance and chi square analysis. No significant differences were found, as illustrated in Tables 3 and 4 (also see Table 6). The substitute decision makers and "other" substitute decision makers were therefore combined for study analyses.

Overview of Results

The hypotheses and exploratory question were supported in one case. Hypothesis 1 was supported, as knowledge scores in the experimental group improved significantly more than those of the control group from pre-test to post-test. Hypothesis 2 was not supported, as decisional conflict scores in the experimental and control groups increased rather than decreased. Hypothesis 3 was not supported. Those in the experimental group who endorsed "unsure" status about tube feeding at pre-test did not report "in favor" or "against" (i.e., decided status) more often than the control group at post-test. The results 
pertaining to the exploratory question indicated that younger adults were more often in favor of tube feeding than older adults. Further, participants were satisfied with their tube feeding decision, and found the decision aid to be acceptable. There was a positive relationship between pre-test knowledge and pre-test decisional conflict. The hypotheses and exploratory questions are presented in detail below (further, see Table 5).

\section{Hypothesis Testing}

Hypothesis 1: Knowledge scores in the experimental group will improve significantly more than those of the control group from pre-test to post-test. This hypothesis was supported.

A 2 (experimental versus control group) x 2 (pre- and post-test knowledge) repeated measures analysis of variance (ANOVA) was conducted to assess differences in knowledge between groups at pre- and post-test. A main effect was revealed for group, $F(1,58)=77.42, p<0.01, \eta=0.57$. There was a significant interaction between group and time, $F(1,58)=20.72, p<0.01, \eta=0.26$. Specifically, the group main effect was accounted for by the post-test group differences, $F(1,58)=48.22, p<0.01, \eta=0.45$. The pre-test scores did not differ, $F(1,58)=0.11, p>.05, \eta=0.00$. Therefore, knowledge improved from pre-test to post-test, and the experimental group demonstrated the most improvement, as illustrated in Figure 1.

Although the Mitchell (2001) study did not have a control group, the results can be compared to those of the present study's experimental group. Mitchell used an alternative scoring procedure, reporting results in terms of percentage of questions answered correctly, rather than total number answered correctly. The percentage correct in the Mitchell study at pre-test was $50.4 \%$, and $84 \%$ at post-test. The present study's 
experimental group participants achieved a comparable 56.9\% correct at pre-test, and $86.5 \%$ correct at post-test.

Hypothesis 2: Decisional conflict scores in the experimental group will improve significantly more than those of the control group from pre-test to post-test (i.e., scores in the control group will decrease reflecting reduced conflict). This hypothesis was not supported.

A 2 (experimental versus control group) x 2 (pre- and post-test decisional conflict) repeated measures ANOVA was conducted to assess differences in decisional conflict between groups at pre- and post-test. A main effect was revealed for group, $F(1,58)=38.60, p<.01, \eta=0.40$, and there was a significant interaction between group and time, $F(1,58)=5.79, p<.05, \eta=0.09$. Significant simple effects of group were found at post-test only, $F(1,58)=6.18, p<.05, \eta=0.10$, with both groups reporting increased decisional conflict scores. Decisional conflict scores in both groups increased at post-test, with the experimental group reporting significantly higher conflict compared to the control group at post-test (Figure 2).

The reference study (Mitchell, 2001), used an alternative scoring procedure, averaging the scores as they were directly reported on the 5-point Likert-type scale (i.e., the scores were not standardized). The mean at pre-test was $2.88(S D=0.62)$ and 2.29 $(S D=0.52)$ at post-test $(p=.004)$. For purposes of comparison, scores in the present study were scored in the same way. The mean for all participants at pre-test was 2.20 (SD $=0.79)$ and $2.66(S D=0.57)$ at post-test. When experimental group participants $(n=29)$ were considered, the pre-test average was $2.20(S D=0.88)$ and post-test was $2.83(S D=$ $0.52)$. When the experimental group's actual substitute decision makers $(n=12)$ were 
considered, the pre-test average was $2.21(S D=1.04)$ and the post-test average was 2.86 $(S D=0.65)$. Therefore, participants in the present study obtained decisional conflict scores at pre-test that were very similar to Mitchell's participants' post-test scores.

Hypothesis 3: Decision of "unsure" participants in the experimental group will change significantly more often than those of the control group from pre-test to post-test. The hypothesis was not supported.

Descriptive statistics indicated that participants who were "unsure" at pre-test in the experimental group did not change to "in favor" or "against" more often than those in the control group (see Figures 3 and 4). In the experimental group, participants who were unsure at pre-test were divided on post-test positions, with three of six maintaining their unsure status, and three of six becoming in favor of tube feeding. In the control group, six participants were unsure at pre-test. Of these, four were against and two were in favor of tube feeding at post-test. That is, none were undecided at post-test.

\section{Exploratory Analysis}

Exploratory Question 1: Do younger adults (18-60 years) make different tube feeding decisions (i.e., decision of "in favor," "against," "unsure") than older adults (60 years and older) at post-test?

Descriptive statistics indicated that older adults were approximately evenly split between being against and in favor of tube feeding at post-test $(n=8$ and 10, respectively), while younger adults were more often in favor of tube feeding $(n=23$, compared to $n=10$ against). Those who endorsed "unsure" were similar in both groups. Due to the limitations previously discussed in analyzing the categorical data, it was not 
possible to determine the significance of these differences. See Table 7 for more information.

\section{Additional Questions}

Exploratory Question 2: Was the decision aid acceptable to experimental group participants? This question was asked as an overall evaluation of the perceived adequacy of the aid.

The experimental group reported that the length was "about right" (76\%), that "most" or "everything" was clear (93\%), the booklet was "completely balanced" (52\%; $31 \%$ endorsed "slightly slanted in favor of tube feeding"), $90 \%$ reported that the booklet was "very" or "somewhat" helpful, and 97\% reported that they would "definitely" or "probably" recommend the booklet.

Participants offered valuable suggestions to improve the decision aid in response to open-ended items in the acceptability section. Selected comments include: interest in including additional information about alternatives to tube feeding, including handfeeding; the constraints of living facility options that tube feeding necessitates, including whether home-care is an option; and how a tube feels, including whether the patient will feel hunger or thirst. Participants asked for an acknowledgement of the complicated nature of the decision, specifically noting the influence of religion and ethics. They noted that more information about this, or referrals, would be helpful. Lastly, one participant noted that including a list of questions to discuss with a physician would be helpful.

The reference study (Mitchell, 2001) also found the decision aid to be acceptable. Participants reported that the aid helpful and that they would recommend it to others $(100 \%)$, clear $(93 \%)$, balanced $(80 \%)$, and appropriate in length $(80 \%)$. Therefore, the 
present study and Mitchell's study had similar findings on components of acceptability, with an exception in the report of balance or bias.

Exploratory Question 3: Do experimental group participants report greater satisfaction with their decision than control group participants? This question was asked as an overall evaluation of satisfaction with decision, and is an extension to the Mitchell (2001) study.

Satisfaction with the decision was similar in both groups (experimental: $M=$ $24.48, S D=3.39$, control $M=23.42, S D=3.14$ ). In the experimental group, $75.7 \%$ of the scores fell between 24 and 30 (30 was the maximum score, indicating greater satisfaction). An analysis of variance failed to find a significant difference in satisfaction between the groups, $F(1,58)=1.59, p>.05$ (see Table 5).

Exploratory Question 4: What information did the actual substitute decision makers in the experimental and control groups report about their patients and physician interaction? This question was asked to assess time physicians spend discussing tube feeding, and is an extension to the Mitchell (2001) study.

Just nine of 27 of the substitute decision makers reported the illness from which their patients suffered, including Alzheimer's Disease $(n=4)$, Parkinson's Disease ( $n=$ 2), autoimmune disease, cancer, and Lewy Body-Related Neurodegeneration. The average patient age was 78.2 years $(S D=12.8)$, and decision makers had been caretakers for an average of 52 months ( $S D=50.0$, range of 4 to 180 months). Physicians had spoken with decision makers about tube feeding for an average of 23.8 minutes $(S D=$ 21.5). Of the ten substitute decision makers who responded to the item, $40 \%$ of 
physicians had discussed tube feeding for 10 minutes or less. See Table 6 for more information.

Exploratory Question 5: How were pre- and post-test knowledge scores related to pre- and post-test decisional conflict scores?

A bivariate, two-tailed correlation analysis showed that pre-test knowledge scores were significantly related to pre-test decisional conflict scores $(r=.26, p<.05, n=60)$. That is, participants who had higher pre-test knowledge scores also had higher pre-test decisional conflict. Similarly, participants who had lower pre-test knowledge scores also had lower pre-test decisional conflict. Other combinations of pre- and post-test knowledge and decisional conflict scores were not significantly correlated.

\section{Discussion}

The present study investigated the effects of a decision aid for surrogate decision makers on tube feeding knowledge, decisional conflict, and decision. Three hypotheses were tested and three exploratory questions were addressed. Of the hypotheses, only the first was supported, although interesting patterns were found throughout the data.

Hypothesis 1 examined whether the experimental group gained greater knowledge than the control group about tube feeding and decision making through use of the decision aid. As expected, the experimental group reported greater knowledge at post-test compared to the control group. At the very least, it appears that the decision aid has potential utility for helping decision makers make more informed decisions. These results are consistent with those of Mitchell (2001), who also found increased knowledge after completion of the decision aid. The present findings, which corroborate those of Mitchell, support the use of the decision aid by surrogates who are seeking fundamental 
information and guidance in making tube feeding decisions. Further, the finding demonstrates that participants read, comprehended, and applied the information in the decision aid and brochure, serving as a basic assessment of participation.

Hypothesis 2 proposed that decisional conflict scores in the experimental group would demonstrate greater improvement (that is, that conflict would decrease) than the control group as a function of the decision aid and brochure, respectively. The hypothesis was not supported. Not only did decisional conflict scores increase for both experimental and control groups, but the experimental group reported the highest scores. There are at least two potential explanations for these unexpected findings. First, for some participants, the tube feeding decision might have brought to mind the emotions and decisions associated with death. Therefore, it is possible that the process of completing the study questionnaires, decision aid, control brochure or some combination of these, prompted the participants to approach this very important decision as overwhelming or anxiety-provoking, at least in the short-term (Anderson, 2003). That is, the importance of the decision, the associated emotional arousal, and perhaps overwhelming amount of information could have influenced the conflict ratings. Second, the greater amount of information presented to the experimental group than the control group could have led to greater indecisiveness. Perhaps having more information complicated the process of decision-making. It is reasonable to suggest that indecisiveness might lead to decisional conflict.

In contrast to the present findings, Mitchell (2001) obtained opposite results, with decisional conflict decreasing for 13 of 15 participants. As previously noted, the pre-test scores were significantly different, with Mitchell's decreased post-test scores being 
nearly the same as the present study's pre-test scores. Therefore, it is difficult to compare the findings. However, there are a couple of possible explanations, though speculative. It is possible that the decreased decisional conflict demonstrated in the Mitchell study at post-test could be attributed to the fact that participants were making a real life tube feeding decision imminently, whereas the participants in the present study were making the decision hypothetically. As previously noted, Mitchell's participants may have had heightened emotional arousal at pre-test due to the significance of the real decision before them. This situation could promote higher decisional conflict scores at pre-test. They may have also had more desire to reach a confident resolution at post-test (i.e., against or in favor of tube feeding) since they were likely to apply the tube feeding decision to their real-life patient. This explanation would point to decreased decisional conflict at posttest. In contrast to Mitchell's study, the participants in the present study would not have expected to apply their tube feeding decision to their patient in the near future.

Related studies about decisional conflict in medical decision-making have supported the Mitchell study (2001) findings. For example, O'Conner et al. (1998) found that tailored decision aids decreased decisional conflict more than general pamphlets. Decisional conflict was also reduced and maintained over several assessment times after a decision aid intervention in a study by Rothert et al. (1997). Whelan et al. (2004) found similar results in an evaluation of decisional conflict on breast cancer surgery decision making.

The increased decisional conflict demonstrated in the present study may represent a positive outcome. One has to take into consideration how these participants, facing a hypothetical situation, entered the experimental condition in a different state of mind than 
the participants in Mitchell's (2001) study. Mitchell's participants would have had time to consider that the tube feeding decision was upon them, and emotions likely played a role in their use of the decision aid and the decision making process. For them, the information provided by the decision aid could have served to decrease decisional conflict and emotional arousal by assisting them in arriving at a decision they knew they needed to make outside of the study situation. In the case of the present study's participants, they likely had not previously considered tube feeding in a serious way. They would have begun the questionnaires and decision aid without prior forethought and the pressure of needing to make a real-life decision. For them, the aid could have served to increase decisional conflict by raising questions about tube feeding. Moreover, the increased conflict could have prompted the participant to seek additional information and promoted more informed decision-making.

These results suggest that substitute decision makers who are facing imminent decisions may approach decision-making differently than those who are not facing imminent decisions. Different motivations, forethought, and concerns may contribute to higher pre-test decisional conflict and decided status at post-test. It is interesting that the substitute decision maker and "other" substitute decision maker groups faced with hypothetical decisions in the present study reported similar changes in decisional conflict (i.e., between-group differences). The differences in scores in the present and Mitchell (2001) study suggest that decisional conflict and related constructs may vary on a continuum of proximity to decision. Perhaps participants in the present study would report pre- and post-test decisional conflict similar to those of the Mitchell study if they were facing an imminent tube feeding decision. 
Finally, the intersection of Hypothesis 1 and 2 were considered in Exploratory Question 5, which investigated the relation between knowledge and decisional conflict. Of the four permutations of pre- and post-test variables, only pre-test knowledge and pretest decisional conflict were correlated. This is a quizzical relation, but perhaps participants judged their performance on the knowledge items, which appeared first, in accordance with their decisional conflict, which was reported later. That is, if participants judged that they had done poorly on the knowledge items, perhaps they also reported high levels of decisional conflict, and vice versa.

Hypothesis 3 examined whether the participants in the experimental group who were "unsure" at pre-test would reach a conclusion (i.e., "against" or "in favor") at posttest more often than participants in the control group. It was expected that completing the decision aid would promote more decisiveness about tube feeding decisions than the active control brochure. However, use of the decision aid did not yield greater decisiveness than use of the control brochure by the control group.

The "undecided" or "indecisiveness" finding in the present study's experimental group may be due to the participants' feeling of being overwhelmed by the potential outcomes of the decision after completing the decision aid. This explanation is grounded in part by the literature acknowledging the role of emotions in decision-making (e.g., Bechara, 2003; Ditto, Hawkins \& Pizarro, 2005; Löckenhoff \& Carstensen, 2004), which argues that emotions may play an important role alongside the consideration of factual information. Secondly, the presentation of choices can be aversive (Schwartz, 2004). Therefore, it may not be surprising that undecided status is maintained in a "preference sensitive" decision involving the weighing of several choices being made on behalf of 
another person. Any doubt or confusion that existed at pre-test may have been compounded by the presentation of new information.

The analysis of this hypothesis was limited by sample size, given the pre-test differences observed in the groups. Compared to those who were "in favor" and "against," few participants chose "unsure" at pre-test. If there had been more participants responding "unsure" at pre-test, different proportions of post-test decisions might have been found. This might have allowed for more confident conclusions about the effects of new and additional knowledge on decisions and decisional conflict.

In Mitchell's (2001) study, the majority of participants who were "unsure" at pretest $(n=7)$ became "in favor" $(n=1)$ or "against" $(n=4)$ tube feeding at post-test. Thus, the decision aid appeared to assist her participants with reaching a conclusion. It is unclear why the initial choices in the Mitchell sample differed from those of the present study. This may have been due in part to the small number of unsure participants in both studies at pretest, which may well have yielded unreliable findings. As noted previously, it is probable that the decision makers in the Mitchell study presented to the study situation with different motivations than the participants in the present study.

Like the present study, participants in the Mitchell (2001) study completed the post-test immediately after completing the decision aid. Since the Mitchell study enrolled participants who were facing an imminent tube feeding decision for their patient, it is again possible that the immediacy, need for the decision, and the potential consequences of the decision influenced responding. Perhaps decision makers who need to make a reallife decision have a greater desire to reach a conclusion after completing the decision aid. Decision makers in both studies had the opportunity to make more informed tube feeding 
decisions based on the decision aid. While one would suspect that this would lead to increased comfort with decisions and decisiveness, this was not the case with the current sample.

Others have described decisional conflict as being related to the certainty of a decision. O'Conner, Jacobsen, and Stacey (2002) proposed that verbalized uncertainty, such as that found when facing a tube feeding decision, is a defining feature of decisional conflict. Further, the authors describe decisional conflict as increasing as a decision maker begins the decision making process and decreasing post-decision. Thus, O'Conner et al. would argue that the decision making process reduces decisional conflict. Perhaps the participants in Mitchell's (2001) study, who had elevated pre-test decisional conflict, had already begun their decision making process at the time of being presented with the aid.

The decision data in the present study yielded additional results that add to the understanding of Hypothesis 3. The decisions of the control group were opposite of what was expected. That is, control group participants were not expected to become more decided at post-test, since they had not completed the decision aid. However, one hundred percent of the control group participants who were "unsure" at pre-test changed decisions (four became "against," and two became "in favor"). It is unclear what could explain the post-test decisiveness. Perhaps participants were less susceptible to feeling overwhelmed because the presentation involved less information. Therefore, the participants may have been more likely to reach a conclusion. That is, these participants were not presented with an overwhelming amount of information, provoking a complicated decision making process leading to increased arousal. These participants 
may have felt more comfortable reaching a conclusion given that they weighed fewer factors in the decision.

Second, decided participants may be different from those who were "unsure." This may be important to consider in the development of decision aids. For example, decided participants in the present study may have weighed new information or handled decisional conflict differently. Control group participants who were "against" or "in favor" of tube feeding at pre-test overwhelmingly maintained this preference, with only one participant deviating. In contrast, the majority of experimental group participants who were "decided" at pre-test maintained their decisions. This majority result was also found in Mitchell's study, where 100\% of participants who were decided at pre-test remained decided at post-test.

Third, several participants in the control and experimental groups changed from decided status at pre-test to "unsure" at post-test. Whereas the decisional patterns of participants who were "unsure" at pre-test were explored above, the present finding further explains "undecided" behavior by focusing on the decisional patterns of those who changed to "unsure" at post-test. Participants who follow this pattern of decisionmaking may be important to recognize as a distinctive population. The pattern could reflect consideration that the tube feeding decision was more complicated than the participants had previously considered. In raising new questions, the decision aid and brochure may have increased decisional conflict in these participants, promoting a shift to undecided status.

Exploratory Question 1 investigated whether there were age effects on tube feeding decisions. The tube feeding decisions of younger adults, aged 18-60 years, were 
compared to those of older adults, aged 60 years and older, at post-test. It was expected that older adults, being more likely to make tube feeding decisions sooner than younger adults, might make different decisions. Differences were born out, but it is not possible to assess their significance. Approximately half of older adults were in favor of tube feeding, where $63 \%$ of younger adults were in favor. Perhaps based on their additional years of experience, familiarity with other's tube feeding experiences, proximity to death, or cohort effects, current older adults are more likely to endorse tube feeding less often than current younger adults. However, this is speculation.

Although no published research about tube feeding decisions by age group was found in the literature, studies by Levinson et al. (2005), Robinson and Thomson (2001), and Meyer, Russo, and Talbot (1995) indicated that age group may be related to decisionmaking involvement and process, but possibly not to the actual decision or outcome.

Exploratory Question 2 investigated the acceptability of the decision aid. Participants found the aid to be highly acceptable. Interestingly, only half of participants found the aid to be balanced, however, and a third found the aid to be biased towards tube feeding. This finding may add meaning to the report of participants being in favor of tube feeding overall. The decision aid was intended to be balanced in its presentation of tube feeding information. However, some might argue that it was biased against tube feeding, given its discussion of factors that are not commonly considered and findings that do not support tube feeding (e.g., tube does not prevent aspiration, prolong survival, or improve function). Therefore, the acceptability findings are perplexing to interpret. Most decision makers maintained their tube feeding decisions from pre- to post-test, and perhaps some participants experienced a confirmation bias. That is, participants may have attended to 
information that supported their pre-test decision, and ignored information that conflicted (Jones, 2001). For example, most participants were in favor of tube feeding at pre-test, maintained the in favor decision at post-test, and a significant number found the aid to be slightly biased towards tube feeding. This is supported by the work of Festinger (1964) on cognitive dissonance, which argued that after a decision is made, new information will be weighed with a bias toward the initial decision.

Although the control group's brochure was not a focus of this investigation, the acceptability question was asked of the control group. Participants widely reported satisfaction with the brochure, even though it addressed few of the questions raised in the pre- and post-questionnaires. This finding further confirms that participants may not desire detailed information to make a tube feeding decision.

Exploratory Question 3 investigated satisfaction with the tube feeding decision. Overall, participants were satisfied with their decisions, and the experimental and control groups' ratings of satisfaction did not differ significantly. It has already been noted that control group participants reported less decisional conflict about their decision, and found the brochure to be acceptable. Taken together, these findings indicate that the brochure was virtually as effective as the decision aid.

Exploratory Question 4 investigated the decision maker-patient and decision maker-physician relationships. These results suggest that the patients who are most likely to face tube feeding (i.e., those with Alzheimer's Disease, Parkinson's Disease, and victims of stroke), are also under their decision makers' care for a long time. Further, although physicians are spending 20 minutes on average discussing tube feeding with decision makers, just half of decision makers in a previous study reported being satisfied 
with the education they received from the health care team (Mitchell, 1999). Therefore, there may be room to improve communication with these decision makers.

In conclusion, these findings support the need for more research about the value of tube feeding decision aids. First, the tube feeding decision aid appears to promote the acquisition of knowledge in medical decision-making. Second, the consideration of tube feeding issues (e.g., answering questions and reading about tube feeding in brief or detailed form) may increase decisional conflict immediately after participation. However, it is unclear why this is the case and whether it is necessarily a negative finding. Third, people who are "decided" about tube feeding tend not to change their responses as a result of learning new information. The influence of the present decision aid on those who are "unsure" about tube feeding is not clear. It is possible that the aid both increased decisional conflict and decisional uncertainty (i.e., "unsure" status at post-test).

The most important implication of these findings may be that exposure to tube feeding information - whether it is a simple brochure, a decision aid, or questionnaires may promote consideration of facts, ethics, and preferences by the decision maker. That is, setting the occasion to ponder the tube feeding decision may be an important element in reaching a decision, in addition to providing thorough information. However, readiness to make a decision is not necessarily equated with informed decision-making. Further, there may be advantages and disadvantages to being "decided" at post-test. Undecided status could be reflective of productive, informed decision-making.

\section{Limitations}

Several limitations of the present study deserve consideration. First, the use of substitute decision makers who were not imminently facing a tube feeding decision 
limited the generalizability of the findings and precluded direct comparisons with the Mitchell (2001) study.

A second limitation was the gender distribution of participants. A minority of participants (30\%) were male. This may have limited the generalizability to male tube feeding decision-makers. Although the proportion of males participating in the present study may not differ much from that of the general caregiving population (The Henry J. Kaiser Family Foundation, Harvard School of Public Health, United Hospital Fund of New York, \& Visiting Nurse Service of New York, 2002), proportion similarity does not address the sample size shortcoming related to generalizability. A third related limitation is the relatively small sample size in general and the number of "unsure" participants at pre-test in particular.

A fourth limitation was the paucity of racially and ethnic diverse participants, which limited the generalizability of the findings. Participants were mostly Caucasian. There is evidence that different decision makers of different races and ethnicities make different tube feeding decisions (Phipps et al., 2003). Therefore, the results of the present study cannot be generalized to races and ethnicities other than Caucasian.

A fifth limitation was the possibility that participants may have responded in ways that they perceived would be pleasing to the experimenter (Hawthorne Effect). This was a particular risk because half of the participants were known to the experimenter.

\section{Future Directions}

The findings of this study raise several interesting questions that could be addressed in future research. First, the present study, or components of it, should be replicated to establish the consistency of findings in knowledge, decisional conflict, and 
tube feeding decisions. Second, a larger sample might result in the detection of more subtle differences between control and experimental groups. Third, the participant sample should be composed of surrogate decision makers who are diverse in culture, race, and gender. Fourth, because people who were decided about tube feeding at pre-test mostly remained decided at post-test, people who are "unsure" at pre-test may represent a valuable target for intervention. Fifth, multiple samples could be employed, using substitute decision makers who are different temporal distances from tube feeding decisions, to further explore the relation between decisional conflict, decisional certainty, and temporal distance from decisions. More information is needed about how the decision aid can particularly accommodate the decision-making process of those who are undecided at pre-test.

The unexpected finding that decisional conflict increased in the experimental and control groups deserves further exploration. O’Conner, Jacobsen, and Stacey (2002) asserted that decisional conflict is derived from the "inherent difficulty" of a decision and mediating, modifiable factors such as lack of knowledge, unclear values, and lack of support. Both factors were likely more salient for Mitchell's sample of decision makers making imminent decisions. For example, decision makers in the present study, on average, may not have considered the possibility that they might not have family support, for example, for their decision. Future research should explore the role of these variables in tube feeding decision-making, and how to address them in a decision aid. Researchers could also explore to what participants attribute their own decisional conflict at pre- and post-test. This could begin to shed light on the question of what factors lead to increased and decreased decisional conflict, and what factors promote change in decisional conflict. 
Lastly, additional information is needed about possible trends in decisional conflict over time. That is, there may be predictable patterns from pre-test, to post-test, and longitudinally in decisional conflict.

In future studies with more participants who are "unsure" at pre-test, the direction of decisional conflict should be further explored. One might expect reports of "unsure" decisions to be associated with increased decisional conflict. Future research should also compare the decisional conflict of participants with decided status with those who are "unsure." Considering the factors that comprise the decisional conflict construct, perhaps participants who maintain decided status do not weigh environmental support, values/ethics, or knowledge as heavily as emotional factors, for example.

Future research should explore individual differences in the study outcomes. For example, more information is needed about the influence of greater knowledge at pre-test on post-test decisions. Participants who are "unsure" at pre-test and post-test may report different knowledge scores than those who are decided. Second, the locus of control for medical decisions might further account for individual differences in decisional conflict and tube feeding decisions. For example, a decision maker's belief about whether the decision maker, or the physician, should make the tube feeding decision, may influence decisional conflict and decisions. Third, the role of emotionality (or personal values, ethics, etc.) and objective information in tube feeding decision-making should be explored. For example, although many decision aids set out to increase knowledge, decision makers who make tube feeding decisions based on emotion might not be expected to change decisions at post-test. That is, factual information might be disregarded. Perhaps a tube feeding decision aid that incorporated factual information and 
information about personal values and ethics would meet the preferences of substitute decision makers better.

In future uses of the Mitchell (2001) pre- and post-questionnaires for research, the following shortcomings and recommendations could be considered. First, several sections use response options that are either difficult to analyze due to categorical data (e.g., the tube feeding decision) or difficult to interpret (e.g., sections that used long Likert-type scales, such as Section F of the post-questionnaire. This section asked about the importance of various issues as they influenced the tube feeding decision, and used 10point Likert-type scales). In the present form, the range of such scales may be too sensitive to illuminate small differences. Second, it is problematic in any reading-based intervention not to be able to control comprehension and time spent reading. If the study were performed in person rather than via mail, time spent reading could be controlled. However, comprehension is arguably more important. Third, it was not possible to control whether the study packet was completed in order, or completely. This could have led to missing or erroneous data. Fourth, the questions were written for an audience of substitute decision makers making an imminent decision. Substitute decision makers who are not in this position may have trouble with some questions (e.g., demographic items about the patient). This experience might lead to lower acceptability scores for the aid, even though the questions are not in the aid. Fifth, participants' comments about the acceptability of the aid should be considered in future revisions.

Researchers should begin to explore the characteristics of individuals who would benefit most and least from the decision aid. Mitchell's (2001) study pointed to participants who were "unsure" at pre-test, and the present findings corroborate this to a 
certain extent. Those who were decided at pre-test remained decided at post-test, so they may or may not have incorporated the decision aid information into their decision. Therefore, further cost-benefit research is warranted about the "unsure" sub-sample and their unique decision making processes that could be especially influenced by a decision aid. Beyond those who are "unsure," there is the question of which medical decision makers want decision aids offered by their medical providers. For example, other studies have indicated that younger adults, and people with more education, prefer more information from their health care providers, and to be more involved in decision-making (Robinson \& Thomson, 2001).

\section{Conclusions}

The present study demonstrated that tube feeding knowledge, decisional conflict, and decisions can be influenced by a decision aid. First, Mitchell's (2001) tube feeding decision aid can be used to increase knowledge about tube feeding. Second, surprisingly, results about decisional conflict were contrary to previous research. Increased knowledge does not necessarily lead to decreased decisional conflict; indeed, it can increase it. Third, decision aids do not necessarily lead to increased decisiveness. However, it is argued that this need not be viewed as a negative outcome. It is possible that increased knowledge, increased decisional conflict, and indecisiveness each promote additional information seeking and, ultimately, informed decision making.

Substitute decision makers' high endorsement of tube feeding is somewhat concerning given the wealth of research confirming that tube feeding does not prolong survival, prevent aspiration, or improve function (Finucane, Christmas \& Travis, 1999). Researchers (e.g., Mitchell \& Lawson, 1999) have demonstrated that surrogates consider 
these factors heavily in their decision, and recommended that better and more information be provided to surrogates. For example, Carey et al. (2006) found that surrogates had high expectations about the improvement of quality of life as a result of implementing tube feeding. Lewis et al. (2006) confirmed that surrogates report wanting more information about tube feeding. However, the present study indicates that substitute decision makers may still decide to tube feed despite the additional information contraindicating its use in many situations. 


\section{References}

American Bar Association Commission on Law and Aging \& American Psychological Association. (2005). Assessment of older adults with diminished capacity: A handbook for lawyers. Washington, DC: American Bar Association and American Psychological Association.

Anderson, C. J. (2003). The psychology of doing nothing: Forms of decision avoidance result from reason and emotion. Psychological Bulletin, 129(1), 139 -67.

Appelbaum, P. S., \& Grisso, T. (1988). Assessing patients' capacities to consent to treatment. The New England Journal of Medicine, 319, 1635-1638.

Bechara, A., Damasio, H., \& Damasio, A. R. (2003). Role of the amygdala in decisionmaking. Annals of the New York Academy of Sciences, 985, 356-69.

Bramstedt, K. A. (2003). Questioning the decision-making capacity of surrogates. Internal Medicine Journal, 33, 257-259.

Brockett, M. (1999). Substitute decision-making for cognitively impaired older people. Canadian Medical Association Journal, 160(12), 1721-1724.

Brown, S. C., \& Park, D. C. (2003). Theoretical models of cognitive aging and implications for translational research in medicine. The Gerontologist, 43, 57-67.

Carey, T. S., Hanson, L., Garrett, J. M., Lewis, C., Phifer, N., Cox, C. E., et al. (2006). Expectations and outcomes of gastric feeding tubes. The American Journal of Medicine, 119, 527.

Ditto, P. H., Hawkins, N. A., \& Pizarro, D. A. (2005). Imagining the end of life: On the psychology of advance medical decision making. Motivation and Emotion, 29(4), 481-502. 
Drickamer, M. A., \& Cooney, L. M. (1993). A geriatrician's guide to enteral feeding. Journal of the American Geriatrics Society, 41(6), 672-679.

Estabrooks, C., Goel, V., Thiel, E., Pinfold, P., Sawka, C., \& Williams, I. (2001).

Decision aids: are the worth it? A systematic review. Journal of Health Services Research \& Policy, 6(3), 170-182.

Federal Interagency Forum on Aging-Related Statistics. (2004). Older Americans 2004:

Key indicators of well-being. Washington, DC: U.S. Government Printing Office.

Federal Patient Self-Determination Act of 1990. House of Representatives Bill 5067 (1990).

Festinger, L. (Ed.). (1964). Conflict decision and dissonance. Stanford, CA: Stanford University Press.

Field, A. (2000). Discovering statistics. Thousand Oaks, CA: Sage.

Finucane, T. E., Christmas, C., \& Travis, K. (1999). Tube feeding in patients with advanced dementia. Journal of the American Medical Association, 282(14), 136571.

Gillick, M. R. (2000). Rethinking the role of tube feeding in patients with advanced dementia. New England Journal of Medicine, 342(3), 206-210.

Hemphill, J. F. (2003). Interpreting the magnitudes of correlation coefficients. American Psychologist, 58(1), 78-80.

Hebert, L. E., Scherr, P. A., Bienias, J. L., Bennett, D. A., \& Evans, D. A. (2003). Alzheimer Disease in the U.S. Population: Prevalence Estimates Using the 2000 Census. Archives of Neurology, 60(8), $1119-1122$. 
Holmes-Rovner, M., Kroll, J., Schmitt, N., Rovner, D. R., Breer, L., Rothert, M. L., Padonu, G., \& Talarczyk, G. (1996). Patient satisfaction with health care decisions: The Satisfaction with Decision Scale. Medical Decision Making, 16, 58-64.

Howell, D. C. (2002). Statistical methods for psychology ( $5^{\text {th }}$ ed.). Pacific Grove, CA: Duxbury.

Johnson, R. W., \& Schaner, S. G. (2005). Many older Americans engage in caregiving activities. Urban Institute: Washington D.C.

Jones, M., \& Sugden, R. (2001). Positive confirmation bias in the acquisition of information. Theory and Decision, 50(1), 59-99.

The Henry J. Kaiser Family Foundation, Harvard School of Public Health, United Hospital Fund of New York, \& Visiting Nurse Service of New York. (2002, June). The wide circle of caregiving: Key findings from a national survey: LongTerm care from the caregiver's perspective. Menlo Park: KFF. Retrieved from http://www.kff.org/kaiserpolls/loader.cfm?url=/commonspot/security/getfile.cfm \&PageID $=13990$

Karp, N., \& Wood. E. (2003). Incapacitated and alone: Health care decision-making for the unbefriended elderly. American Bar Association Commission on Law and Aging.

Kayser-Jones, J. (1990). The use of nasogastric feeding tubes in nursing homes - patient, family and health care provider perspectives. Gerontologist, 12, 469-79. 
Krynski, M. D. (1991). A study of the parameters significant in elderly decision-making regarding enteral tube feeding. Dissertation Abstracts International, 52(6-A), 2242-2243. (UMI No. PUZ9131168)

Krynski, M. D., Tymchuk, A. J., \& Ouslander, J. G. (1994). How informed can consent be? New light on comprehension among elderly people making decisions about enteral tube feeding. The Gerontologist, 34(1), 36-43.

Lacey, D. (2004). Tube feeding in advanced Alzheimer's disease: When language misleads. American Journal of Alzheimer's Disease and Other Dementias, 19(2), $125-127$.

Levinson, W., Kao, A., Kuby, A., \& Thisted, R. A. (2005). Not all patients want to participate in decision making: A national study of public preferences. Journal of General Internal Medicine, 20(6), 531-535.

Lewis, C. L., Hanson, L. C., Golin, C., Garrett, J. M., Cox, C. E., Jackman, A., et al. (2006). Surrogates' perceptions about feeding tube placement decisions. Patient Education and Counseling, 61(2), 246-52.

Löckenhoff, C. E., \& Carstensen, L. L. (2004). Socioemotional selectivity theory, aging, and health: The increasingly delicate balance between regulating emotions and making tough choices. Journal of Personality, 72(6), 1395-1424.

Maitland, S. B., Intrieri, R. C., Schaie, K. W., \& Willis, S. L. (2000). Gender differences and changes in cognitive abilities across the adult life span. Aging, Neuropsychology, and Cognition, 7(1), 32-53.

McNamara, E. P., \& Kennedy, N. P. (2001). Tube feeding patients with advanced dementia: an ethical dilemma. Proceedings of the Nutrition Society, 60, 179-185. 
Merck \& Co. (2005). Hospitalization [Electronic version]. The Merck manual of geriatrics. M. H. Beers (Ed.), Retrieved from http://www.merck.com/mrkshared/mmg/sec1/ch11/ch11g.jsp

Merck Institute of Aging and Health. (2004). The state of aging and health in America 2004. Washington, D.C.: Author.

Meyer, B. J., Russo, C., \& Talbot, A. (1995). Discourse comprehension and problem solving: Decisions about the treatment of breast cancer by women across the life span. Psychology and Aging, 10(1), 84-103.

Mitchell, S. L., Berkowitz, R. E., Lawson, F. M., \& Lipsitz, L. A. (2000). A crossnational survey of tube-feeding decisions in cognitively impaired older persons. Journal of the American Geriatrics Society, 48, 391-397.

Mitchell, S. L., \& Lawson, F. M. (1999). Decision-making for long-term tube-feeding in cognitively impaired elderly people. Canadian Medical Association Journal, 160(12), 1705-1709.

Mitchell, S. L., Tetroe, J., \& O’Conner, A. M. (1999). Making choices: Long-term feeding tube placement in elderly patients. Ottawa, ON: Ottawa Health Research Institute. Retrieved from http://decisionaid.ohri.ca/decaids.html

Mitchell, S. L., Tetroe, J., \& O'Conner, A. M. (2001). A decision aid for long-term tube feeding in cognitively impaired older persons. Journal of the American Geriatrics Society, 49, 313-316.

Molenaar, S., Sprangers, M. A. G., Postma-Schuit, F. C. E., Rutgers, E. J., Noorlander, J., Hendriks, J., \& DeHaes, H. C. J. M. (2000). Feasibility and effects of decision aids. Medical Decision Making, 20, 112-127. 
National Center for Health Statistics, Centers for Disease Control. (2002). Mortality report. U.S. Department of Health and Human Services, Hyattsville, MD.

National Center for Health Statistics, Centers for Disease Control. (2004). Health, United States, 2004. Retrieved from http://www.cdc.gov/nchs/hus.htm

O’Brien, L. A., Siegert, E. A., Grisso, J. A., Maislin, G., LaPann, K., Evans, L. K., \& Krotki, K. P. (1997). Tube feeding preferences among nursing home residents. Journal of General Internal Medicine, 12(6), 364-371.

O’Conner, A. M. (1995). Validation of a decisional conflict scale. Medical Decision Making, 15, 25-30.

O’Conner, A. M. (1996). User Manual - Measures of Decision/Choice Predisposition. Retrieved from http://decisionaid.ohri.ca/docs/Eval_Meas/User_Manuals/UM_ChoicePredispositi on_Decision.pdf.

O'Conner, A. M. (2002). Definitions of determinants of decisions in the Ottawa Decision Support Framework. Retrieved from http://decisionaid.ohri.ca/docs/ODSF.pdf.

O'Connor, A. M., Jacobsen, M., \& Stacey, D. (2002). An evidence-based approach to managing women's decisional conflict. Journal of Obstetric, Gynecologic \& Neonatal Nursing, 31(5), 570-581.

O’Conner, A. M., Rostom, A., Fiset, V., Tetroe, J., Entwistle, V., Llewellyn-Thomas, H., Holmes-Rovner, M., Barry, M., \& Jones, J. (1999). Decision aids for patients facing health treatment or screening decisions: systematic review. British Medical Journal, 319(7212), 731-734. 
O’Conner, A. M., Stacey, D., Entwistle, V., Llewellyn-Thomas, H., Rovner, D., HolmesRovner, M., Tait, V., Tetroe, J., Fiset, V., Barry, M., \& Jones, J. (2005). Decision aids for people facing health treatment or screening decisions. (Cochrane Review). In: The Cochrane Library, Issue 3. Chichester, UK: John Wiley \& Sons, Ltd.

O'Connor, A. M., Tugwell, P., Wells, G. A., Elmslie, T., Jolly, E., Hollingsworth, G., McPherson, R., Drake, E., Hopman, W., \& MacKenzie, T. (1998). Randomized trial of a portable, self-administered decision aid for postmenopausal women considering long-term preventive hormone therapy. Medical Decision Making, 18(3), 295-303.

Ottawa Health Research Institute. (2005a). Ottawa Decision Support Framework. Retrieved from http://decisionaid.ohri.ca/odsf.html

Ottawa Health Research Institute. (2005b). User manual - Decisional Conflict Scale. Retrieved from http://decisionaid.ohri.ca/docs/Eval_Meas/User_Manuals/Decisional_Conflict.pdf Ouslander, J. G., Tymchuk, A. J., \& Krynski, M. D. (1993). Decisions about enteral tube feeding among the elderly. Journal of the American Geriatrics Society, 41, 70-77.

Ouslander, J. G., Tymchuk, A. J., \& Rahbar, B. (1989). Health care decisions among elderly long-term care residents and their potential proxies. Archives of Internal Medicine, 149, 1367-1372.

Pallant, J. (2005). SPSS survival manual. New York: McGraw-Hill. 
Park, D. C. (1999). Aging and the controlled and automatic processing of medical information and medical intentions. In D. Park, R. Morrell, \& K. Shifren (Eds.), Processing of Medical Information in Aging Patients: Cognitive and Human Factors Perspectives (pp. 3-21). Mahwah, NJ: Lawrence Erlbaum Associates.

Perry, S. (2002). Legal Implications for Failure to Comply with Advance Directives: An Examination of the Incompetent Individual's Right to Refuse Life-Sustaining Medical Treatment. Behavioral Sciences and the Law, 20, 253-269.

Phipps, E., True, G., Harris, D., Chong, U., Tester, W., Chavin, S. I., \& Braitman, L. E. (2003). Approaching the end of life: Attitudes, preferences, and behaviors of African-American and White patients and their family caregivers. Journal of Clinical Oncology, 21(3), 549-554.

Rabeneck, L., Wray, N. P., \& Petersen, N. J. (1996). Long-term outcomes of patients receiving percutaneous endoscopic gastrostomy tubes. Journal of General Internal Medicine, 11, 287-293.

Ratnaike, R. N., \& Hatherly, S. (2002). Dysphagia in older persons, part I: Oropharyngeal dysphagia. Clinical Geriatrics, 10(3). Retrieved from http://www.hmpcommunications.com/cg/displayArticle.cfm?articleID=cgac559

Robinson, A., \& Thomson, R. (2001). Variability in patient preferences for participating in medical decision making: implication for the use of decision support tools. Quality in Health Care, 10, i34-i38.

Rothert, M. L., Holmes-Rovner, M., Rovner, D., Kroll, J., Breer, L., Talarczyk, G., Schmitt, N., Padonu, G., \& Wills, C. (1997). An educational intervention as 
decision support for menopausal women. Research in Nursing \& Health, 20(5), $377-387$.

Salthouse, T. A. (1999). Cognitive and information-processing perspectives on aging. In I. H. Nordhus, G. R. VandenBos, S. Berg, \& P. Fromholt (Eds.), Clinical geropsychology (pp. 231-257). Washington DC: American Psychological Association.

Sanfey, A. G., \& Hastie, R. (2000). Judgment and decision making across the adult life span: A tutorial review of psychological research. In D. Park \& N. Schwartz (Eds.), Cognitive aging: A primer (pp.253-273). Philadelphia, PA: Taylor and Francis Group.

Schwartz, B. (2004). The paradox of choice. New York: Harper Collins.

Society of Critical Care Medicine. (2002). What are my choices regarding life support? [Brochure]. Des Plaines, IL: Author.

Solomon, M. Z., O’Donnell, L., Jennings, B., Guilfoy, V., Wolf, S. M., Nolan, K., Jackson, R., Koch-Weser, D., \& Donnelley, S. (1993). Decisions near the end of life: Professional views on life-sustaining treatments. American Journal of Public Health, 83(1), 14-23.

Tabachnick, B. G., \& Fidell, L. S. (2001). Using multivariate statistics. Needham Heights, MA: Allyn \& Bacon.

Uniform Health-Care Decisions Act. (1993). Retrieved from http://www.law.upenn.edu/bll/ulc/fnact99/1990s/uhcda93.pdf U. S. Administration on Aging. (2003). A profile of older Americans: 2003. Retrieved from http://www.aoa.gov/prof/statistics/profile/2003/2_pf.asp 
U. S. Administration on Aging. (1996, May). Aging into the $21^{\text {st }}$ century. Retrieved from http://www.aoa.gov/prof/Statistics/future_growth/aging21/aging_21.asp

VanRosendaal, G. M., Verhoef, M. J., \& Kinsella, T. D. (1999). How are decisions made about the use of percutaneous endoscopic gastrostomy for long-term nutritional support? American Journal of Gastroenterology, 94, 3225-3228.

VanRosendaal, G. M., Verhoef, M. J., Mace, S. R., \& Kinsella, T. D. (1997). Decisionmaking and outcomes for percutaneous endoscopic gastrostomy: a pilot study. Journal of Clinical Gastroenterology, 24, 71-73.

Volicer, L. (1993). Vignette on enteral feeding. Journal of the American Geriatrics Society, 41(6), 687-688.

Volicer, L., Seltzer, B., Rheaume, Y., Karner, J., Glennon, M., Riley, M. E., \& Crino, P. (1989). Eating difficulties in patients with probable dementia of the Alzheimer type. Journal of Geriatric Psychiatry and Neurology, 2 (4), 188-95.

Whelan, T., Levine, M., Willan, A., Gafni, A., Sanders, K., Mirsky, D., Chambers, S., O'Brien, M., Reid, S., \& Dubois, S. (2004). Effect of a decision aid on knowledge and treatment decision making for breast cancer surgery: A randomized trial. Journal of the American Medical Association, 292(4), 435-41.

Zwahr, M. D. (1999). Cognitive processes and medical decisions. In D. C. Park, R. W. Morrell, \& K. Shifren (Eds.), Processing of medical information in aging patients: Cognitive and human factors perspectives (pp. 55-68). Mahwah, NJ: Lawrence Erlbaum. 
Table 1

Study Design by Dependent Variable

\begin{tabular}{lll}
\hline \multicolumn{1}{c}{ Group } & \multicolumn{1}{c}{ Pre-Test } & \multicolumn{1}{c}{ Post-Test } \\
\hline & & Knowledge \\
Kontrol Group & Decisional conflict & Decisional conflict \\
& Decision & Decision \\
& & Acceptability* \\
& & Satisfaction with decision \\
& Knowledge & Knowledge \\
Experimental Group & Decisional conflict & Decisional conflict \\
& Decision & Decision \\
& & Acceptability \\
& & Satisfaction with decision \\
\hline
\end{tabular}

* Although the control reading was not evaluated in this project, the control group's acceptability scores were of interest in comparison to those of the experimental group's. 
Table 2

Participant Characteristics by Group

\begin{tabular}{lcccc}
\hline & \multicolumn{2}{c}{$\begin{array}{c}\text { Experimental Group } \\
(n=29)\end{array}$} & \multicolumn{2}{c}{$\begin{array}{c}\text { Control Group } \\
(n=31)\end{array}$} \\
\cline { 2 - 5 } Variable & $M$ & $S D$ & $M$ & $S D$ \\
\hline Participant Age & 50.25 & 16.51 & 54.39 & 14.07 \\
\hline & $n$ & $\%$ & $n$ & $\%$ \\
\hline Gender & & & & \\
$\quad$ Male & 7 & 24.14 & 11 & 35.48 \\
$\quad$ Female & 22 & 75.86 & 20 & 64.52 \\
Race & & & & \\
$\quad$ White & 26 & 92.86 & 28 & 90.32 \\
$\quad$ African American/Black & 2 & 7.14 & 1 & 3.23 \\
$\quad$ Asian & 0 & 0 & 2 & 6.45 \\
Ethnicity & & & & 0 \\
$\quad$ Hispanic/Latino & 1 & 3.70 & 0 & 100.00 \\
$\quad$ Not Hispanic/Latino & 26 & 96.30 & 31 & 48.39 \\
Actual Substitute Decision Makers & 12 & 41.38 & 15 & 51.61 \\
Other Substitute Decision Makers & 17 & 58.62 & 16 & \\
\hline
\end{tabular}


Table 3

Comparison of Substitute Decision Makers on Dependent Measures

\begin{tabular}{|c|c|c|c|c|c|c|}
\hline \multirow[b]{2}{*}{ Variable } & \multicolumn{3}{|c|}{ Pre-Test } & \multicolumn{3}{|c|}{ Post-Test } \\
\hline & $M$ & $S D$ & $n$ & $M$ & $S D$ & $n$ \\
\hline \multicolumn{7}{|c|}{ Actual Substitute Decision Makers } \\
\hline Knowledge Total & 19.07 & 6.46 & 27 & 25.67 & 5.41 & 27 \\
\hline Decisional Conflict & 52.84 & 21.98 & 27 & 65.86 & 17.16 & 27 \\
\hline \multicolumn{7}{|c|}{ Other Substitute Decision Makers } \\
\hline Knowledge Total & 20.12 & 6.44 & 33 & 26.91 & 5.92 & 33 \\
\hline Decisional Conflict & 55.63 & 16.96 & 33 & 66.24 & 11.85 & 33 \\
\hline
\end{tabular}


Table 4

Comparison of Substitute Decision Makers on Dependent Measures: T-Test Results

\begin{tabular}{lccccccc}
\hline & \multicolumn{2}{c}{$\begin{array}{l}\text { Actual Substitute } \\
\text { Decision Makers }\end{array}$} & \multicolumn{2}{c}{$\begin{array}{c}\text { Other Substitute } \\
\text { Decision Makers }\end{array}$} & & \\
\cline { 2 - 6 } Variable & $M$ & $S D$ & $M$ & $S D$ & & $d f$ & $t$ \\
\hline Knowledge Total - Pre & 19.07 & 6.46 & 20.12 & 6.44 & & 58 & -0.63 \\
Knowledge Total - Post & 25.67 & 5.41 & 26.91 & 5.92 & & 58 & -0.84 \\
Decisional Conflict - Pre & 52.84 & 21.98 & 55.63 & 16.96 & & 58 & -0.56 \\
Decisional Conflict - Post & 65.86 & 17.16 & 66.24 & 11.85 & & 58 & -0.10 \\
\hline
\end{tabular}

No $p$ values were less than .05. 
Table 5

Descriptive Statistics for Dependent Variables by Group

\begin{tabular}{|c|c|c|c|c|}
\hline \multirow[b]{2}{*}{ Variable } & \multicolumn{2}{|c|}{$\begin{array}{l}\text { Experimental Group } \\
(n=29)\end{array}$} & \multicolumn{2}{|c|}{$\begin{array}{c}\text { Control Group } \\
(n=31)\end{array}$} \\
\hline & $M$ & $S D$ & $M$ & $S D$ \\
\hline Knowledge Total - Pre & 19.93 & 5.50 & 19.39 & 7.25 \\
\hline Knowledge Total - Post & 30.28 & 3.43 & 22.68 & 4.87 \\
\hline Decisional Conflict - Pre & 54.20 & 20.59 & 54.54 & 18.27 \\
\hline Decisional Conflict - Post & 70.64 & 13.12 & 61.79 & 14.34 \\
\hline Satisfaction Total & 24.48 & 3.39 & 23.42 & 3.14 \\
\hline Who should decide? - Pre & 2.18 & 0.82 & 2.23 & 0.72 \\
\hline Who should decide? - Post & 2.15 & 0.72 & 2.20 & 0.71 \\
\hline $\begin{array}{l}\text { I feel that my patient would agree with } \\
\text { my choice - Pre }\end{array}$ & 3.93 & 0.92 & 3.90 & 0.61 \\
\hline \multirow[t]{2}{*}{$\begin{array}{l}\text { I feel that my patient would agree with } \\
\text { my choice - Post }\end{array}$} & 4.17 & 0.71 & 3.90 & 0.65 \\
\hline & $n$ & $\%$ & $n$ & $\%$ \\
\hline \multicolumn{5}{|l|}{ Decision - Pre } \\
\hline Against & 11 & 40.7 & 8 & 26.7 \\
\hline In favor & 8 & 29.6 & 15 & 50.0 \\
\hline Unsure & 8 & 29.6 & 7 & 23.3 \\
\hline \multicolumn{5}{|l|}{ Decision - Post } \\
\hline Against & 8 & 29.6 & 10 & 34.5 \\
\hline In favor & 14 & 51.9 & 19 & 65.5 \\
\hline Unsure & 5 & 18.5 & 0 & 0 \\
\hline \multicolumn{5}{|l|}{ Perceived Decision of Patient - Pre } \\
\hline No & 12 & 41.4 & 10 & 34.5 \\
\hline Yes & 8 & 27.6 & 8 & 27.6 \\
\hline Unsure & 9 & 31.0 & 11 & 37.9 \\
\hline \multicolumn{5}{|l|}{ Perceived Decision of Patient - Post } \\
\hline No & 12 & 44.4 & 10 & 33.3 \\
\hline Yes & 11 & 40.7 & 12 & 40.0 \\
\hline Unsure & 4 & 14.8 & 8 & 26.7 \\
\hline \multicolumn{5}{|l|}{ I would want same decision for self - Pre } \\
\hline No & 2 & 6.9 & 1 & 3.2 \\
\hline Yes & 16 & 55.2 & 19 & 61.3 \\
\hline Maybe & 11 & 37.9 & 11 & 35.5 \\
\hline \multicolumn{5}{|l|}{$\begin{array}{l}\text { I would want same decision for self - } \\
\text { Post }\end{array}$} \\
\hline No & 2 & 7.1 & 1 & 3.3 \\
\hline
\end{tabular}




\begin{tabular}{|c|c|c|c|c|}
\hline Yes & 19 & 67.9 & 22 & 73.3 \\
\hline Maybe & 7 & 25.0 & 7 & 23.3 \\
\hline \multicolumn{5}{|l|}{ Acceptability - Length of Workbook } \\
\hline Much too long & 1 & 3.4 & 0 & 0 \\
\hline A little too long & 4 & 13.8 & 0 & 0 \\
\hline About right & 22 & 75.9 & 16 & 51.6 \\
\hline Should have been a little longer & 1 & 3.4 & 7 & 22.6 \\
\hline Should have been much longer & 1 & 3.4 & 8 & 25.8 \\
\hline \multicolumn{5}{|l|}{ Acceptability - Clarity of Workbook } \\
\hline Everything was clear & 11 & 37.9 & 10 & 32.3 \\
\hline Most things were clear & 16 & 55.2 & 17 & 54.8 \\
\hline Some things were unclear & 2 & 6.9 & 4 & 12.9 \\
\hline \multicolumn{5}{|l|}{$\begin{array}{l}\text { Acceptability - Balanced and Fair } \\
\text { Workbook }\end{array}$} \\
\hline $\begin{array}{l}\text { Clearly slanted in favor of tube } \\
\text { feeding }\end{array}$ & 2 & 6.9 & 1 & 3.2 \\
\hline $\begin{array}{l}\text { Slightly slanted in favor of tube } \\
\text { feeding }\end{array}$ & 9 & 31.0 & 3 & 9.7 \\
\hline Completely balanced & 15 & 51.7 & 21 & 67.7 \\
\hline Slightly slanted against tube feeding & 3 & 10.3 & 6 & 19.4 \\
\hline Clearly slanted against tube feeding & 0 & 0 & 0 & 0 \\
\hline \multicolumn{5}{|l|}{ Acceptability - Workbook was Helpful } \\
\hline Very helpful & 15 & 51.7 & 6 & 19.4 \\
\hline Somewhat helpful & 11 & 37.9 & 13 & 41.9 \\
\hline A little helpful & 2 & 6.9 & 10 & 32.3 \\
\hline Not helpful & 1 & 3.4 & 2 & 6.5 \\
\hline \multicolumn{5}{|l|}{ Acceptability - Recommend Workbook } \\
\hline I would definitely recommend & 17 & 58.6 & 12 & 38.7 \\
\hline I would probably recommend & 11 & 37.9 & 11 & 35.5 \\
\hline I would probably not recommend & 1 & 3.4 & 7 & 22.6 \\
\hline I would not recommend & 0 & 0 & 1 & 3.2 \\
\hline
\end{tabular}




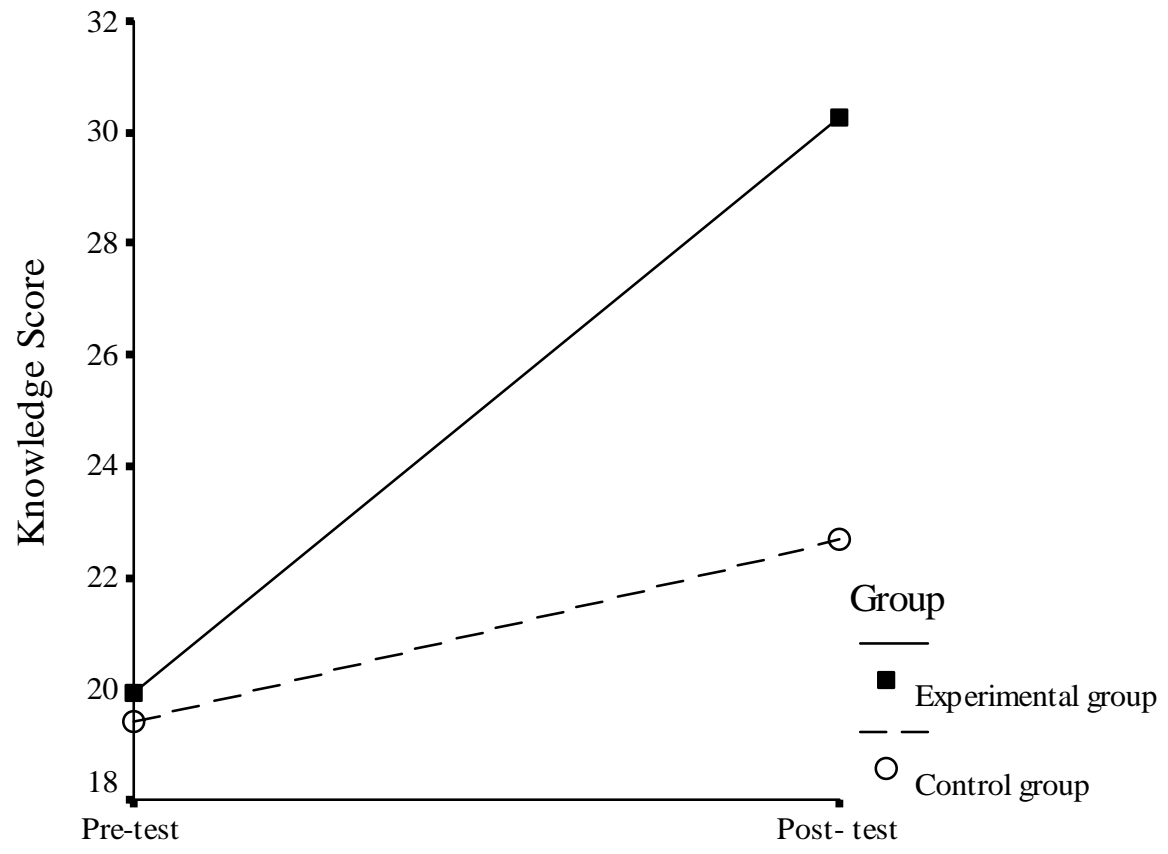

Time

Figure 1. Interaction between group and time on knowledge scores. Higher scores (maximum score $=35$ ) indicate greater knowledge. 


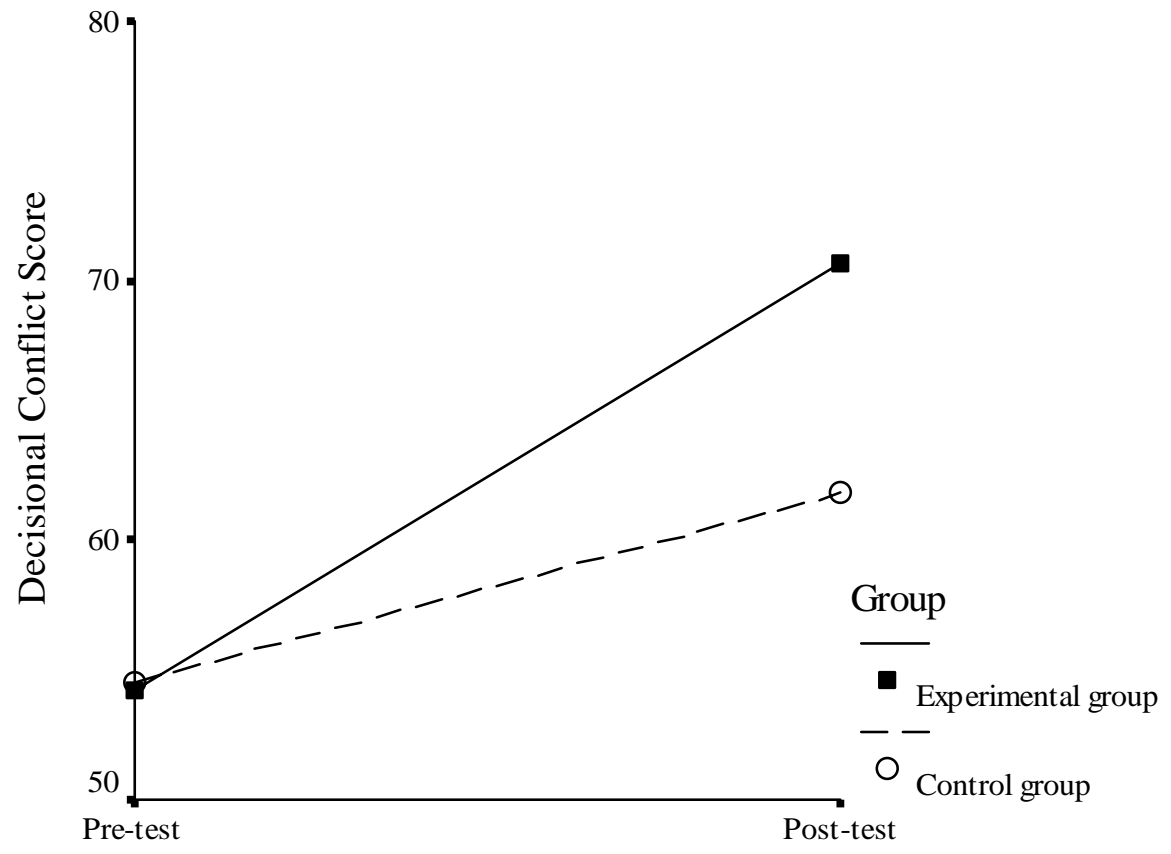

Time

Figure 2. Interaction between group and time on decisional conflict scores. Higher scores (maximum score $=100$ ) indicate greater decisional conflict. 


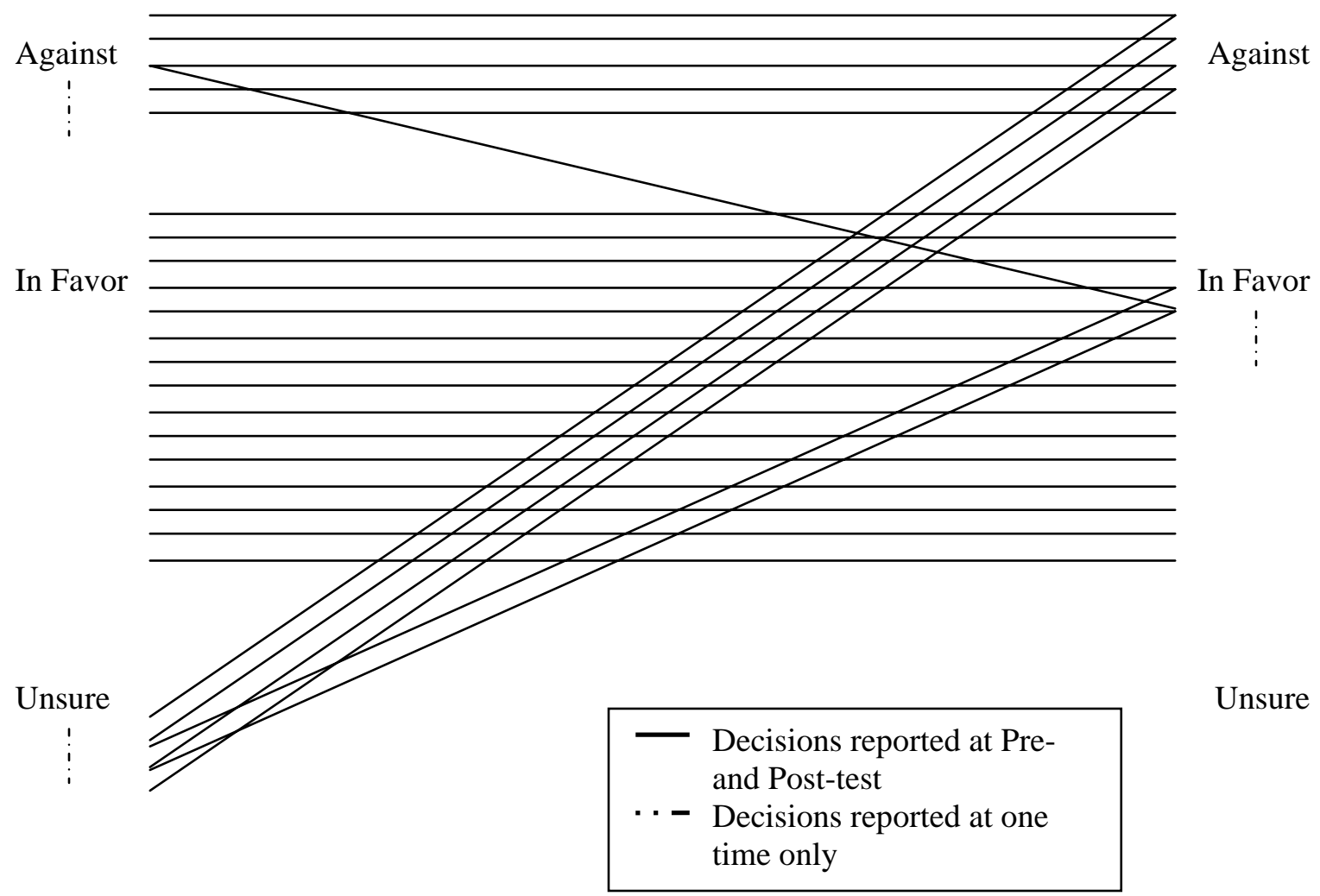

Figure 3. Tube feeding decision at pre-and post-test: Control group 


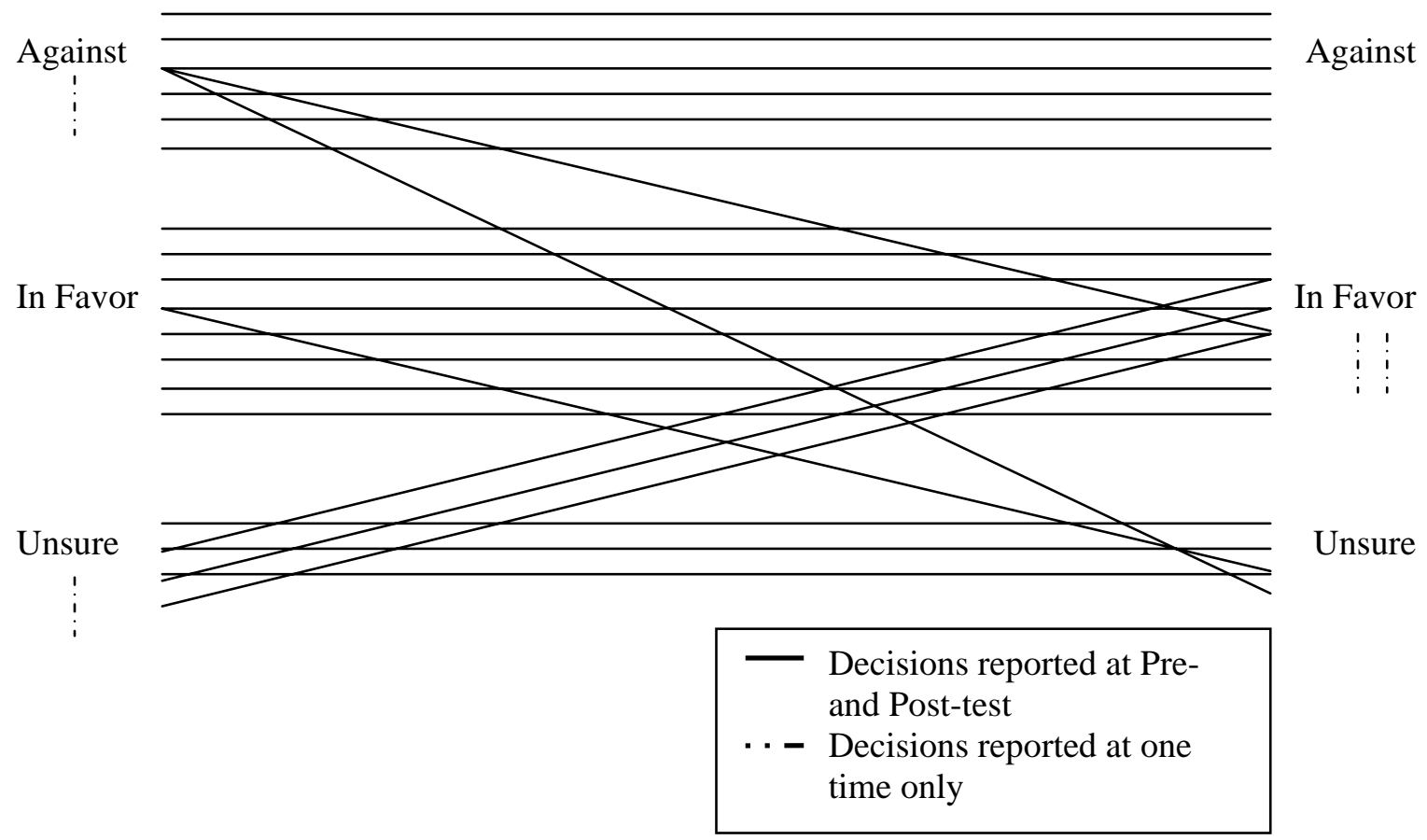

Figure 4. Tube feeding decision at pre-and post-test: Experimental group 
Table 6

Questionnaire Responses by Actual Substitute Decision Makers

\begin{tabular}{|c|c|c|c|c|c|c|c|c|}
\hline \multirow[b]{2}{*}{ Variable } & \multicolumn{4}{|c|}{$\begin{array}{l}\text { Experimental Group } \\
\qquad(n=12)\end{array}$} & \multicolumn{4}{|c|}{$\begin{array}{l}\text { Control Group } \\
(n=15)\end{array}$} \\
\hline & $M$ & $S D$ & $n$ & $\%^{\mathrm{a}}$ & $M$ & $S D$ & $n$ & $\%^{a}$ \\
\hline Patient Age & 74.00 & 17.34 & 11 & 91.67 & 81.20 & 7.38 & 15 & 100.00 \\
\hline Months Caregiving & 63.50 & 73.68 & 8 & 66.67 & 45.60 & 33.12 & 15 & 100.00 \\
\hline $\begin{array}{l}\text { How long did the health } \\
\text { care team talk with } \\
\text { you about tube } \\
\text { feeding? }\end{array}$ & 42.50 & 20.62 & 4 & 33.33 & 11.33 & 10.58 & 6 & 40.00 \\
\hline
\end{tabular}

Note. ${ }^{\text {a }}$ Percentage of participants responding.

\begin{tabular}{|c|c|c|c|c|}
\hline \multirow[b]{2}{*}{ Variable } & \multicolumn{2}{|c|}{$\begin{array}{l}\text { Experimental Group } \\
(n=12)\end{array}$} & \multicolumn{2}{|c|}{$\begin{array}{l}\text { Control Group } \\
(n=15)\end{array}$} \\
\hline & $n$ & $\%$ & $n$ & $\%$ \\
\hline \multicolumn{5}{|c|}{ Relationship to Patient } \\
\hline Partner & 4 & 36.36 & 2 & 13.33 \\
\hline Son/Daughter & 7 & 63.63 & 10 & 66.67 \\
\hline Friend & 0 & 0 & 1 & 6.67 \\
\hline Grandchild & 0 & 0 & 1 & 6.67 \\
\hline Other & 0 & 0 & 1 & 6.67 \\
\hline \multicolumn{5}{|c|}{$\begin{array}{l}\text { The health care team talked with me } \\
\text { about tube feeding }\end{array}$} \\
\hline No & 7 & 58.33 & 9 & 60.00 \\
\hline Yes & 5 & 41.67 & 6 & 40.00 \\
\hline \multicolumn{5}{|c|}{$\begin{array}{l}\text { Does the patient have a living will or } \\
\text { advance directive? }\end{array}$} \\
\hline No & 2 & 16.67 & 4 & 26.67 \\
\hline Yes & 10 & 83.33 & 10 & 66.67 \\
\hline Unsure & 0 & 0 & 1 & 6.67 \\
\hline \multicolumn{5}{|c|}{$\begin{array}{l}\text { Did the patient express in writing or } \\
\text { previous discussion his or her wishes } \\
\text { regarding tube feeding? }\end{array}$} \\
\hline No & 3 & 25.00 & 5 & 35.71 \\
\hline Yes & 7 & 58.33 & 6 & 42.86 \\
\hline Unsure & 2 & 16.67 & 3 & 21.43 \\
\hline \multicolumn{5}{|c|}{$\begin{array}{l}\text { Do you expect the patient's } \\
\text { eating/swallowing problem to } \\
\text { improve? }\end{array}$} \\
\hline Unlikely & 6 & 75.00 & 2 & 50.00 \\
\hline Likely & 0 & 0 & 1 & 25.00 \\
\hline Unsure & 2 & 25.00 & 1 & 25.00 \\
\hline
\end{tabular}


Table 7

Post-Test Tube Feeding Decision by Age Group

\begin{tabular}{lccc}
\hline & \multicolumn{2}{c}{ Grouped Age } & \\
\cline { 2 - 3 } Post-Test Decision & Above 60 Years Old & Under 60 Years Old & \multirow{2}{*}{ Total } \\
\cline { 2 - 3 } & $n(\%$ of total) & $n(\%$ of total) & 18 \\
\hline Against & $8(42.1 \%)$ & $10(27.8 \%)$ & 33 \\
In favor & $10(52.6 \%)$ & $23(63.9 \%)$ & 4 \\
Unsure & $1(5.3 \%)$ & $3(8.3 \%)$ & 55 \\
Total & 19 & 36 & 5 \\
\hline
\end{tabular}




\section{CONSENT AND INFORMATION FORM}

\section{Evaluation of a Tube Feeding Decision Aid}

\section{Introduction}

You, have been asked to participate in this research study, which has been explained to you by . This study is being conducted by Emily Bower, B.S., Barry Edelstein, Ph.D., William Fremouw, Ph.D., and JoNell Strough, Ph.D., in the Department of Psychology at West Virginia University.

This research is being conducted to fulfill the requirements for a master's thesis in Clinical Psychology in the Department of Psychology at West Virginia University, under the supervision of Barry Edelstein, Ph.D.

\section{Purposes of the Study}

The purpose of this study is to evaluate a tube feeding decision aid. A total of approximately 60 subjects are expected to participate in this study. Participants are adults over the age of 18 .

\section{Description of Procedure}

This study involves answering paper-and-pencil questionnaires and reading a brochure, and will take approximately an hour and a half for you to complete. You do not have to answer all the questions in the questionnaires. You will have the opportunity to see the questionnaire before signing this consent form. The study will be performed in locations convenient for caregivers, including their homes, the WVU Department of Psychology, community senior centers, and religious institutions. 
1. Pre-questionnaire: Participants will complete identical pre-questionnaires about tube feeding and other decision making issues. This questionnaire also includes demographic information.

2. Reading Materials: Participants will be divided into two groups ("treatment" and "control" groups). Both groups will receive reading material about tube feeding, but the treatment group will receive extra reading.

3. Post-questionnaire: Both groups will again complete identical questionnaires about tube feeding and other medical decision making issues.

\section{Risks and Discomforts}

There are no known or expected risks from participating in this study, except for the mild frustration associated with answering the questions.

\section{Alternatives}

You do not have to participate in this study.

\section{Benefits}

You may not receive any direct benefit from this study. The knowledge gained from this study may eventually benefit others.

\section{Financial Considerations}

You will have an option to record your name for an opportunity to win $\$ 50$ in a raffle, separate from study materials. There will be no way to connect your name with your study responses.

\section{Confidentiality}

Any information about you that is obtained as a result of your participation in this research will be kept as confidential as legally possible. Your research records and test results, just like hospital records, may be subpoenaed by court order or may be inspected by federal regulatory authorities without your additional consent.

$5 / 1 / 06$

Page 2 of 5

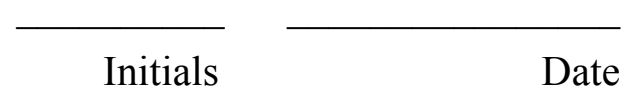


In any publications that result from this research, neither your name nor any information from which you might be identified will be published without your consent.

\section{Voluntary Participation}

Participation in this study is voluntary. You are free to withdraw your consent to participate in this study at any time. Refusal to participate or withdrawal will not affect your future care and will involve no penalty to you.

In the event new information becomes available that may affect your willingness to participate in this study, this information will be given to you so that you can make an informed decision about whether or not to continue your participation. If completing this form in the presence of the researcher, you have been given the opportunity to ask questions about the research in person. If you are completing this form on your own, to mail back to the researcher, you are invited to ask questions by calling the researcher at the toll-free number (866-535-3343 ext. 31631). You have received answers concerning areas you did not understand. Upon signing this form, you will receive a copy.

I willingly consent to participate in this research.

Signature of Subject or Subject's Legal Representative

Printed Name

$\overline{\text { Date }}$ Time

The participant has had the opportunity to have questions addressed. The participant willingly agrees to be in the study.

Signature of Investigator or Investigator's Representative

Printed Name

$\overline{\text { Date }}$ Time

$5 / 1 / 06$

Page 3 of 5

Initials

Date 


\section{Contact Persons}

In the event you have questions or concerns related to this research, you should contact Emily Bower, B.S., at 304-293-2001 ext. 31631, or toll free at 866-535-3343 ext. 31631. For more information, you may contact Barry Edelstein, Ph.D., at 304293-2001 ext. 31661. For information regarding your rights as a research subject, you may contact the WVU Office of Research Compliance at 304-293-7073. 


\section{Future Contact for Research Purposes}

I, , hereby give my consent to be contacted by the Principal Investigator of this study or a representative from the Psychology Department at West Virginia University for an indefinite period following my completion of the present study for the following purposes:

1. Follow-up research related to the present study.

2. Information regarding the results of the present study.

3. Information regarding participation in related studies being conducted by the Department of Psychology.

I understand that I can refuse to participate in any future studies, to provide any information, and can withdrawal my consent at any time. I also understand that my contact information, demographic information, or any other identifying information will not be shared with any other agency, company, individual or researcher at any time.

Signature of Participant

Date

Time

Email

Phone

$\square$ Participant declined consent to be contacted for future research purposes.

$\overline{\text { Initial of PI or RA }}$

$5 / 1 / 06$

Page 5 of 5

Initials

Date 


\section{Emily Bower \\ Graduate Student \\ WVU Department of Psychology \\ 53 Campus Drive \\ Morgantown, WV 26506-6040 \\ ebower@mix.wvu.edu}

Toll free 866-535-3343 ext. 31631

February 28, 2006

Greetings, and thank you for your interest in this research study. Your efforts are critical to the completion of this project, and we appreciate your time.

For my masters degree research project, I am seeking the medical decision makers for people currently dealing with the symptoms of dementia, Parkinson's, and stroke. For research purposes, "medical decision makers" may be formally designated through legal means (e.g., Power of Attorney or surrogate), but may also be informal and not stated legally (e.g., the decision maker and resident have discussed wishes verbally). If you fit this description, we invite you to participate. If you do not fit the description, or have questions about your fit, please give us a call.

The study provides critical information about tube feeding and guides decision makers through the process of arriving at the best decision for their family member/patient, should they be in a position to receive this treatment. Your participation is anonymous. Should you choose to provide your name for follow-up purposes, it will be impossible to connect your study responses to your contact information for follow-up.

There are five envelopes included in this packet, each with special directions (see instructions page). Please follow the directions carefully, working your way through the envelopes starting with Envelope A and ending with Envelope E. The forms will likely take about 1.5 hours to complete, and then simply drop the envelope in the mail to us within 1 week. Participants are eligible to be included in a raffle for two $\$ 50$ cash prizes at the end of the study.

Again, we appreciate your support! Feel free to contact us with questions.

Sincerely, 
Emily Bower

Graduate Student

WVU Department of Psychology

53 Campus Drive

Morgantown, WV 26506-6040

ebower@mix.wvu.edu

Toll free 866-535-3343 ext. 31631

February 28, 2006

Greetings, and thank you for your interest in this research study. Your efforts are critical to the completion of this project, and we appreciate your time.

For my masters degree research project, I am investigating how people make medical decisions for another person. In particular, I am focusing on tube feeding for older adults. The study provides critical information about tube feeding and guides decision makers through the process of arriving at the best decision for their family member/patient, should they be in a position to receive this treatment. Note that the participant materials were written assuming that you are currently in a position to make medical decisions for a loved one who is sick. Please answer items as if you were in fact making decisions for a loved one. Your participation is anonymous. Should you choose to provide your name for follow-up purposes, it will be impossible to connect your study responses to your contact information for follow-up.

There are five envelopes included in this packet, each with special directions (see instructions page). Please follow the directions carefully, working your way through the envelopes starting with Envelope A and ending with Envelope E. The forms will likely take about 1.5 hours to complete, and then simply drop the envelope in the mail to us within 1 week. Participants are eligible to be included in a raffle for two $\mathbf{\$ 5 0}$ cash prizes at the end of the study.

Again, we appreciate your support! Feel free to contact us with questions.

Sincerely,

Emily Bower 


\section{I nstructions}

Thank you again for your support of this research. This page will walk you through the process of completing the questionnaires. Please use the included colored ink pen for all your responses. Please answer the questions on your own in one sitting, and do not consult others (even if you are a co-decision maker). There are no "right answers;" we simply want to know what you think! Please complete the project within 1 week after receiving the packet.

\section{Envelope A: Start}

Contains: consent form, consent form duplicate, and the Pre-Questionnaire

1. As you review the consent form, if you have any questions, please feel free to call us at the toll free number. Then sign one copy if you agree to participate. Place the signed copy in Envelope E.

2. The duplicate copy of the consent form is yours to keep; set it aside.

3. Now answer the questions in the Pre-Questionnaire using your best judgment. When the Pre-Questionnaire is complete, place it back in Envelope A and seal the envelope. Place Envelope A inside Envelope E.

\section{Envelope B}

Contains: reading material

1. Read the brochure, taking your time to attend to details. Please do not mark in the brochure, as other participants will use it in the future.

2. After you have read the brochure, place it back in Envelope B and seal it. Please do not refer to the brochure to answer future questions. Place Envelope B inside Envelope E.

3. This is a good time to take a break for a few minutes if you need one.

\section{Envelope C}

\section{Contains: Post-Questionnaire}

1. Without relying on any other resources, please answer the questions in the PostQuestionnaire the best you can. Remember that there are "no right answers" and we just want you to do your best.

2. When the Post-Questionnaire is complete, please place it in Envelope E. You're almost done! 


\section{Envelope D}

Contains: "More Information" page about tube feeding, raffle signup, results sign up, friend referral

1. You can keep the page with more information about tube feeding; it is for your future reference.

2. If you would like to have your name included in the raffle for one of two $\$ 50$ cash prizes at the end of the study, complete the raffle signup question.

3. If you would like to receive a summary of the results of the study, complete the results signup question.

4. Do you have a friend who is eligible to participate in the study? Every participant is important, and we would appreciate your personal referral. If we may contact your friend about participating, complete the friend referral form and place it in Envelope E.

\section{Envelope E: End}

1. Please double check that Envelope E now contains:

- Signed consent form

- Pre-Questionnaire sealed in Envelope A

- Reading brochure sealed in Envelope B

- Post-Questionnaire

- Raffle signup page (optional)

- Summarized results signup page (optional)

- Friend referral form (optional, but we would love it!)

- Pen

2. This envelope is stamped, addressed, and ready to go. Drop it in the mail to us.

Again, thank you for your help with this project! We welcome your feedback and questions any time.

\section{Contact:}

Emily Bower

Graduate Student

WVU Department of Psychology

53 Campus Drive

Morgantown, WV 26506-6040

ebower@mix.wvu.edu

Toll free 866-535-3343 ext. 31631 


\section{Making Choices: Long-term Feeding Tube Placement in Elderly Patients}

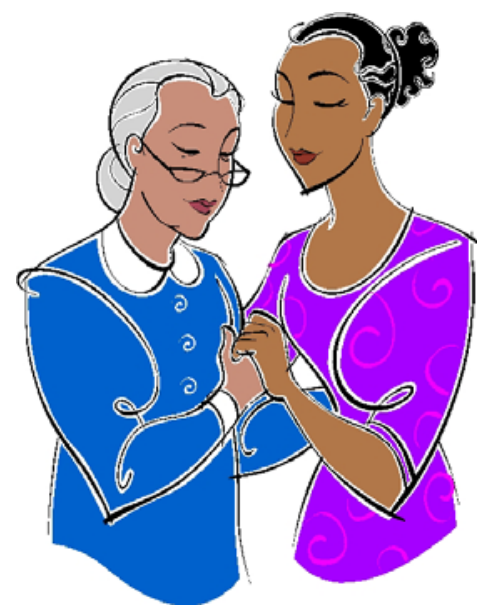

Pre-questionnaire 
Sometimes people who have dementia, Parkinson's Disease, or who have had a stroke, develop a situation where swallowing is difficult. Eating on their own, or being fed by someone else, may be questioned as the best course of care. In these situations, tube feeding may be considered.

Today, we would like you to put yourself in an imaginary position. You will consider whether or not to approve tube feeding for the patient you care for. We will call you the "substitute decision maker," assuming, for the purposes of this study, that the patient will not be able to make this decision for him or herself. When answering questions about the patient, consider their current health status.

Part A. Questions about you (the substitute decision maker), and your family member

\begin{tabular}{|c|c|}
\hline $\begin{array}{l}\text { Al. What is your relationship to the } \\
\text { patient being considered for tube feeding? } \\
\text { (i.e., "I am the patient's }\end{array}$ & $\begin{array}{l}\text { I. Husband, wife, or partner } \\
\text { 2. Son or daughter } \\
\text { 3. Brother or sister } \\
\text { 4. Niece or nephew } \\
\text { 5. Friend } \\
\text { 6. Guardian } \\
\text { 7. Other (please specify) }\end{array}$ \\
\hline A2. What is your age? & \\
\hline $\begin{array}{l}\text { A3. What is the age of the patient being } \\
\text { considered for tube feeding? }\end{array}$ & \\
\hline $\begin{array}{l}\text { A4. How long have you been the } \\
\text { patient's caregiver or substitute decision- } \\
\text { maker? }\end{array}$ & $\begin{array}{ll} & \text { months or years (circle } \\
\text { one) } & \end{array}$ \\
\hline $\begin{array}{l}\text { A5. Have you had to make other } \\
\text { medical decisions for the patient in the } \\
\text { past? }\end{array}$ & $\begin{array}{r}\text { 0. No } \\
\text { I. Yes }\end{array}$ \\
\hline
\end{tabular}




\begin{tabular}{|c|c|}
\hline $\begin{array}{l}\text { A5a. Ethnic Category } \\
\text { Please put a check next to the single most } \\
\text { appropriate category: }\end{array}$ & $\begin{array}{l}\text { 0. Hispanic or Latino: A } \\
\text { person of Cuban, Mexican, Puerto } \\
\text { Rican, South or Central American, or } \\
\text { other Spanish culture or origin, } \\
\text { regardless of race. } \\
\text { I. Not Hispanic or Latino }\end{array}$ \\
\hline $\begin{array}{l}\text { A5b. Racial Category } \\
\text { Please put a check next to all that apply: }\end{array}$ & $\begin{array}{l}\text { I. American Indian or Alaska } \\
\text { Native: A person having origins in } \\
\text { any of the original peoples of North, } \\
\text { Central, or South America and } \\
\text { maintains tribal affiliations or } \\
\text { community. } \\
\text { 2. Asian: A person having origins } \\
\text { in any of the original peoples of the Far } \\
\text { East, Southern Asia, or the Indian } \\
\text { subcontinent including, for example, } \\
\text { Cambodia, China, India, Japan, Korea, } \\
\text { Malaysia, Pakistan, the Philippine } \\
\text { Islands, Thailand, and Vietnam. } \\
\text { 3. Black or African American: } \\
\text { A person having origins in any of the } \\
\text { black racial groups of Africa. } \\
4 \text {. Native Hawaiian or Other } \\
\text { Pacific Islander: A person having } \\
\text { origins in any of the original people of } \\
\text { Hawaii, Guam, Samoa, or other Pacific } \\
\text { Islands. } \\
\text { 5. White: A person having } \\
\text { origins in any of the original peoples of } \\
\text { Europe, North Africa, or the Middle } \\
\text { East. }\end{array}$ \\
\hline
\end{tabular}




\begin{tabular}{|c|c|}
\hline $\begin{array}{l}\text { A6. Some people want the physician to } \\
\text { make all decisions about treatments based } \\
\text { only on the best medical practice. Other } \\
\text { people also want the physician to ask } \\
\text { substitute decision-makers their opinion } \\
\text { about the decision. Finally, some decision- } \\
\text { makers want to make the decisions } \\
\text { themselves after getting the physician's } \\
\text { advice or opinion. Who do you think } \\
\text { should make the decision about whether or } \\
\text { not the patient should get a feeding tube? }\end{array}$ & $\begin{array}{l}\text { I. You should make the decision, } \\
\text { using all you know or learn about tube- } \\
\text { feeding } \\
\text { 2. You should make the decision } \\
\text { but strongly consider the physician's } \\
\text { opinion } \\
\text { 3. You and the physician should } \\
\text { make the decision together on an } \\
\text { equal basis } \\
\text { 4. The physician should make the } \\
\text { decision but strongly consider your } \\
\text { opinion } \\
\text { 5. The physician should make the } \\
\text { decision using all that's known about } \\
\text { tube-feeding }\end{array}$ \\
\hline $\begin{array}{l}\text { A7. Has the health care team providing } \\
\text { care for the patient ever discussed tube } \\
\text { feeding with you? }\end{array}$ & $\begin{array}{l}\text { 0. No } \\
\text { I. Yes } \\
\text { If yes, how long did they spend } \\
\text { with you? minutes }\end{array}$ \\
\hline $\begin{array}{l}\text { A8. At the present time, what is your } \\
\text { overall leaning about placing a feeding tube } \\
\text { in the patient (if it were medically indicated } \\
\text { due to swallowing problems)? }\end{array}$ & $\begin{array}{r}\text { I. Against } \\
\text { 2. In favor } \\
\text { 3. Unsure }\end{array}$ \\
\hline
\end{tabular}

make all decisions about treatments based
only on the best medical practice. Other
people also want the physician to ask
substitute decision-makers their opinion
about the decision. Finally, some decision-
makers want to make the decisions
themselves after getting the physician's
advice or opinion. Who do you think
should make the decision about whether
not the patient should get a feeding tube?
A7. Has the health care team providing
care for the patient ever discussed tube
feeding with you?
A8. At the present time, what is your
in the patient (if it were medically indicated
due to swallowing problems)?
all leaning about placing a feeding tube

Part B. Questions about the patient being considered for tube-feeding

\begin{tabular}{|l|r|}
$\begin{array}{l}\text { B I. Does your patient currently have } \\
\text { difficulty with swallowing such that they are } \\
\text { being considered for a feeding tube? }\end{array}$ & I. No (go to B5) \\
\hline
\end{tabular}




\begin{tabular}{|c|c|}
\hline $\begin{array}{l}\text { B2. How long has your patient had } \\
\text { problems with eating/swallowing? }\end{array}$ & $\begin{array}{l}\text { I. Less than one week } \\
\text { 2. I week - I month } \\
\text { 3. 2- } 6 \text { months } \\
\text { 4. Over } 6 \text { months } \\
\text { 5. Unsure }\end{array}$ \\
\hline $\begin{array}{l}\text { B3. What condition is causing (or could } \\
\text { cause) the patient's problem with } \\
\text { eating/swallowing? }\end{array}$ & $\begin{array}{l}\text { 0. Unsure } \\
\text { I. Please specify }\end{array}$ \\
\hline $\begin{array}{l}\text { B4. Do you expect that the patient's } \\
\text { eating/swallowing problem will improve? }\end{array}$ & $\begin{array}{l}\text { I. Unlikely } \\
\text { 2. Likely } \\
\text { 3. Unsure }\end{array}$ \\
\hline $\begin{array}{l}\text { B5. Does the patient have a living will or } \\
\text { advance care directive? }\end{array}$ & $\begin{array}{l}\text { I. No } \\
\text { 2. Yes } \\
\text { 3. Unsure }\end{array}$ \\
\hline $\begin{array}{l}\text { B6. To the best of your knowledge, did } \\
\text { the patient ever express in writing or in a } \\
\text { previous discussion his or her wishes } \\
\text { regarding tube feeding in this type of } \\
\text { situation? }\end{array}$ & $\begin{array}{l}\text { I. No } \\
\text { 2. Yes } \\
\text { 3. Unsure }\end{array}$ \\
\hline $\begin{array}{l}\text { B7. If the patient was able to make } \\
\text { his/her own health care decisions, what do } \\
\text { you feel would be the patient's overall } \\
\text { leaning about getting a feeding tube? }\end{array}$ & $\begin{array}{l}\text { I. No } \\
\text { 2. Yes } \\
\text { 3. Unsure }\end{array}$ \\
\hline
\end{tabular}


Part C. Questions about eating/swallowing problems

Cl. Some possible causes of eating/swallowing problems are:

$\begin{array}{llccc} & \text { False } & \text { True } & \text { Unsure } \\ \text { Cla. Depression } & 0 & 0 & 0\end{array}$

Clc. Stroke

o

o

O

CId. Alzheimer's disease

O $\quad 0$

o

Cle. Arthritis o

o

$\mathrm{O}$

CIf. Cancer of the esophagus

O $\quad 0$

$\mathrm{O}$

C2. Some of the ways eating/swallowing problems may affect a patient and those close to them are:

False True Unsure

C2a. Patient may lose weight

o $\quad 0 \quad 0$

C2b. Patient may aspirate (inhale) food

O

O

$\mathrm{O}$

C2c. All patients with eating / swallowing problems feel hunger

O

o

O or thirst

C2d. It is impossible for friends and family to interact with a patient who has eating / swallowing problems

C2e. All patients with eating / swallowing problems who do not

o

O

o get a feeding tube can be handfed

C2f. Patients with a feeding tube cannot be hand-fed

o $\quad$ o

O

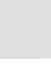


Part D. Questions about substitute decision-making

\begin{tabular}{|c|c|c|c|c|}
\hline & & False & True & Unsure \\
\hline Dla. & $\begin{array}{l}\text { A substitute decision-maker is } \\
\text { always appointed in a court of } \\
\text { law }\end{array}$ & $\mathrm{O}$ & $\mathrm{O}$ & O \\
\hline DIb. & $\begin{array}{l}\text { The first step in substitute } \\
\text { decision-making is to consider } \\
\text { any previously expressed wishes } \\
\text { of the patient }\end{array}$ & $\mathrm{O}$ & $\mathrm{O}$ & $\mathrm{O}$ \\
\hline D I c. & $\begin{array}{l}\text { Substitute decision-makers } \\
\text { should base their decisions on } \\
\text { what they would want for } \\
\text { themselves if they were in the } \\
\text { same condition as the patient }\end{array}$ & $\mathrm{O}$ & $\mathrm{O}$ & O \\
\hline DId. & $\begin{array}{l}\text { A feeding tube cannot be placed } \\
\text { without the consent of the } \\
\text { substitute decision-maker }\end{array}$ & $\mathrm{O}$ & $\mathrm{O}$ & $\mathrm{O}$ \\
\hline
\end{tabular}

Part E. Questions about feeding tubes

EI. A gastrostomy or "PEG" feeding tube....

False True Unsure

Ela. A PEG can only be used for a couple of weeks

$\begin{array}{lll}0 & 0 & 0\end{array}$

EIb. Tube-feeding with a PEG is a medical treatment

o $\quad$ o

EIc. A PEG goes into the stomach through a hole in the abdomen

$\mathrm{O}$

O

$\mathrm{O}$

EId. Patient needs a general anesthetic to get a PEG

O

O

$\mathrm{O}$

Ele. Once the PEG is placed, it is technically difficult to remove

O

O

O 
E2. What is involved in tube feeding?

False True Unsure
E2a. Specially prepared liquid food is delivered through the tube
o
o
o
E2b. Medications cannot be put through the tube

o $\quad 0$
E2c. Once the PEG is in place, no special care is needed

o $\quad 0$
E2d. Most PEG tubes need to be replaced within 6 months to a year

o $\quad$ o

Part F. Questions about health outcomes related to tube-feeding

FI. Possible complications of putting in a PEG

\begin{tabular}{|lccc}
\hline FIa. & False & True & Unsure \\
$\begin{array}{l}\text { It is very unlikely that a patient } \\
\text { will have a major bleed requiring } \\
\text { a blood transfusion from tube } \\
\text { placement }\end{array}$ & 0 & 0 & 0 \\
\hline FIb. $\begin{array}{l}\text { Serious infections are common } \\
\text { complications from putting in a } \\
\text { tube }\end{array}$ & 0 & 0 & 0 \\
\hline FIc. $\begin{array}{l}\text { Some patients may get temporary } \\
\text { diarrhea or nausea from tube- } \\
\text { feeding }\end{array}$ & 0 & 0 & 0 \\
\hline FId. Some patients with feeding tubes & 0 & 0 & 0 \\
may become agitated & 0 & & 0
\end{tabular}


F2. General outcomes of tube-feeding

\begin{tabular}{|c|c|c|c|c|}
\hline & & False & True & Unsure \\
\hline F2a. & $\begin{array}{l}\text { Tube-feeding will prevent } \\
\text { aspiration (inhaling food or } \\
\text { saliva) }\end{array}$ & $\mathrm{O}$ & $\mathrm{O}$ & O \\
\hline F2b. & $\begin{array}{l}\text { Tube-feeding will definitely } \\
\text { prolong the patient's life }\end{array}$ & $\mathrm{O}$ & 0 & $\mathrm{O}$ \\
\hline F2c. & $\begin{array}{l}\text { Tube-feeding may not prevent } \\
\text { the development of bedsores }\end{array}$ & o & o & 0 \\
\hline F2d. & $\begin{array}{l}\text { Tube-fed patients over } 85 \text { years } \\
\text { of age have a smaller chance of } \\
\text { survival compared to younger } \\
\text { tube-fed patients }\end{array}$ & $\mathrm{O}$ & o & O \\
\hline F2e. & $\begin{array}{l}\text { Tube-feeding may not improve } \\
\text { the patient's quality of life }\end{array}$ & o & o & o \\
\hline F2f. & $\begin{array}{l}\text { Tube-fed patients can be cared } \\
\text { for in all types of long-term care } \\
\text { facilities }\end{array}$ & o & O & $\mathrm{O}$ \\
\hline
\end{tabular}

Part G: Questions about your decision for or against tube feeding*

The following statements all refer to your decision for or against tube feeding in the patient with potential eating / swallowing problems.

\begin{tabular}{|c|c|c|c|c|c|}
\hline & $\begin{array}{l}\text { Strongly } \\
\text { disagree }\end{array}$ & $\begin{array}{c}\text { Disagree } \\
2\end{array}$ & $\begin{array}{l}\text { Neither } \\
\text { agree } \\
\text { nor } \\
\text { disagree }\end{array}$ & $\begin{array}{c}\text { Agree } \\
4\end{array}$ & $\begin{array}{l}\text { Strongly } \\
\text { agree }\end{array}$ \\
\hline $\begin{array}{l}\text { GI. This decision is easy for me } \\
\text { to make }\end{array}$ & $\square$ & $\square$ & $\square$ & $\square$ & $\square$ \\
\hline $\begin{array}{l}\text { G2. I'm sure of what to do in } \\
\text { this situation }\end{array}$ & $\square$ & $\square$ & $\square$ & $\square$ & $\square$ \\
\hline $\begin{array}{l}\text { G3. It is clear what choice is } \\
\text { best for the patient (or family } \\
\text { member) }\end{array}$ & [ & $\square$ & $\square$ & $\square$ & $\square$ \\
\hline
\end{tabular}




Strongly
$\begin{aligned} & \text { disagree } \\ & \text { G4. I am aware of the }\end{aligned}$
treatment choices being offered
to manage my patient's
eating/swallowing problem

GII. I feel I know how important the unknowns of tube feeding would be to the patient

GI2. I feel I know which would be most important to the patient, the advantages, the disadvantages, or the unknowns of tube feeding

GI3. I am making this choice without any pressure from others

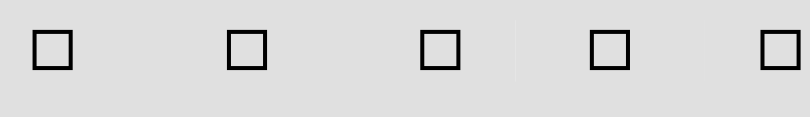

GI4. I have the right amount of support from others in making this choice 


\begin{tabular}{|c|c|c|c|c|}
\hline $\begin{array}{l}\text { Strongly } \\
\text { disagree }\end{array}$ & Disagree & $\begin{array}{c}\text { Neither } \\
\text { agree } \\
\text { nor }\end{array}$ & $\begin{array}{c}\text { Agree } \\
4\end{array}$ & $\begin{array}{c}\text { Strongly } \\
\text { agree }\end{array}$ \\
\hline
\end{tabular}

G I5. I feel I am making an informed choice

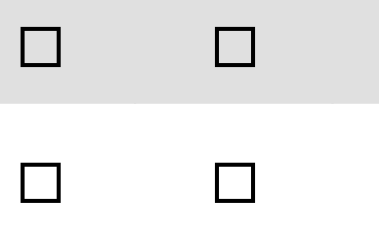

GI6. My decision shows what I think is important to my patient (family member)

G I7. I expect to stick with my decision

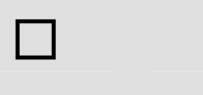

G I 8. I am satisfied with my decision

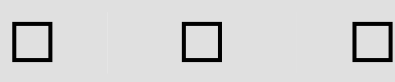

G I9. I feel that my patient (family member) would agree with my choice.
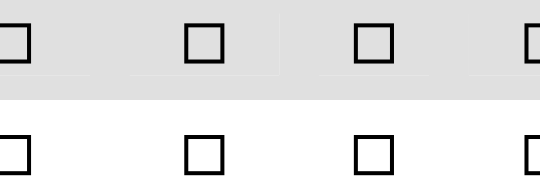

G20. I would want the same decision to be made for me if I were the patient in this dilemma.

$\square$,No

$\square{ }_{2}$ Yes

$\square$ Maybe

Thank you!

\section{Scan back through the packet to make sure all the questions were answered.}

* Adapted from DCS, O’Conner, 2005, and Mitchell, 1999 


\section{Making Choices: Long-term Feeding Tube Placement in Elderly Patients}

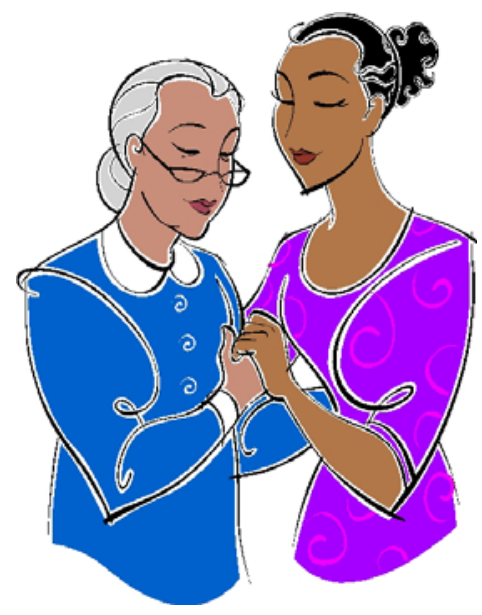

\section{Post-questionnaire}


Sometimes people who have dementia, Parkinson's Disease, or who have had a stroke, develop a situation where swallowing is difficult. Eating on their own, or being fed by someone else, may be questioned as the best course of care. In these situations, tube feeding may be considered.

Today, we would like you to put yourself in an imaginary position. You will consider whether or not to approve tube feeding for the patient you care for. We will call you the "substitute decision maker," assuming, for the purposes of this study, that the patient will not be able to make this decision for himself or herself. When answering questions about the patient, consider their current health status.

Part A. Questions about you (the substitute decision maker), and your family member

\begin{tabular}{|c|c|}
\hline $\begin{array}{l}\text { Al. Some people want the physician to } \\
\text { make all the decisions about treatments } \\
\text { based only on the best medical practice. } \\
\text { Other people want the physician to ask } \\
\text { substitute decision-makers their opinion } \\
\text { about the decision. Finally, some decision- } \\
\text { makers want to make the decisions } \\
\text { themselves after getting the physician's } \\
\text { advice or opinion. Who do you think } \\
\text { should make the decision about whether or } \\
\text { not the patient should get a feeding tube? }\end{array}$ & $\begin{array}{l}\text { I. I should make the decision, } \\
\text { using all I know or learn about tube } \\
\text { feeding } \\
\text { 2. I should make the decision but } \\
\text { strongly consider the physician's } \\
\text { opinion } \\
\text { 3. The physician and I should } \\
\text { make the decision together on an } \\
\text { equal basis } \\
\text { 4. The physician should make the } \\
\text { decision but strongly consider my } \\
\text { opinion } \\
\text { 5. The physician should make the } \\
\text { decision using all that's known about } \\
\text { tube-feeding }\end{array}$ \\
\hline $\begin{array}{l}\text { A2. At the present time, what is your } \\
\text { overall leaning about placing a feeding tube } \\
\text { in the patient (if it were medically indicated } \\
\text { due to swallowing problems)? }\end{array}$ & $\begin{array}{r}\text { I. Against } \\
\text { 2. In favor } \\
\text { 3. Unsure }\end{array}$ \\
\hline $\begin{array}{l}\text { A3. If the patient was able to make } \\
\text { his/her own health care decisions, what do } \\
\text { you feel would be the patient's overall } \\
\text { leaning about getting a feeding tube? }\end{array}$ & $\begin{array}{r}\text { I. Against } \\
\text { 2. In favor } \\
\text { 3. Unsure }\end{array}$ \\
\hline
\end{tabular}


Part B. Questions about eating/swallowing problems

BI. Some possible causes of eating/swallowing problems are:

\begin{tabular}{llccc} 
& False & True & Unsure \\
BIa. Depression & 0 & 0 & 0 \\
\hline BIb. Heart attack & 0 & 0 & 0 \\
\hline BIc. Stroke & 0 & 0 & 0 \\
\hline BId. Alzheimer's disease & 0 & 0 & 0 \\
\hline Ble. Arthritis & 0 & 0 & 0 \\
\hline B If. Cancer of the esophagus & 0 & 0 & 0
\end{tabular}

B2. Some of the ways eating/swallowing problems may affect a patient and those close to them are:

\begin{tabular}{lllcc}
\hline B2a. & False & True & Unsure \\
\hline B2b. & Patient may aspirate (inhale) food & O & O & O \\
\hline B2c. $\quad \begin{array}{l}\text { All patients with eating / } \\
\text { swallowing problems feel hunger } \\
\text { or thirst }\end{array}$ & O & O & O \\
\hline B2d. $\begin{array}{l}\text { It is impossible for friends and } \\
\text { family to interact with a patient } \\
\text { who has eating / swallowing } \\
\text { problems }\end{array}$ & O & O & O \\
\hline $\begin{array}{l}\text { All patients with eating / } \\
\text { swallowing problems who do not } \\
\text { get a feeding tube can be hand- } \\
\text { fed }\end{array}$ & O & O & O \\
\hline $\begin{array}{l}\text { Patients with a feeding tube } \\
\text { cannot be hand-fed }\end{array}$ & O & O & O
\end{tabular}


Part C. Questions about substitute decision-making

\begin{tabular}{|c|c|c|c|c|}
\hline & & False & True & Unsur \\
\hline Cla. & $\begin{array}{l}\text { A substitute decision-maker is } \\
\text { always appointed in a court of } \\
\text { law }\end{array}$ & O & o & 0 \\
\hline Clb. & $\begin{array}{l}\text { The first step in substitute } \\
\text { decision-making is to consider } \\
\text { any previously expressed wishes } \\
\text { of the patient }\end{array}$ & $\mathrm{O}$ & 0 & $\mathrm{O}$ \\
\hline Clc. & $\begin{array}{l}\text { Substitute decision-makers } \\
\text { should base their decisions on } \\
\text { what they would want for } \\
\text { themselves if they were in the } \\
\text { same condition as the patient }\end{array}$ & 0 & 0 & O \\
\hline Cld. & $\begin{array}{l}\text { A feeding tube cannot be placed } \\
\text { without the consent of the } \\
\text { substitute decision-maker }\end{array}$ & $\mathrm{O}$ & 0 & 0 \\
\hline
\end{tabular}

Part D. Questions about feeding tubes

DI. A gastrostomy or "PEG" feeding tube....

\begin{tabular}{|c|c|c|c|c|}
\hline & & False & True & Unsure \\
\hline Dla. & $\begin{array}{l}\text { A PEG can only be used for a } \\
\text { couple of weeks }\end{array}$ & O & o & O \\
\hline DIb. & $\begin{array}{l}\text { Tube-feeding with a PEG is a } \\
\text { medical treatment }\end{array}$ & $\mathrm{O}$ & o & o \\
\hline DIc. & $\begin{array}{l}\text { A PEG goes into the stomach } \\
\text { through a hole in the abdomen }\end{array}$ & O & 0 & O \\
\hline DId. & $\begin{array}{l}\text { Patient needs a general anesthetic } \\
\text { to get a PEG }\end{array}$ & o & $\mathrm{O}$ & $\mathrm{O}$ \\
\hline Dle. & $\begin{array}{l}\text { Once the PEG is placed, it is } \\
\text { technically difficult to remove }\end{array}$ & o & 0 & 0 \\
\hline
\end{tabular}


D2. What is involved in tube feeding?

D2a. Specially prepared liquid food is delivered through the tube
False
True
Unsure

o

o

$\mathrm{O}$

D2b. Medications cannot be put through the tube

$\begin{array}{lll}0 & 0 & 0\end{array}$

D2c. Once the PEG is in place, no special care is needed

o

o

o

D2d. Most PEG tubes need to be replaced within 6 months to a year

Part E. Questions about health outcomes related to tube-feeding

EI. Possible complications of putting in a PEG

\begin{tabular}{|c|c|c|c|c|}
\hline & & False & True & Unsure \\
\hline Ela. & $\begin{array}{l}\text { It is very unlikely that a patient } \\
\text { will have a major bleed requiring } \\
\text { a blood transfusion from tube } \\
\text { placement }\end{array}$ & 0 & 0 & 0 \\
\hline Elb. & $\begin{array}{l}\text { Serious infections are common } \\
\text { complications from putting in a } \\
\text { tube }\end{array}$ & $\mathrm{O}$ & $\mathrm{O}$ & $\mathrm{O}$ \\
\hline EIc. & $\begin{array}{l}\text { Some patients may get temporary } \\
\text { diarrhea or nausea from tube- } \\
\text { feeding }\end{array}$ & 0 & 0 & $\mathrm{O}$ \\
\hline EId. & $\begin{array}{l}\text { Some patients with feeding tubes } \\
\text { may become agitated }\end{array}$ & $\mathrm{O}$ & 0 & $\mathrm{O}$ \\
\hline
\end{tabular}


E2. General outcomes of tube-feeding

\begin{tabular}{|lccc}
\hline E2a. & False & True & Unsure \\
\hline $\begin{array}{l}\text { Tube-feeding will prevent } \\
\text { aspiration (inhaling food or } \\
\text { saliva) }\end{array}$ & O & O & O \\
\hline E2b. $\begin{array}{l}\text { Tube-feeding will definitely } \\
\text { prolong the patient's life }\end{array}$ & 0 & 0 & 0 \\
\hline E2c. $\begin{array}{l}\text { Tube-feeding may not prevent } \\
\text { the development of bedsores }\end{array}$ & 0 & 0 & 0 \\
\hline E2d. $\begin{array}{l}\text { Tube-fed patients over } 85 \text { years } \\
\text { of age have a smaller chance of } \\
\text { survival compared to younger } \\
\text { tube-fed patients }\end{array}$ & 0 & 0 & 0 \\
\hline E2e. $\begin{array}{l}\text { Tube-feeding may not improve } \\
\text { the patient's quality of life }\end{array}$ & 0 & 0 & 0 \\
\hline E2f. $\begin{array}{l}\text { Tube-fed patients can be cared } \\
\text { for in all types of long-term care } \\
\text { facilities }\end{array}$ & 0 & 0 & 0 \\
\hline
\end{tabular}

Part F. Factors that would be important to my family member when making a decision about tube feeding

There are several factors that people might consider important in making a decision about placing a feeding tube. Please show how important you think these factors would be to your family member by marking the circle below.

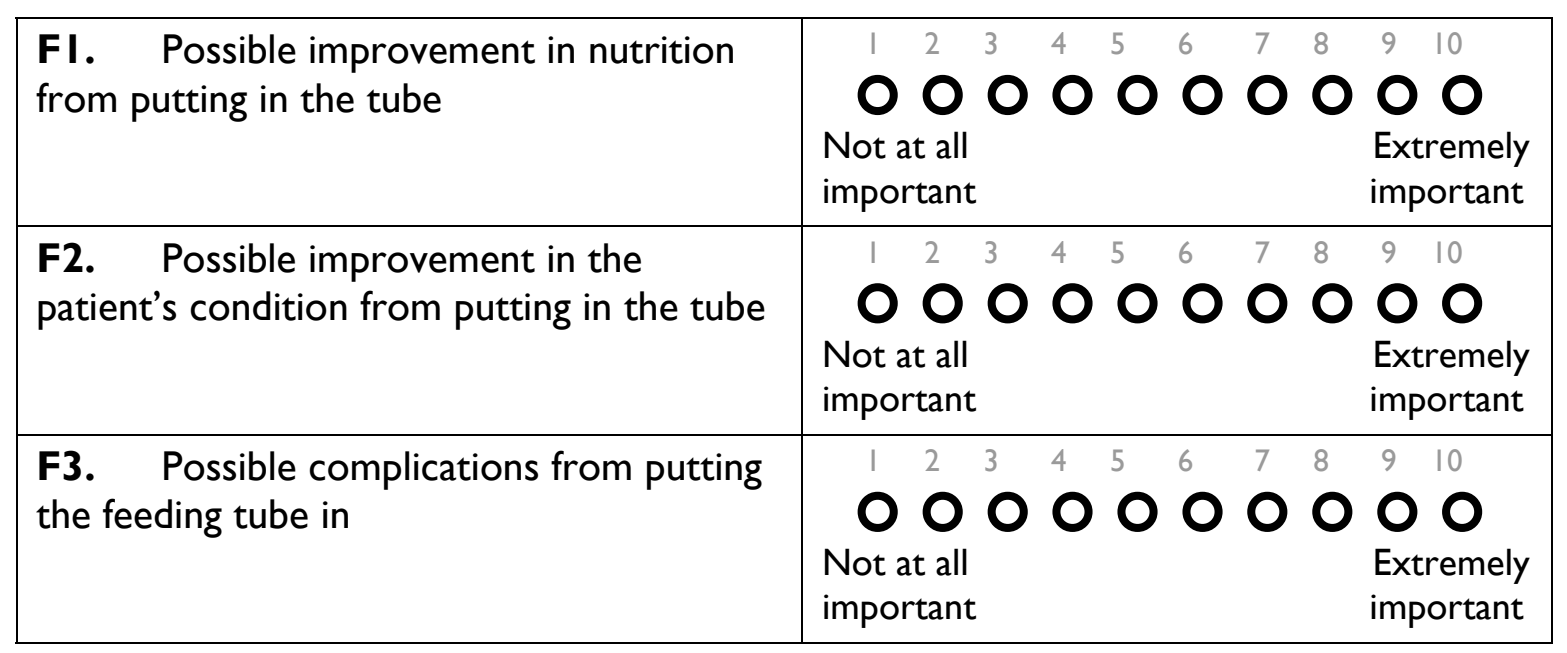




\begin{tabular}{|c|c|c|c|c|c|c|c|c|}
\hline $\begin{array}{l}\text { F4. The possibility of the patient } \\
\text { becoming agitated with the tube }\end{array}$ & $\underset{\substack{\text { Not at all } \\
\text { important }}}{\mathbf{O}} \mathrm{O}^{2} \mathbf{0}$ & & & & $\mathbf{0}^{7}$ & 8 & & $\begin{array}{ll}9 & 10 \\
0 & 0 \\
\text { Extremely } \\
\text { mportant }\end{array}$ \\
\hline $\begin{array}{l}\text { F5. The chance that the patient would } \\
\text { have to be moved to another facility }\end{array}$ & $\underset{\substack{\text { Not at all } \\
\text { important }}}{\mathbf{O}} \mathbf{O}^{2} \mathbf{O}$ & & & & $\mathbf{7}^{7}$ & 8 & & 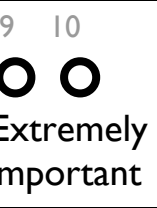 \\
\hline $\begin{array}{l}\text { F6. The fact that the feeding tube will } \\
\text { not prevent aspiration (inhaling food) }\end{array}$ & $\underset{\substack{\text { Not at all } \\
\text { important }}}{\mathbf{O}^{2}} \mathbf{O}^{3} \mathbf{O}$ & & & & & 8 & & $\begin{array}{ll}9 & 10 \\
0 & 0 \\
\text { Extremely } \\
\text { mportant }\end{array}$ \\
\hline $\begin{array}{l}\text { F7. Whether the feeding tube will } \\
\text { provide a quality of life that is acceptable to } \\
\text { the patient }\end{array}$ & $\underset{\substack{\text { Not at all } \\
\text { important }}}{\mathbf{O}} \mathbf{0}$ & $\begin{array}{l}4 \\
\mathbf{O}\end{array}$ & & & & & & $\begin{array}{ll}9 & 10 \\
0 & 0 \\
\text { Extremely } \\
\text { mportant }\end{array}$ \\
\hline
\end{tabular}

Part G. Questions about the risks associated with feeding tubes

In the next questions, please check the answer that shows your opinion about the number of people out of 100 with a feeding tube.

GI. Out of 100 people who have a feeding tube, the number who will still be alive one year after getting the tube is:
I. 0 out of 100

2. I to 10 out of 100

3. II to 20 out of 100

4. 21 to 30 out of 100

5. 31 to 40 out of 100

6. 41 to 50 out of 100

7. 51 to 60 out of 100

8. 61 to 70 out of 100

9. 71 to 80 out of 100

10. 81 to 90 out of 100

II. 91 to 100 out of 100

12. 100 out of 100

13. I have no idea of the number 


\begin{tabular}{|c|c|}
\hline $\begin{array}{l}\text { G2. Out of } 100 \text { people who have a } \\
\text { feeding tube, the number who might } \\
\text { aspirate (inhale food) is: }\end{array}$ & $\begin{array}{l}\text { I. } 0 \text { out of } 100 \\
\text { 2. I to } 10 \text { out of } 100 \\
\text { 3. II to } 20 \text { out of } 100 \\
\text { 4. } 21 \text { to } 30 \text { out of } 100 \\
\text { 5. } 31 \text { to } 40 \text { out of } 100 \\
\text { 6. } 41 \text { to } 50 \text { out of } 100 \\
\text { 7. } 51 \text { to } 60 \text { out of } 100 \\
\text { 8. } 61 \text { to } 70 \text { out of } 100 \\
\text { 9. } 71 \text { to } 80 \text { out of } 100 \\
\text { 10. } 81 \text { to } 90 \text { out of } 100 \\
\text { II. } 91 \text { to } 100 \text { out of } 100 \\
\text { 12. I00 out of } 100 \\
\text { 13. I have no idea of the number }\end{array}$ \\
\hline $\begin{array}{l}\text { G3. Out of } 100 \text { people who have a } \\
\text { feeding tube, the number who might have } \\
\text { temporary diarrhea or vomiting is: }\end{array}$ & $\begin{array}{l}\text { I. } 0 \text { out of } 100 \\
\text { 2. I to } 10 \text { out of } 100 \\
\text { 3. } 11 \text { to } 20 \text { out of } 100 \\
\text { 4. } 21 \text { to } 30 \text { out of } 100 \\
\text { 5. } 31 \text { to } 40 \text { out of } 100 \\
\text { 6. } 41 \text { to } 50 \text { out of } 100 \\
\text { 7. } 51 \text { to } 60 \text { out of } 100 \\
\text { 8. } 61 \text { to } 70 \text { out of } 100 \\
\text { 9. } 71 \text { to } 80 \text { out of } 100 \\
\text { 10. } 81 \text { to } 90 \text { out of } 100 \\
\text { II. } 91 \text { to } 100 \text { out of } 100 \\
\text { 12. } 100 \text { out of } 100 \\
\text { 13. I have no idea of the number }\end{array}$ \\
\hline
\end{tabular}


Part H: Questions about your decision for or against tube feeding*

The following statements all refer to your decision for or against tube feeding in the patient with potential eating / swallowing problems.

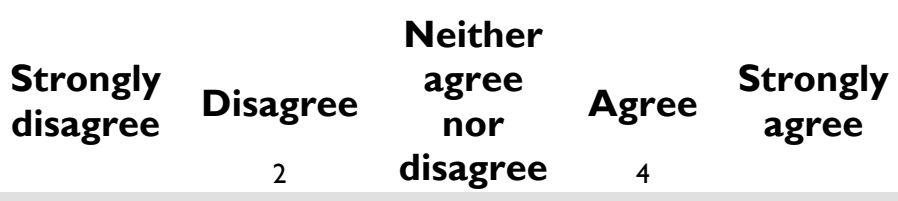

HI. This decision is easy for me to make

$\square$

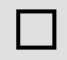

$\square$

H2. I'm sure of what to do in this situation

H3. It is clear what choice is best for the patient (or family member)

H4. I am aware of the treatment choices being offered to manage my patient's eating/swallowing problem

H5. I feel I know the advantages of tube feeding

H6. I feel I know the disadvantages of tube feeding

H7. I feel I have had enough advice about the choices being offered to manage my patient's eating/swallowing problem

H8. I feel I know how important the advantages of tube feeding would be to the patient

H9. I feel I know how important the disadvantages of tube feeding would be to the patient

HIO. I feel I know which would be most important to the patient: the advantages or disadvantages

HII. I am making this choice without any pressure from others 


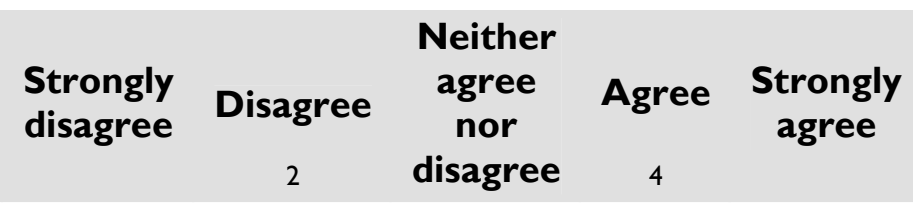

HI2. I have the right amount of support from others in making this choice

HI3. I feel I am making an informed choice

HI4. My decision shows what I think is important to my patient (family member)

HI5. I expect to stick with my decision

H I6. I am satisfied with my decision

HI7. I feel that my patient (family member) would agree with my choice.

HI8. I would want the same decision to be made for me if I were the patient in this dilemma.

$\square$,No

$\square{ }_{2}$ Yes

$\square$ Maybe

Part I: Your satisfaction with the decision aid ${ }^{\dagger}$

\begin{tabular}{|l|c|c|c|c|c|}
\hline & $\begin{array}{c}\text { Strongly } \\
\text { disagree }\end{array}$ & $\begin{array}{c}\text { Disagree } \\
2\end{array}$ & $\begin{array}{c}\text { Neither } \\
\text { agree nor } \\
\text { disagree }\end{array}$ & $\begin{array}{c}\text { Agree } \\
4\end{array}$ & $\begin{array}{c}\text { Strongly } \\
\text { agree }\end{array}$ \\
\hline $\begin{array}{l}\text { II. I am satisfied that I am } \\
\text { adequately informed about } \\
\text { the issues important to my } \\
\text { decision. }\end{array}$ & $\square$ & $\square$ & $\square$ & $\square$ & $\square$ \\
\hline $\begin{array}{l}\text { I2. The decision I made } \\
\text { was the best decision } \\
\text { possible for me, on behalf of } \\
\text { my patient. }\end{array}$ & $\square$ & $\square$ & $\square$ & $\square$ & $\square$ \\
\hline
\end{tabular}




\begin{tabular}{|l|c|c|c|c|c|}
\hline & $\begin{array}{c}\text { Strongly } \\
\text { disagree }\end{array}$ & $\begin{array}{c}\text { Disagree } \\
2\end{array}$ & $\begin{array}{c}\text { Neither } \\
\text { agree nor } \\
\text { disagree }\end{array}$ & $\begin{array}{c}\text { Agree } \\
4\end{array}$ & $\begin{array}{c}\text { Strongly } \\
\text { agree }\end{array}$ \\
\hline $\begin{array}{l}\text { I3. I am satisfied that my } \\
\text { decision was consistent with } \\
\text { my personal values. }\end{array}$ & $\square$ & $\square$ & $\square$ & $\square$ & $\square$ \\
\hline $\begin{array}{l}\text { I4. I expect that if } \\
\text { presented with the dilemma } \\
\text { to tube feed, I would be able } \\
\text { to successfully carry out the } \\
\text { decision I made. }\end{array}$ & $\square$ & $\square$ & $\square$ & $\square$ & $\square$ \\
\hline $\begin{array}{l}\text { I5. I am satisfied that this } \\
\text { was my decision to make. }\end{array}$ & $\square$ & $\square$ & $\square$ & $\square$ & $\square$ \\
\hline $\begin{array}{l}\text { I6. I am satisfied with my } \\
\text { decision. }\end{array}$ & $\square$ & $\square$ & $\square$ & $\square$ & $\square$ \\
\hline
\end{tabular}

\section{Part J: Your thoughts on the workbook}

JI. How would you rate the length of the workbook/brochure?

$\square$ Much too long

$\square$ A little too long

$\square$ About right

$\square$ Should have been a little longer

$\square$ Should have been much longer

J2. How would you rate the clarity of the information in the workbook?

$\square$ Everything was clear

$\square$ Most things were clear

$\square$ Some things were unclear

$\square$ Many things were unclear

J3. What things were unclear? 
J4. How balanced and fair did you find the workbook?

$\square$ Clearly slanted in favor of tube feeding

$\square$ Slightly slanted in favor of tube feeding

$\square$ Completely balanced

$\square$ Slightly slanted against tube feeding

$\square$ Clearly slanted against tube feeding

j5. How helpful was the workbook in making a decision about tube feeding?

$\square$ Very helpful

$\square$ Somewhat helpful

$\square$ A little helpful

$\square$ Not helpful

j6. Is there any other information about tube feeding that was not in the decision aid that you wish you knew more about? Please explain:

J7. Would you recommend the workbook to other substitute decision makers who are facing a decision about tube feeding?

$\square$ I would definitely recommend it.

$\square$ I would probably recommend it.

$\square$ I would probably not recommend it.

$\square$ I would not recommend it.

J8. Do you have any other suggestions for improving the workbook? 


\section{Thank you! That's the end!}

Scan back through the packet to make sure all the questions were answered.

* Adapted from DCS, O’Conner, 2005, and Mitchell, 1999

† Adapted from SWD, Holmes-Rovner, 1996 

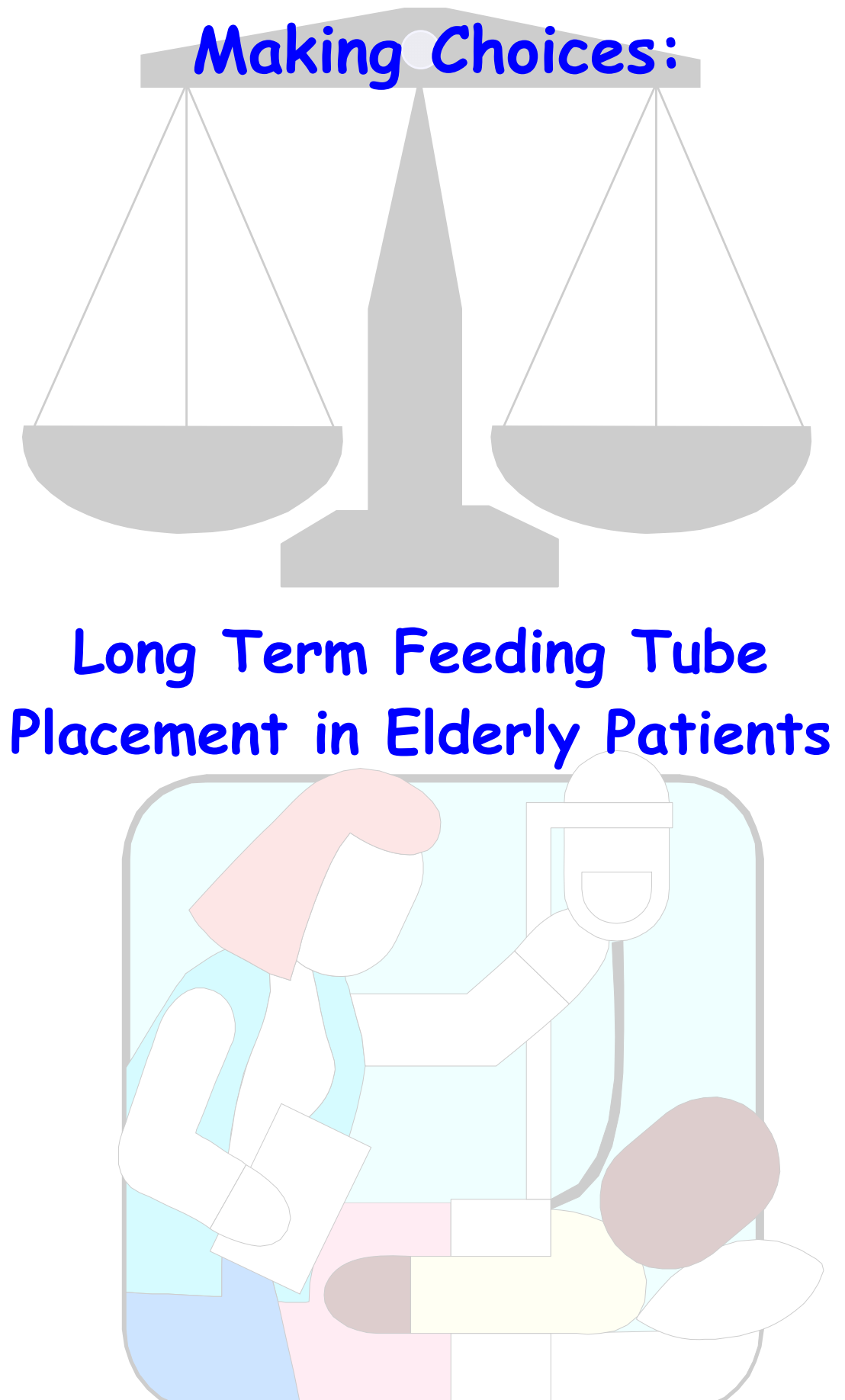

A booklet and audio tape for substitute decision makers

(C) Mitchell, Tetroe and O'Connor
SL Mitchell MD MPH FRCPC JM Tetroe MA

AM O'Connor RN PhD

A Rostom MD FRCPC

C Villeneuve BSc RD

B Hall RN BScN
Geriatric Medicine, Epidemiology Health Research

Nursing, Epidemiology

Gastroenterology, Epidemiology

Dietitian

Geriatric Nursing
Division of Geriatric Medicine Clinical Epidemiology Program Ottawa Hospital - Civic Campus Ottawa Health Research Institute 1053 Carling Ave Ottawa Ontario K1Y 4E9

Canada

Telephone: 1-888-240-7002 Fax: 1-613-761-5402

E-mail: ohdec@ohri.ca SL Mitchell: smitchell@hrca.harvard.ca 


\section{$x$}

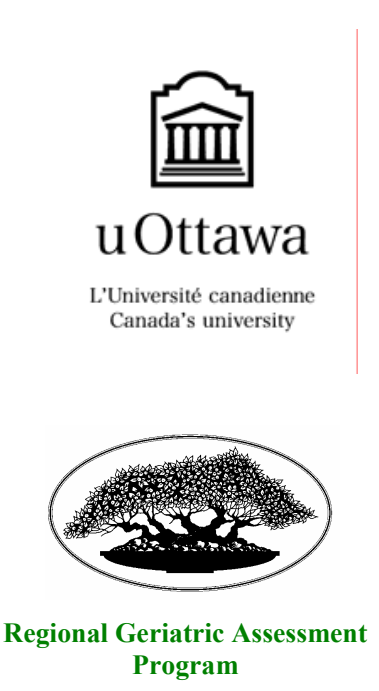

Ottawa Health Research Institute OHRI

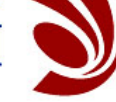

$\mathrm{I} \mathrm{RSO}$

Supported by a grant from Physician Services Incorporated. Dr. Mitchell is a recipient of an Ontario Ministry of Health Career Scientist Award

\section{Welcome}

This workbook and cassette tape have been designed to prepare you for a decision about placing a feeding tube in an elderly patient. As you go through the booklet and tape, you will learn about substitute decision making as well as the advantages and disadvantages of placing a feeding tube in your friend or family member.

\section{Set aside about 45 minutes}

2. Listen to the cassette while reading through the booklet.

3. Please stay on the page until you hear the sound to turn to the next page.

4. Please fill out the worksheet.

Research studies that support statements in this booklet are referenced by numbers like this: ${ }^{1}$. The complete list of references is at the back of the booklet, starting on page 37 . 


\section{Table of Contents}

Overview

Eating and Swallowing Problems

What is a "PEG" (gastric tube)?

Substitute Decision Making

Health Outcomes From Feeding Tubes

What Are My Treatment Choices?

What is Supportive Care?

Can Tube Feeding Be Discontinued?

Advantages and Disadvantages

How to Decide for Your Family Member: 6 Steps

Examples of How To Decide

References

Personal Worksheet for Feeding Tube Placement

\section{This workbook is for you if:}

- you are the substitute decision maker for an older person who is currently unable to make his/her own health care decisions

- you need to decide whether the person should have a long term feeding tube known as a gastrostomy tube (PEG) or a jejunostomy tube (j-tube)

- this workbook does not deal with the decision to place very temporary feeding tubes called nasogastric $(\mathrm{NG})$ tubes

\section{You will learn about:}

- eating and swallowing problems

- feeding tubes

- substitute decision-making

- advantages and disadvantages of feeding tube placement

- treatment options

- how to decide 


\section{Why do people develop eating and}

swallowing problems?

Damage to the muscles and nerves needed for proper swallowing,

Possible causes are:

- Stroke

- Parkinson's disease

- Amyotrophic lateral sclerosis

(Lou Gehrig's disease)

Inability to eat independently because of:

- Alzheimer's disease

- other dementias

Blockage of the esophagus (the tube that goes from the mouth to the stomach):

- cancer of the esophagus

- stricture

Severe loss of appetite or interest in eating: major depression
How do eating and swallowing problems affect older patients and those close to them?

\section{PHYSICAL}

Aspiration: Food or saliva may be inhaled into the lungs if the patient is very drowsy or if he has problems with the nerves or muscles needed to swallow. This may result in lung infections.

Poor nutrition: The patient will:

- become weaker

- lose weight

- become less aware of what is going on

- not recover as quickly from a sudden illness

Comfort: A patient who is very aware may feel hungry and thirsty. Patients who are not very aware may not feel hunger or thirst. ${ }^{1}$ 


\section{EMOTIONAL}

Friends and family may find it difficult to accept a patient's serious illness. They may find it hard to see a person close to them not eat enough. They might feel worried that the patient may feel hunger or thirst.

\section{SOCIAL}

- Eating is social and symbolic of care giving.

- Helping a patient to eat can be a pleasant way to interact with him or her

- If a patient cannot be hand fed, the family may feel a loss of this personal interaction. However, other ways of socializing with him or her are always possible.

\section{What is a percutaneous endoscopic}

gastrostomy (PEG)* tube?

- A tube placed directly into the stomach of someone with eating problems

\section{- An optional medical treatment}

- Percutaneous - through the skin

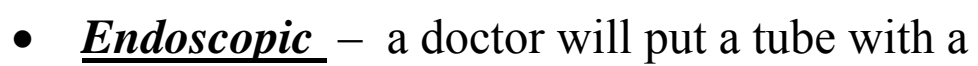
camera in it (an endoscope) down into the patient's stomach to help guide the tube into the correct spot

- Gastrostomy - a procedure where a tube is put into the stomach through a small hole in the abdomen

* Another type of long-term feeding-tube called a jejunostomy tube may be offered to your patient. The procedure to place this tube differs slightly. You should ask your doctor about this. 


\section{How is the tube put into place?}

- The patient is mildly sedated (not put to sleep).

- The endoscope is placed through the mouth and

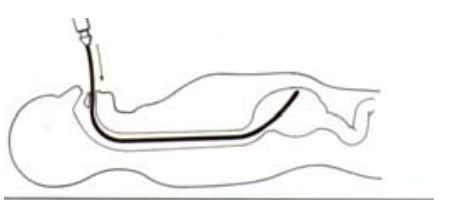

into the stomach. This can be a bit uncomfortable, but it does not hurt. It is needed to see where the

best place is to put the tube.

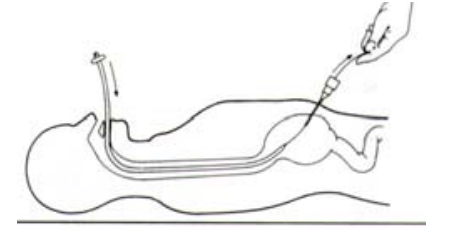

- The patient is given a local anaesthetic to freeze the skin on the abdomen so that a small cut can be

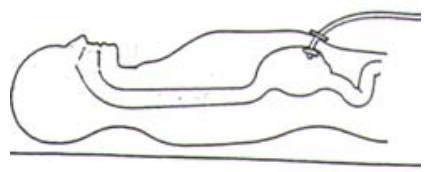
made. The tube is inserted through the mouth and pulled out through the opening in the abdomen.

- This procedure takes about 15

$$
\underline{\text { minutes. }}
$$

- Sometimes it is not possible to insert the endoscope because the esophagus is blocked by a growth or tumour. In these cases, the feeding tube would be placed surgically.
How Does the person with the feeding

tube get their food?

- Liquid food is put into a bag and then delivered into the stomach through a tube.

- The food is a commercially prepared liquid that provides a balanced diet for the patient. It is something like a milkshake.

- Most patients will be fed through the tube at usual

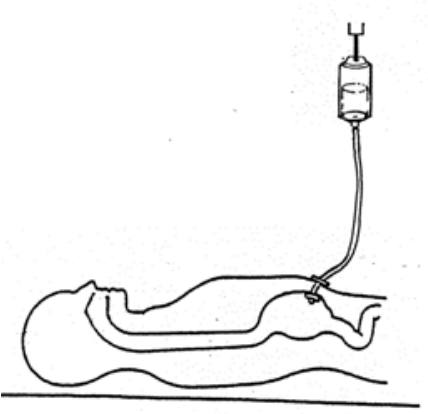
meal times. The feeding will take about one hour. Some patients will receive continuous feedings in which the same amount of food is given, but at a slower

rate over 24 hours.

- Medications as well as water will also be given through the tube. 


\section{What is involved in the care of the tube?}

- Care must be taken not to pull out the tube.

- The nurse will check for tube leakage, blockage and will make sure that the food is going in properly.

- The nurse will clean around the tube at least once a day and check the surrounding skin.

- The tube will usually need to be replaced within six months to one year.

\section{Will the person with a gastrostomy tube have to stay in bed?}

No, the tube is very portable. When the tube is not in use, it will not restrict the patient's usual activities.

\section{What is "substitute decision making"?}

- deciding for others who are unable to make their own health care decisions

- what the patient would want may not be the same as what you would choose for yourself in the same situation

- substitute decision making can be very difficult and emotional

\section{Who becomes a "substitute decision- maker"?}

- a person previously named by the patient (someone who has power of attorney for health care)

- next-of-kin

- appointed guardian 


\section{What are the steps involved in substitute}

\section{decision making?}

Can a feeding tube be placed without the written consent of the substitute decision-

maker?

1) Consider the previously expressed wishes of the patient from either:

- living will (sometimes called an "advance directive")

- previous discussions the patient had with you and/or others

These wishes should be respected, even if you do not agree with them.

2) Consider all you know about the values of your patient when she was well. From what you know do you think she would choose to get a feeding tube in this situation or not? This is called "substituted judgement".

3) If there are no previously expressed wishes and you cannot judge what your patient would want, consider what is in his "best interests".

- what are the possible advantages of tube feeding

- what are the possible disadvantages of tube feeding

- how will this decision affect his quality of life 


\section{Possible health outcomes from Feeding} Tubes

Tube feeding is a medical treatment that can have a variety of possible health outcomes or consequences.

These outcomes can be divided into two types:

- Specific complications from the feeding tube itself

- General health outcomes that most commonly come up in discussions about feeding tubes, for example:

- survival

- aspiration (breathing in of food)

In the next few pages, we will talk about these outcomes so that you can have a better understanding of the advantages, disadvantages and other considerations about tube feeding.

\section{Ranking studies about tube feeding}

In order to learn about health outcomes, you need to understand about the different types of research studies that can be done. There are basically three kinds:

\section{Randomized Trials \\ Gold

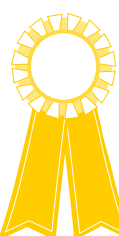 \\ - whether or not someone gets a feeding tube is based on a toss of a coin \\ - patients with a feeding tube are comparable to patients without a feeding tube \\ - more confident in the results \\ (There are no randomized trials of tube feeding)}

\section{Non-Randomized Trials}

Silver

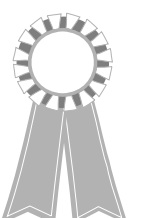

- patients who have chosen to have feeding tubes are compared to patients without feeding tubes

- tube fed patients may be different from patients without feeding tubes in ways that may affect the outcomes

- less confident in the results

\section{Case Series}

Bronze

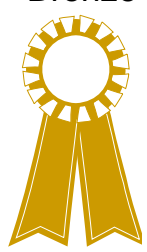
A group of patients with feeding tubes are followed over time to see how they do




\section{Complications from feeding tube placement}

We have tried to summarize the studies for you so that you can have some idea of the chances of your family member having a complication. The numbers below are averages (taken from articles published in medical journals) which vary from patient to patient.

\begin{tabular}{|c|c|}
\hline Type of Complication & $\begin{array}{l}\text { How many out of } 100 * \\
\text { patients might get it? }\end{array}$ \\
\hline $\begin{array}{l}\text { Infections } \\
\text { - } \quad \text { minor (skin) })^{3,5-10} \\
\text { - } \quad \text { major (life threatening) }{ }^{4,5,8,9}\end{array}$ & $\begin{array}{l}4 \text { out of } 100 \\
1 \text { out of } 100\end{array}$ \\
\hline $\begin{array}{l}\text { Bleeding } \\
\text { - } \quad \text { minor (no transfusion) })^{3,4,7} \\
\text { - } \quad \text { major (need transfusion) })^{3,4,7}\end{array}$ & $\begin{array}{l}\text { less than } 1 \text { out of } 100 \\
\text { nearly } 0 \text { out of } 100\end{array}$ \\
\hline $\begin{array}{l}\text { Temporary diarrhea, cramping } \\
\text { Temporary vomiting, nausea } \\
\text { Tem, }\end{array}$ & $\begin{array}{r}12 \text { out of } 100 \\
9 \text { out of } 100 \\
\end{array}$ \\
\hline $\begin{array}{l}\text { Tube problems } \\
\text { minor (dislodgment, blockage, } \\
\text { leaking) } \\
\text { major (perforation of } \\
\text { bowel) })^{3,4,6-8,10}\end{array}$ & $\begin{array}{l}4 \text { out of } 100 \\
\text { less than } 1 \text { out of } 100\end{array}$ \\
\hline $\begin{array}{l}\text { Death } \\
\text { - from putting the tube in }{ }^{5,8,9}\end{array}$ & less than 1 out of 100 \\
\hline
\end{tabular}

* These values are for PEG tubes only. The values may differ for jejunostomy tubes.

\section{Will putting in a feeding tube increase the} patient's chance of survival?

Gold

There are no randomized trials comparing similar patients with and without feeding tubes to see who lived longer. Because of this, there is no straightforward answer to this question of survival.

Silver sere

Non-randomized trials in nursing homes have found that tube fed patients do not live longer than similar patients without feeding tubes. However, it is not clear how long these patients would have lived if they had never been given a feeding tube. It could be that patients who are given tubes are sicker than patients who are not given tubes.

Bronze

It is difficult to predict how long your patient would live with or without a tube. Case series of patients with feeding tubes have shown that those with the following characteristics have a shorter survival:

- $\quad$ very old patients (over 85 years) ( $^{7,10,20,23}$

- patients who tend to aspirate (breathe in) their food ${ }^{10}$

- patients who are already very undernourished 7,15

- patients with a previous diagnosis of malignancy ${ }^{20,23,33}$ 


\section{How long can I expect my family member to live?}

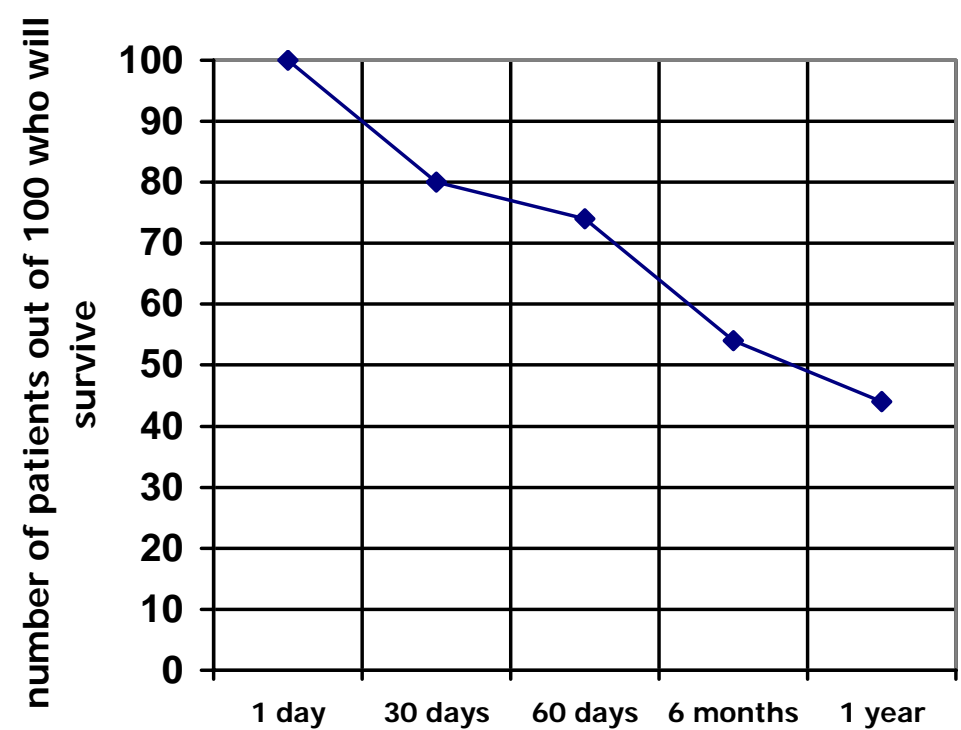

This chart shows you how many out of 100 elderly patients who have feeding tubes will still be alive in 30 days ${ }^{4,5,7-}$ $9,10,12,16-25,60$ days ${ }^{4,12,18,24,25}, 6$ months ${ }^{5,12,25}$ and 1 year $10,12,13,20,23$, after putting the tube in. The numbers on the chart are averaged over many studies. It is difficult to know for sure how long any one patient will live.

Prolonging life may or may not be what your family member would want. This may depend on his quality of life and personal values or beliefs.

\section{What is aspiration and how does it affect} my family member?

- aspiration means that the patient inhales or breathes food or saliva into her lungs. This happens because the patient has trouble swallowing.

- it can be an uncomfortable feeling for patients to experience.

- It can also be dangerous because it can cause pneumonia, an infection in the lungs.

Gold

There are no randomized trials comparing the chances of aspiration in patients with and without feeding tubes.

Non randomized trials $s^{14,26}$ comparing patients with and without feeding tubes show that patients with tubes are more likely to be aspirators. However, it is not clear from the studies if getting a feeding tube increases the chances of aspirating, or whether being an aspirator increases the chances of getting a feeding tube.

Bronze

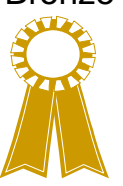

It is clear from several case series ${ }^{23,27,28}$ that putting in a feeding tube will not necessarily stop a patient from aspirating. More than half of patients in these studies who aspirated before they were given a tube, still aspirated after they were given a tube. On average, 16 out of 100 patients with a feeding tube will aspirate $e^{3,6,7,10}$. 


\section{What other factors are important to} consider when deciding about placing a feeding tube?

Stroke patients who have swallowing problems may recover better if the feeding tube is placed earlier on in their illness, rather than waiting a few weeks. ${ }^{32}$

Patients who have been totally unaware of their surroundings and dependent on others to look after their basic needs for several months are less likely to improve, whether they have a feeding tube or not. ${ }^{18}$

Whether or not a patient gets a feeding tube may determine what kind of facility he can live in. You should discuss this with the health care team.

Some patients with feeding tubes may become agitated and/or may try to pull the tube out. The health care team may suggest restraints or medications to stop the patient from doing this. As the substitute decision-maker, you should be involved in this decision. This should not happen without your consent.

\section{What are my treatment choices?}

Because the person in your care is having eating and/or swallowing problems, the health care team is offering the choice of:

\section{supportive care} plus

placement of a feeding tube

or

supportive care 


\section{What is supportive care?}

Supportive care involves:

1. hand-feeding if possible

2. other treatments to keep the patient comfortable

1. Hand-feeding

- patients with eating problems who do not receive a feeding tube may or may not be able to be hand fed

- some patients with a feeding tube may also be able to get some food by mouth

How is it decided if a patient can be hand-fed?

- members of the health care team (for example, doctor, nurse, dietitian, speech and language pathologist, occupational therapist) will decide how safe it is to hand feed a patient

- a special swallowing study may be done to see what consistency of food the patient can tolerate easily
Who hand feeds the patient?

- trained health care professionals (nurse, nursing assistant or aide)

- family, friends, volunteers

How are patients hand-fed?

- proper feeding techniques are needed to help prevent patients with eating problems from aspirating. These techniques include:

- $\quad$ sitting her up in bed

- choosing food of the right consistency

- suctioning the mouth when necessary

- hand-feeding a meal can take as long as two hours

2. Other treatments to keep the patient comfortable

- keeping the patient's mouth moist with a glycerin swab or ice chips

- pain control, with medication

- oxygen, for breathing problems

- treatment of constipation

- spiritual or emotional support

- skin care 


\section{Can tube feeding be discontinued?}

Before you decide to put in the tube, you may want to think about what may be involved in deciding to remove the tube or stop tube-feeding at a later date. Technical Considerations

It is technically easy to remove the tube by:

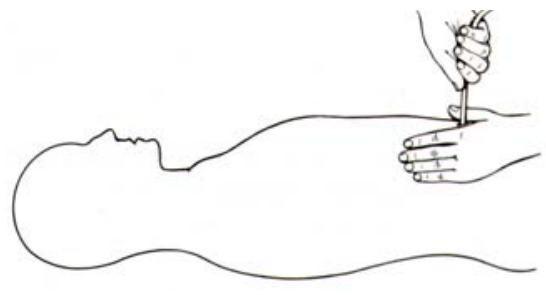

1) pulling it out using traction - the tube is designed to be removed this way it is safe, and nearly painless

or

2) cutting the tube on the outside, then using an endoscope to remove it through the mouth.

\section{Possible reasons for discontinuing tube feeding}

- The patient may have improved enough to be able to eat normally

\section{OR}

- The patient may not have improved and the tube may no longer be in their best interests As a substitute decision-maker, it is your choice to stop tube feeding. You should discuss this decision with the patients' health care team.
What are the advantages, disadvantages and other considerations of feeding tube placement?

\section{Advantages}

+ patient may improve enough to be able to eat again

+ patient gets more nutrition

\section{Disadvantages}

- complications from tube feeding, such as minor or major bleeding, infections, tube problems or death

- may become agitated with the tube

- feeding tube may limit where patient can receive care

\section{Other Considerations}

- will not prevent aspiration in those who are likely to aspirate

- certain factors are associated with decreased chances of survival

- feeding tube may or may not improve quality of life

- Steps to making the decision 


\section{Steps To Making the Decision}

(1) What is your family member's situation?

- is the underlying condition causing the eating problem likely to get better?

- is the feeding tube needed to help provide nutrition?

- how concerned are you about specific complications of the feeding tube (such as minor or major tube problems, bleeding, infections)?

- is the patient likely to become agitated with the tube and need to be restrained to keep it in?

- will feeding tube placement make a difference as to where the patient can live?

- is the patient an aspirator?

- does the patient have any of the factors associated with decreased chances of survival?

- how will the feeding tube affect quality of life?

2 What would your family member want?

- has she ever expressed her wishes (in a living will or previous discussion) about the use of medical technologies like feeding tubes?

- what are his beliefs and values about end-of-life care?

- if she could weigh the advantages and disadvantages, what do you think she would choose

- what do you feel is in your family member's best interests?
3 How the decision is affecting you:

- feelings of guilt

- feelings of pressure from others

- conflict between your personal beliefs and those of the patient

- worry about the future decisions regarding continuing with the tube

(4) What questions need answering before you can decide?

(5) Who should decide about placing the tube?

(6 What is my overall "leaning" about placing a feeding tube? 


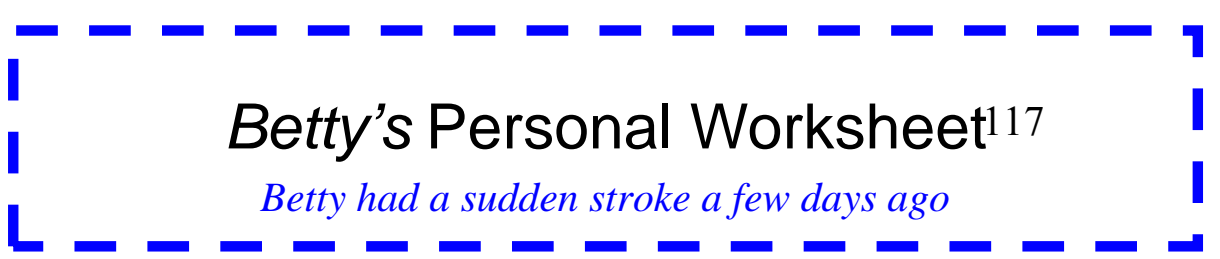

We have developed a worksheet to help you as you go through the steps

Over the next few pages, we will show you some examples of substitute decision makers like you as they work through the 6 steps of making their decision about placing a feeding tube.

The examples are meant to show you how to record the facts about your patient and how to weigh all of the factors that might influence your final decision.

The examples are not meant to suggest a right or wrong way to make the decision.

(1) Your family member's health situation

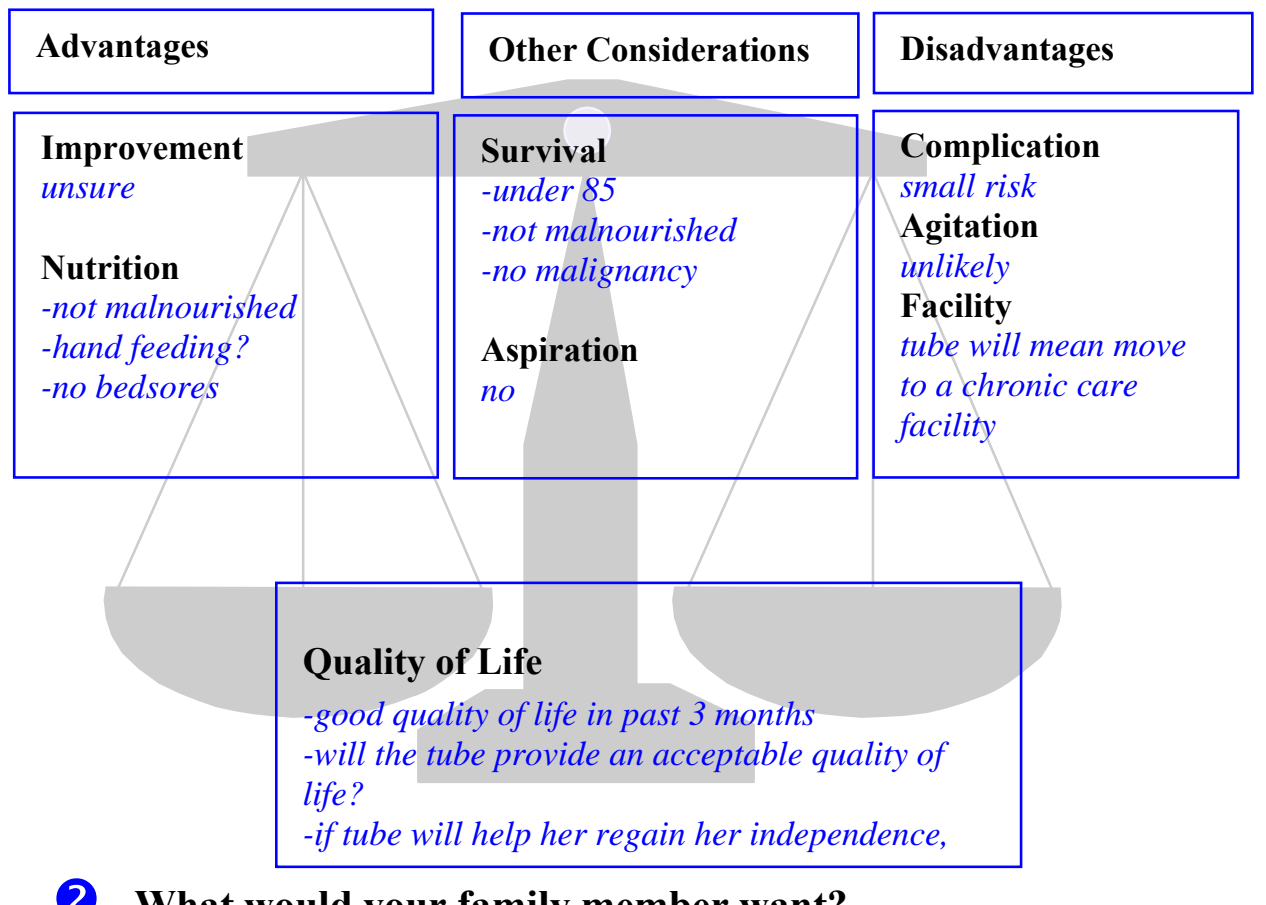

2 What would your family member want?

\begin{tabular}{|c|c|c|c|}
\hline & Patient's fe & ling abo & feeding tube \\
\hline Living will - no & $\begin{array}{l}\square \square \square \\
\text { in } \\
\text { favour }\end{array}$ & $\begin{array}{l}\square \square \\
\text { unsure }\end{array}$ & $\square \underset{\text { against }}{\square}$ \\
\hline
\end{tabular}




\begin{tabular}{|c|c|}
\hline \multicolumn{2}{|c|}{ (3) How is the decision affecting you? } \\
\hline guilt - not much & pressure from others - not much \\
\hline conflict- not much & worry about future $-a$ lot \\
\hline
\end{tabular}

\section{What questions need answering before you can decide?}

How likely is she to recover from the stroke? If she doesn't improve in the next couple of months I doubt Betty would want to continue with the tube. Can we decide to remove it at that point? How hard is it to remove?

\section{(5) Who should decide about placing the tube?}

Based on Betty's previously expressed wishes, her doctor and I will decide together.

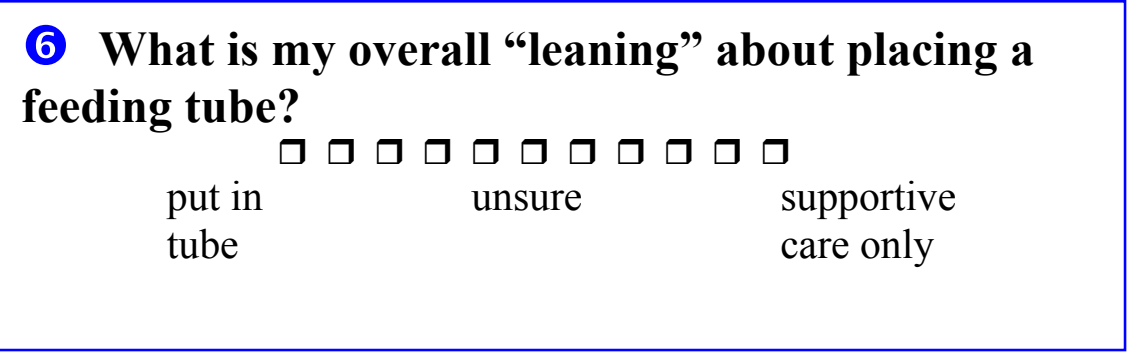

(1) Your family member's health situation

\begin{tabular}{|l|l|l|l|}
\hline Advantages & Other Considerations & Disadvantages \\
\hline $\begin{array}{l}\text { Improvement } \\
\text { Nutikely } \\
\text {-very malnourished } \\
\text {-hand feeding possible? } \\
\text {-has bedsores }\end{array}$ & $\begin{array}{l}\text { Survival } \\
\text {-over 85 } \\
\text { - very malnourished } \\
\text {-no malignancy } \\
\text { Aspiration } \\
\text { yes }\end{array}$ & $\begin{array}{l}\text { Complications } \\
\text { unlikely } \\
\text { Agitation } \\
\text { likely } \\
\text { Facility } \\
\text { unsure if tube will } \\
\text { mean change in } \\
\text { facility }\end{array}$ \\
\hline & $\begin{array}{l}\text { Quality of Life } \\
\text {-poor quality of life in past } 3 \text { months } \\
\text {-unlikely that tube will provide acceptable } \\
\text { quality of life to Harold } \\
\text {-major goal is comfort }\end{array}$ \\
\hline
\end{tabular}

2 What would your family member want?

\begin{tabular}{|c|c|c|c|c|c|}
\hline Previous discussion -no & $\begin{array}{l}\text { Patient } \\
\text { tube? }\end{array}$ & feel & ng about & eedi & \\
\hline Living will - yes & $\begin{array}{l}\square \square \\
\text { in } \\
\text { favour }\end{array}$ & $\square$ & $\begin{array}{l}\square \square \\
\text { unsure }\end{array}$ & $\square$ & $\begin{array}{c}\nabla \\
\text { against }\end{array}$ \\
\hline
\end{tabular}




\section{How is the decision affecting you?}

guilt - somewhat

conflict- not much

pressure from others - not much

worry about future - not much

\section{What questions need answering before you} can decide?

Will Harold feel hunger and thirst without the tube?

Does his nursing home accept tube-fed patients?

\section{Who should decide about placing the tube?}

Harold hasn't told me what to do in this situation, so I must decide for him based on what I think he would want. I'll talk it over with his doctor who has known him for a long time.

\section{What is my overall "leaning" about placing a} feeding tube?

$\square \square \square \square \square \square \square \square \square オ \square$

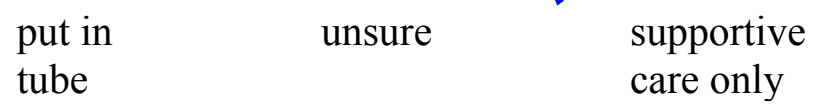

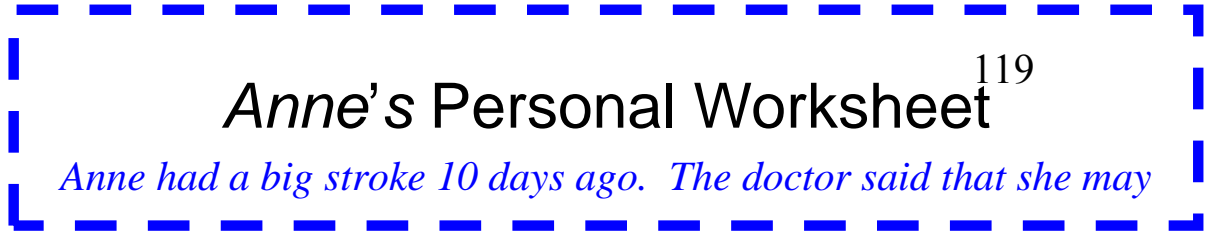

(1) Your family member's health situation

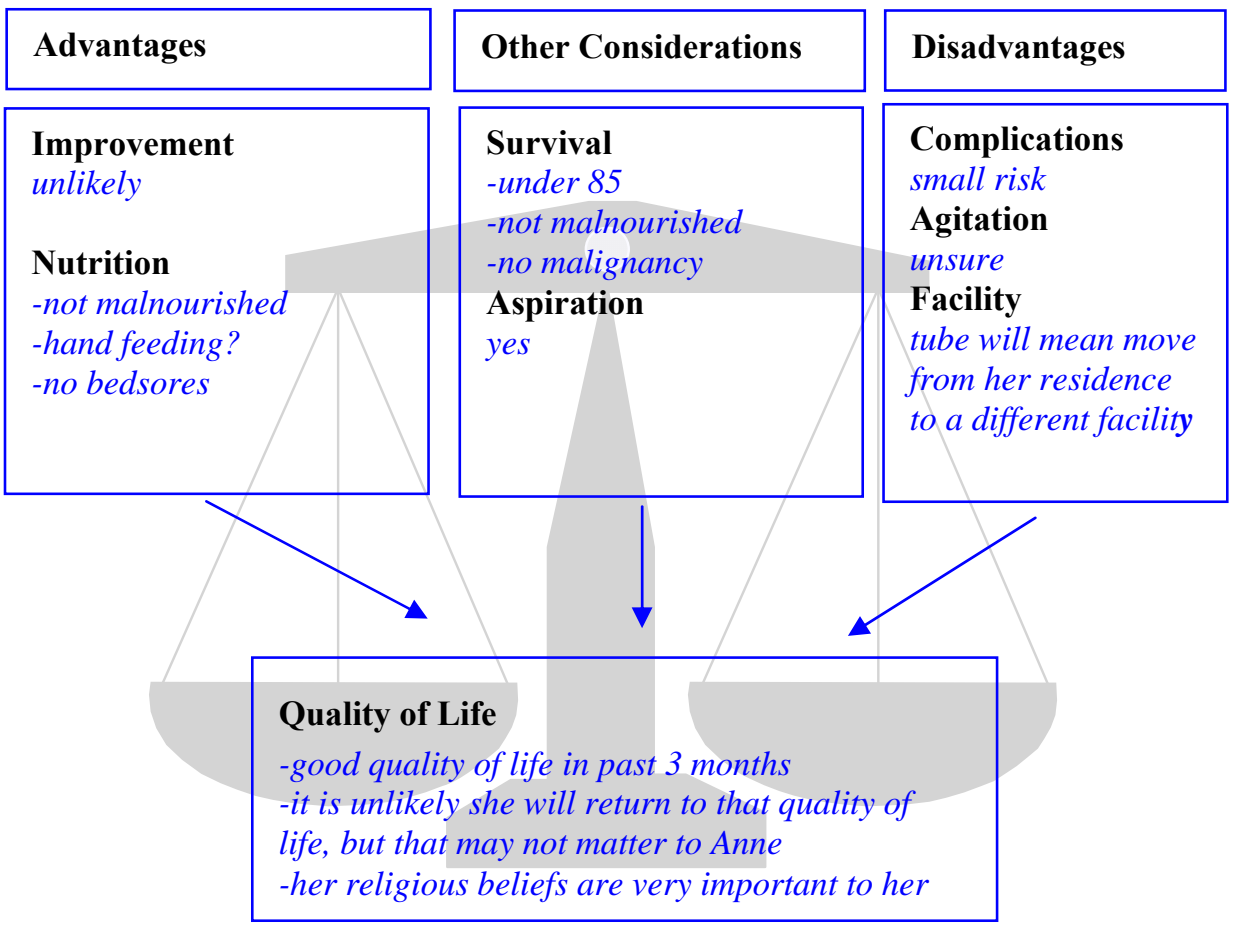

2 What would your family member want?

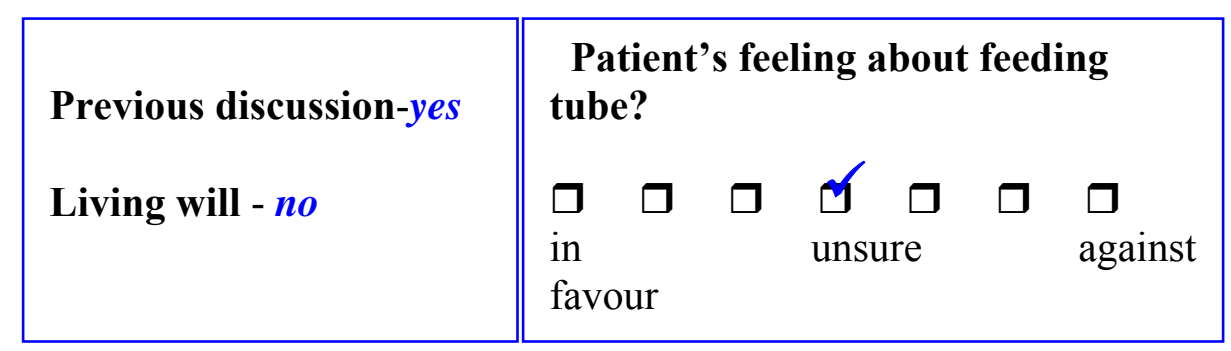




\section{How is the decision affecting you?}

guilt $-a$ lot

pressure from others - somewhat

conflict - a lot, I wouldn't worry about future - somewhat

want a tube if I

\section{(4) What questions need answering before you can decide?}

What decision would best respect her religious beliefs?

\section{Who should decide about placing the tube?}

I will decide after talking to the doctor and Anne's pastor, who knows her well.

\section{What is my overall "leaning" about placing a feeding tube?$$
\text { ㅁㅁㅁㅁㅁㅁ }
$$

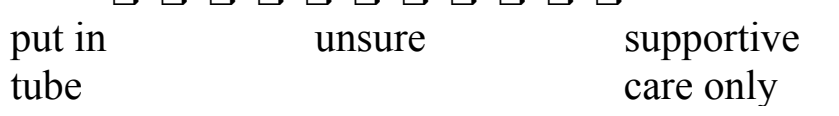

\section{References}

1. McCann RM, Hill WJ, Groth-Junker A. Comfort care for terminally ill patients: the appropriate use of nutrition and hydration. JAMA 1994;272:1263-6.

2. Buchanan A. Deciding for others. Milbank Quarterly 1986; 64(suppl 2):17-94.

3. Bourdel-Marchasson I, Dumas F, Pinganaud G, Emeriau J-P, Decamps A. Audit of percutaneous endoscopic gastrostomy in long-term enteral feeding in a nursing home. International Journal for Quality in Health Care 1997; 9(4):297-302.

4. Grant JP. Percutaneous endoscopic gastrostomy. Initial placement by single endoscopic technique and long-term follow-up. Annals of Surgery $1993 ; 217(2): 168-174$.

5. Hull MA, Rawlings J, Murray FE, Filed J, McIntyre AS, Mahida YR Hawkey CJ, Allison SP. Audit of outcome of long-term enteral nutrition by percutaneous endoscopic gastrostomy. The Lancet 1993; 341(April 3):869-872.

6. James A, Kapur K, Hawthorne AB. Long-term outcome of percutaneous endoscopic gastrostomy feeding in patients with dysphagic stroke. Age and Ageing 1998; 27:671-676.

7. Kaw M, Sekas G. Long-term follow-up of consequences of percutaneous endoscopic gastrostomy (PEG) tubes in nursing home patients. Digestive Diseases and Sciences 1994; 39(4):738-743.

8. Raha S, Woodhouse K. The use of percutaneous endoscopic gastrostomy (PEG) in 161 consecutive elderly patients. Age and Ageing 1994; 23:162-163. 
9. Sali A, Wong P-T, Read A, McQillan T, Conboy D. Percutaneous endoscopic gastrostomy: The heidelberg repatriation hospital experience. Australian and New Zealand Journal of Surgery 1993; 63:545-550

10. Light VL, Slezak FA, Porter JA, Gerson LW, McCord G. Predictive factors for early mortality after percutaneous endoscopic gastrostomy. Gastrointestinal Endoscopy 1995; 42(4);330-335.

11. Panos MZ, Moran A, Reilly T, Wallis PJW, Wears R, Chesner IM. Percutaneous endoscopic gastrostomy in a general hospital: prospective evaluation of indications, outcome, and randomised comparison of two tube designs. Gut 1994; 35:1551-1556.

12. Cowen ME, Simpson SL, Vettese TE. Survival estimates for patients with abnormal swallowing studies. Journal of General Internal Medicine 1997;12(February);88-94.

13. Mitchell SL, Kiely DK, Lipsitz LA. Does artificial enteral nutrition prolong the survival of institutionalized elders with chewing and swallowing problems? Journal of Gerontology 1998; 53A(no.3):M207M213.

14. Mitchell SL, Kiely DK, Lipsitz LA. The risk factors and impact on survival of feeding tube placement in nursing home residents with severe cognitive impairment. Archives of Internal Medicine 1997; 157:327-332.

15. Friedenberg F, Jensen G, Gujral N, Braitman LE, Levine GM. Serum albumin is predictive of 30-day survival after percutaneous endoscopic gastrostomy. Journal of Parenteral and Enteral Nutrition 1997; 21(2):72-74

16. Horton WL, Colwell DL, Burlon DT. Experience with percutaneous endoscopic gastrostomy in a community hospital. American Journal of Gastroenterology 1991; 86:168-169.
17. Jarnagin WR, Duh QY, Mulvihill SJ, Ridge JA, Schrock TR, Way LW. The efficacy and limitations of percutaneous endoscopic gastrostomy. Archives of Surgery 1992; 127:261-264.

18. Fay DE, Popausky M, Gruber M, Lance P. Long-term enteral feeding: a retrospective comparison of delivery via percutaneous endoscopic gastrostomy and nasoenteric tubes. American Journal of Gastroenterology 1991; 86:1604-1609.

19. Kadakia LTCSC, Sullivan HO, Starnes E. Percutaneous endoscopic gastrostomy or jejunostomy and the incidence of aspiration in 79 patients. The American Journal of Surgery 1992; 164(August):114118.

20. Rabenek L, Wray NP, Petersen NJ. Long-term outcomes of patients receiving percutaneous endoscopic gastrostomy tubes. Journal of General Internal Medicine 1996; 11:287-293.

21. Samii Am, Suguitan EA. Comparison of operative gastostomy with percutaneous endoscopic gastrostomy. Mil Med 1990; 155:534-535.

22. Stuart SP, Tiley EH, Boland JP. Feeding gastrostomy: a critical review of its indications and mortality rate. Southern Medical Journal 1993; $86: 1689-172$

23. Taylor CA, Larson DE, Ballard DJ, Bergstrom LR, Silverstein MD, Zinsmeister AR, DiMagno EP. Predictors of outcome after percutaneous endoscopic gastrostomy: A community-based study. Mayo Clinic Proceedings 1992; 67:1042-1049.

24. Tealey AR. Percutaneous endoscopic gastrostomy in the elderly. Gastroenterology Nursing 1994; February:151-157. 
25. Wolfsen HC, Kozarek RA, Ball TJ. Long-term survival in patients undergoing percutaneous endoscopic gastrostomy and jejunostomy. American Journal of Gastroenterology 1990; 85:1120-1122.

26. Pick N, McDonald A, Bennett N, Litche M, Dietsche L, Legerwood R, Spurgas R, LaForce FM. Pulmonary aspiration in a long-term care setting: clinical and laboratory observations and an analysis of risk factors. Journal of the American Geriatrics Society 1996; 44:764-798

27. Patel PH, Thomas E. Risk factors for pneumonia after percutaneous endoscopic gastrostomy. Journal of Clinical Gastroenterology 1990; 12(4):389-392.

28. Finucane TE, Bynum JD. Use of tube feeding to prevent aspiration pneumonia. The Lancet 1996;348(9039):1421-1441.

29. Wanklyn P, Cox N, Belfield P. Outcome in patients who require a gastrostomy after stroke. Age and Ageing 1995; 24:510-514.

30. Fisman DN, Levy AR, Gifford DR, Tamblyn R. Survival after percutaneous endoscopic gastrostomy among older residents of Quebec. Journal of the American Geriatrics Society 1999; 47:349-353. 


\section{Personal Worksheet for Feeding Tube Placement}

1 Advantages

Conditions may improve

Underlying condition

Likelihood of recovery
$\square$ Likely
$\square$ Unlikely
$\square$ Unsure

Likelihood of eating again independently $\square$ Likely $\square$ Unlikely $\square$ Unsure

\section{May improve nutrition}

Patient is very malnourished
$\square$ Yes
$\square$ No

Possibility of handfeeding
$\square$ Yes
$\square$ No
$\square$ Maybe

\section{Other Considerations}

Factors associated with decreased survival with tube feeding

$\begin{array}{ll}\text { The patient is over 85 } & \square \text { Yes } \quad \square \text { No } \\ \text { Undernourished } & \square \text { Yes } \quad \square \text { No } \\ \text { Previous malignancy } & \square \text { Yes } \quad \square \text { No }\end{array}$

\section{Aspiration}

Feeding tube will not prevent aspiration in those who are likely to aspirate

\begin{tabular}{|l|}
\hline \multicolumn{1}{|c|}{ Disadvantages } \\
\hline Complications from the feeding tube: \\
Minor: infection, bleeding, temporary \\
diarrhea, tube problems \\
$\begin{array}{l}\text { Major: infection, bleeding, tube problems, } \\
\text { death }\end{array}$ \\
\hline
\end{tabular}

\section{Agitation with the tube}

Is the patient likely to get agitated with the feeding tube?

$\square$ Likely $\quad \square$ Unlikely $\square$ Unsure

\section{Need for special facility}

Will feeding tube limit where patient can receive care?
$\square$ Likely
$\square$ Unlikely
$\square$ Unsure

\begin{tabular}{|c|c|c|c|}
\hline \multicolumn{4}{|c|}{ Quality of Life } \\
\hline Patient's quality of life in the last 3 months & $\square$ Good & $\square$ Poor & $\square$ Unsure \\
\hline Will feeding tube provide quality of life acceptable to patient? & $\square$ Likely & $\square$ Unlikely & $\square$ Unsure \\
\hline Is feeding tube likely to prolong a poor quality of life? & $\square$ Likely & $\square$ Unlikely & $\square$ Unsure \\
\hline
\end{tabular}

\section{What would your family member want?}

Your family member has previously expressed wishes about their health care?
Previous discussion
$\square$ Yes
$\square$ No
Living will
$\square$ Yes
$\square$ No

What do you think (based on a living will, previous discussion or your family member's beliefs) is the patient's overall feeling in this situation about the use of medical technologies like feeding tubes?
In Favour
Against 


\section{Personal Worksheet for Feeding Tube Placement}

3 How the decision is affecting you?

Feelings of guilt

Not much

$\square$

Feelings of pressure from others

Conflict between your personal beliefs and hose of the patients

Worry about future decisions regarding continuing with the tube
Somewhat

$\square$

$\square$

$\square$

$\square$
A lot

$\square$

$\square$

$\square$

$\square$

(4) What questions need answering before you can decide?

5 Who should decide about placing the tube?

6 What is my overall "leaning" about placing the feeding tube?

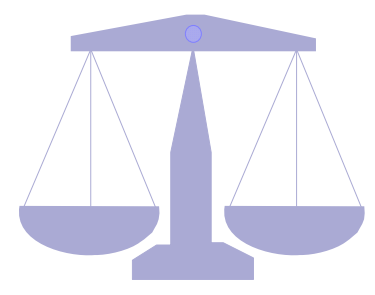

Put in tube

$\square \quad \square$

$\square$

$\square$
Unsure

$\square$

$\square$

$\square \quad \square$

Supportive care only 


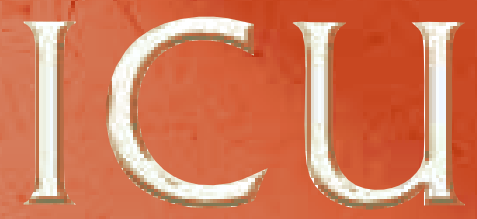

Is sues \& Answers

What Are My Choices Regarding Life Support?

When you need to make decisions about specific forms of life support, gather the facts you need to make informed decisions.

Society of $\mathbb{4}$

Critical Care Medicine (๑) 2002 SCCM 


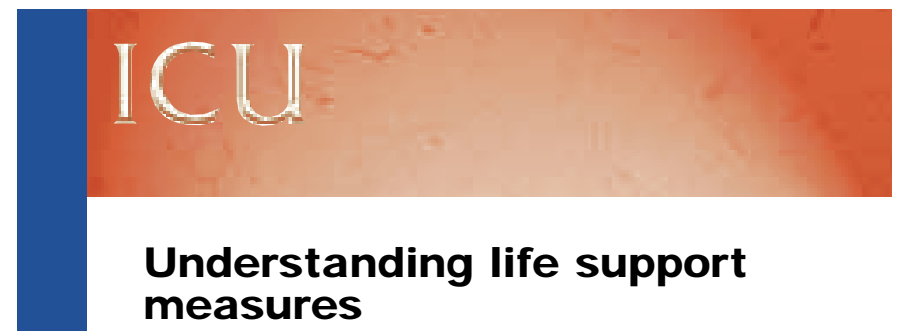

Life support replaces or supports a failing bodily function. In treatable or curable conditions, life support is used temporarily until the body can resume normal functioning. But, in situations where a cure is not possible, life support may prolong suffering. This brochure is meant to explain various life support terminology and measures the intensivistled team may need to address while your loved one is in the intensive care unit.

A treatment may be beneficial if it relieves suffering, restores functioning, or enhances the quality of life. The same treatment can be considered detrimental if it causes pain or prolongs the dying process without offering benefit. That treatment may diminish a person's quality of life.

The decision to forego life support is a personal one. It is important to talk to your physician regarding the risk and benefit of each therapy. All life support measures are optional treatments. 
Is sues \& Answers

\section{Commonly used life support terminology}

\section{Do-not-resuscitate order (DNR)}

A DNR order is an order written by your physician instructing health care providers not to attempt cardiopulmonary resuscitation (CPR) in case of cardiac (heart stops beating) or respiratory (breathing stops) arrest. A person with a valid DNR order will not be given CPR under these circumstances.

\section{Do-not-resuscitate/Full care}

Remember: Do-not-resuscitate does not mean do not treat. Patients have the right to receive any and all treatments. When cure is not possible, your physician may decide that the use of CPR may not be medically appropriate. It is a choice to say no to CPR, but yes to all other medically appropriate treatments.

\section{Palliative care: Comfort care/ Hospice care}

Palliative care is a comprehensive approach to treating the symptoms of illness when cure is not possible. Comfort care focuses on the physical, psychological, and spiritual needs of the patient. The goal is to achieve the best quality of life available by relieving suffering, controlling pain, and achieving maximum independence. Respect for the patient's culture, beliefs, and values is an essential component. 
Pain and discomfort associated with terminal illness can always be treated.

\section{Commonly used life support measures}

\section{Cardiopulmonary resuscitation (CPR/ACLS)}

CPR/ACLS are a group of treatments used when someone's heart and/or breathing stops. CPR is used in an attempt to restart the heart and breathing. It may consist of artificial breathing, and it can include pressing on the chest to mimic the heart's function to restart circulation. Electric shocks (defibrillation) and drugs can also be used to stimulate the heart.

\section{What is defibrillation?}

Defibrillation is the sending of a powerful electric shock through the heart. It is used when the heart stops beating effectively on its own.

\section{Does defibrillation always restart the heart?}

If the heart has lost all of its electrical activity or is so damaged that it no longer has enough muscle to pump blood through the body, defibrillation may not be successful in restarting the heart.

If you do not wish to receive CPR, your physician must write a do-not-resuscitate (DNR) order on the chart. This order can be revoked 
at any time for any reason.

\section{Vasopressors}

Vasopressors are a group of powerful drugs that cause blood vessels to get smaller and tighter, thereby raising blood pressure. This therapy is only given in the intensive care unit.

\section{Artificial nutrition and hydration (tube feeding)}

Tube feeding is the administration of a chemically balanced mix of nutrients and fluids through a feeding tube. Most commonly, a feeding tube is inserted into the stomach via the nasal passage (nasogastric or "NG" tube) or through the wall of the abdomen (gastronomy tube or "PEG") by means of a surgical procedure. Another type of feeding tube is inserted surgically through the abdominal wall into the small intestine (jejunostomy tube).

\section{Intravenous feeding}

Intravenous (IV) feedings are given to patients who are unable to tolerate tube feedings. Similar to tube feedings, the IV feeding provides the patient with the needed amount of protein, carbohydrate, fat, vitamins, and minerals.

Nutrition and hydration may be supplied temporarily, until the patient recovers adequate ability to eat and drink, or it can be supplied indefinitely. Although potentially valuable and life saving in many sit- 
uations, artificial nutrition and hydration do not provide comfort care for dying patients. Available scientific evidence has shown that death without artificial nutrition or hydration may cause less suffering.

\section{Mechanical ventilation (MV)}

Mechanical ventilation is used to support or replace the function of the lungs. A machine called a ventilator (or respirator) forces air into the lungs. The ventilator is attached to a tube inserted in the nose or mouth and down into the windpipe (trachea). MV may be used short term (i.e., treating pneumonia), or it may be needed indefinitely for permanent lung disease or trauma to the brain. Some patients on long term MV live a quality of life that is acceptable to them. For some patients, MV may only prolong the dying process.

\section{Dialysis}

Dialysis does the work of the kidneys, which remove waste from the blood and manage fluid levels. This procedure requires a special central venous catheter. Blood circulates from the body through the dialysis machine, where it is filtered and then returned. Dialysis can be performed in the ICU or in the dialysis unit, depending upon the condition of the patient. Some patients may live on dialysis for years. But, dialysis for the chronically ill/dying patient may only prolong the dying process. 
I s sues \& Answers

\section{Pacemakers}

A pacemaker is a device that produces a low electrical current that stimulates the heart muscle to beat. The heart can be paced temporarily until healing occurs. A surgical procedure to insert a permanent pacer may be required. Patients with noncurable heart disease may choose not to have a pacemaker.

\section{Resources}

- www.sccm.org

- www.icu-usa.com

- www.cityofhope.org

- www.patientspartner.com

- National self-help clearinghouse 212-642-2944 www.selfhelpweb.org

- www.mayoclinic.com

- Partnership for caring America's voices for the dying 1-800-989-9455

www.partnershipforcaring.org

- www.dyingwell.org

- Hospice link: 1-800-331-1620

- ICU Issues \& Answers from SCCM

- Participating in Care: What Questions Should I ask?

- Taking Care of Yourself While a Loved One is in the ICU

- Why Do ICU Patients Look and Act This Way?

- Common Problems of Critical Illness

- What Are My Choices Regarding Life Support? 
Developed by the Patient and Family Support Committee of the Society of Critical Care Medicine

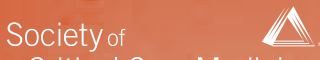

Critical Care Medicine The Intonsive care Profossionals

701 Lee Street, Suite 200 Des Plaines, IL 60016 www.sccm.org

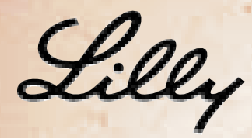

Developed with an unrestricted educational grant from Eli Lilly and Company 